\title{
$(\varphi)$
}

UNIVERSIDAD PERUANA DE CIENCIAS APLICADAS

FACULTAD DE NEGOCIOS

CARRERA DE MARKETING

\section{Percepción de La Calidad del Servicio de Cajeros Automáticos en Universidades Particulares del distrito de San Isidro}

\author{
TESIS \\ para optar el título profesional de Licenciado en Marketing \\ AUTOR(ES): \\ Acosta Quiroz, Marybel (0000-0003-2103-5539) \\ Caldas Coz, Heliana Jeanette (0000-0002-1882-3000)
}

ASESOR:

Ikeda Tsukazan, Lucía Midori (0000-0003-2466-7232)

Lima, 7 de julio de 2018 
En agradecimiento a toda mi familia que siempre me ha apoyado en todo momento y a mi hijo Gael, quien ha llegado a mi vida para iluminar mis dias y darme fuerzas para llevar a cabo esta nueva meta trazada en mi vida. Marybel Acosta $Q$.

En honor a mi madre que es mi luz, mi guía y mi mayor motivación, a mi padre quien siempre me apoya y alienta a seguir adelante, a mis hermanos que complementan mis dias y cada uno de mis amigos que en el camino me dio una palabra de aliento para continuar. Heliana Caldas C 


\section{RESUMEN}

Con el objetivo de determinar la percepción de calidad de los servicios de cajeros ATM, en los alumnos de las universidades particulares del distrito San Isidro, se realizó un estudio cualitativo - cuantitativo en el que se entrevistaron a especialistas en cajeros ATM y se encuestaron a 232 estudiantes de la modalidad Working Adult de la UPC mediante el cuestionario SERVQUAL. El análisis cualitativo reveló que los especialistas consideran que las principales necesidades son las operaciones de servicio de pago, las diferentes cuentas de ahorro, cuentas corrientes y la facilidad de poder retirar dinero de bajo valor. Por otro lado, el análisis cuantitativo reflejó que los estudiantes universitarios tienen una baja-media insatisfacción con la calidad de servicio de los cajeros ATM. Respecto a las dimensiones, los estudiantes tienen una alta insatisfacción con la Capacidad de respuesta principalmente porque el servicio no se encuentra vinculado a la universidad, muestran baja-media insatisfacción con la Empatía y Seguridad, y consideran que por poco se cumplen sus expectativas en cuanto a la Fiabilidad y los Aspectos tangibles. Todas las dimensiones se correlacionaron directamente con la calidad del servicio, pero en mayor medida la Fiabilidad $(r=0.918, p<0.001)$. En conclusión, la calidad del servicio percibida por ambos actores especialistas y estudiantes- difieren en alguna medida, por lo tanto, las entidades bancarias deberían orientar esfuerzos en mejorar la administración de sus agencias y cajeros ATM y satisfacer las necesidades de los estudiantes dado que ellos son sus principales clientes.

Palabras clave: SERVQUAL, calidad de servicio, dimensiones. 


\section{ABSTRACT}

In order to determine the perception of quality of ATM services in students of the private universities of the San Isidro district, a qualitative-quantitative study was carried out in which ATM specialists were interviewed, and 232 students of the Working Adult modality of the UPC were surveyed using the SERVQUAL questionnaire. The qualitative analysis revealed that the specialists consider that the main needs are the payment service operations, the different savings accounts, current accounts, and the ease of being able to withdraw money of low value. On the other hand, the quantitative analysis reflected that university students have a low-average dissatisfaction with the quality of service of ATMs. Regarding the dimensions, the students have a high dissatisfaction with the Response Capacity mainly because the service is not linked to the university, they show low-medium dissatisfaction with Empathy and Security and consider that almost meet their expectations in terms of Reliability and Tangible Aspects. All dimensions correlated directly with the quality of service, but to a greater extent Reliability $(r=0.918, p<0.001)$. In conclusion, the quality of service perceived by both actors -specialists and students- differ to some extent, therefore, banks should direct efforts to improve the administration of their agencies and ATMs and meet the needs of students, due that they are their main customers.

Key words: SERVQUAL, quality of service, dimensions. 


\section{Tabla de contenido}

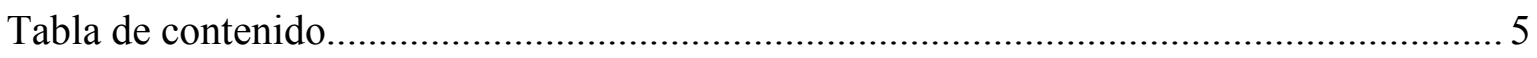

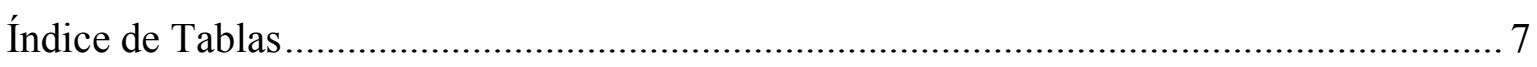

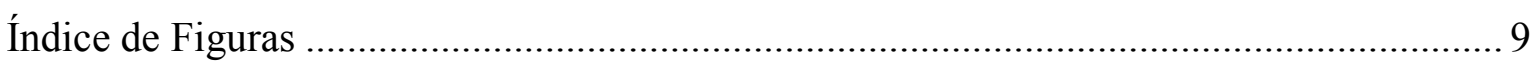

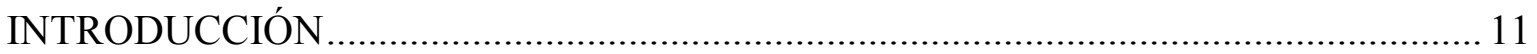

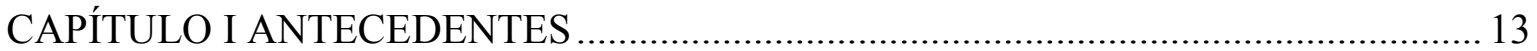

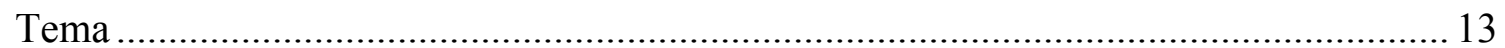

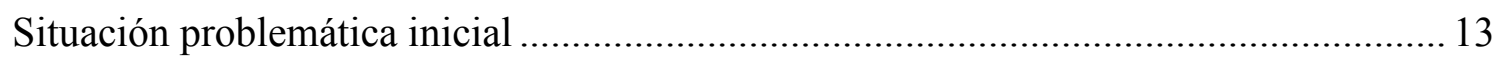

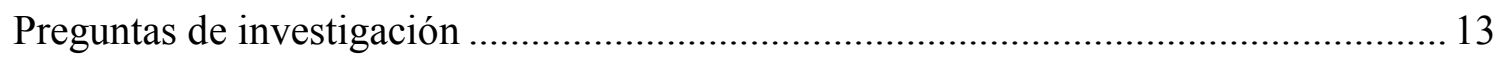

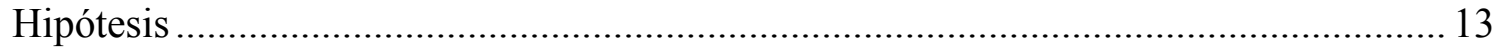

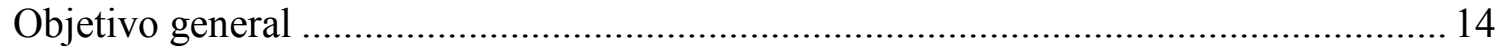

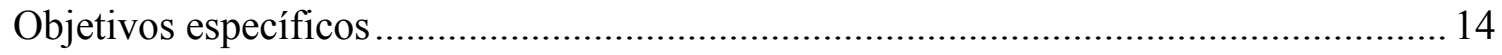

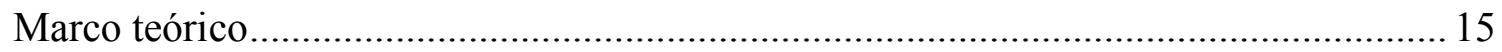

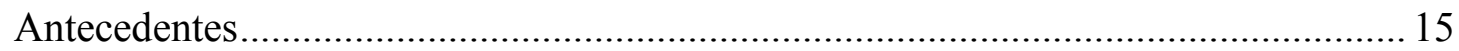

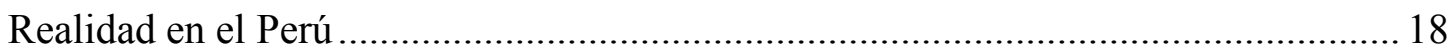

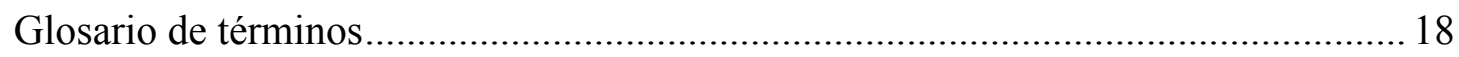

Los cajeros automáticos y el sistema financiero: .................................................... 20

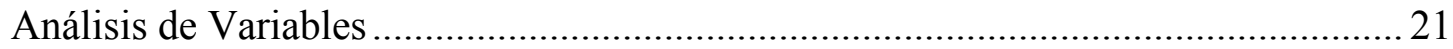

CAPÍTULO II METODOLOGÍA DE INVESTIGACIÓN ................................................. 23

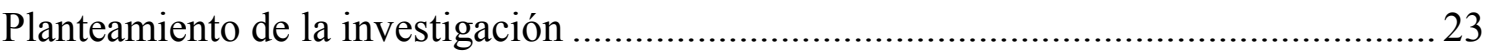

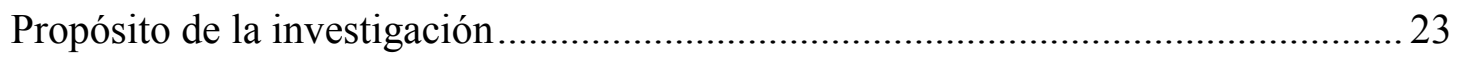

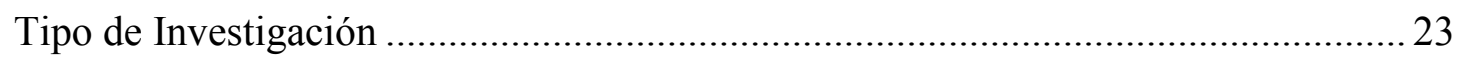

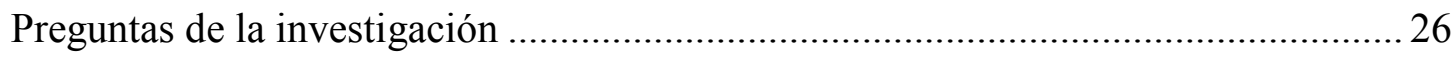

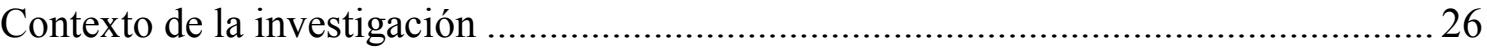

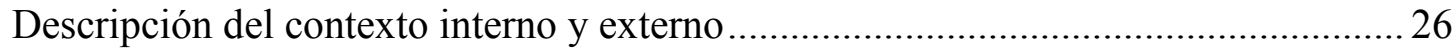

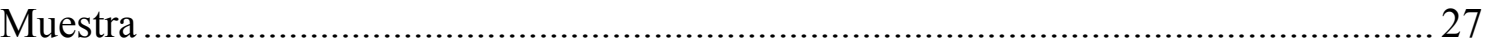

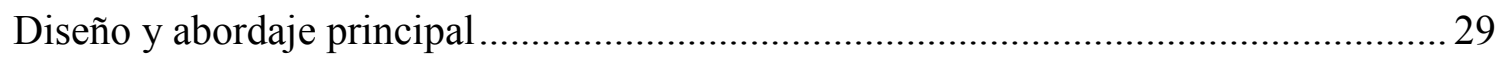

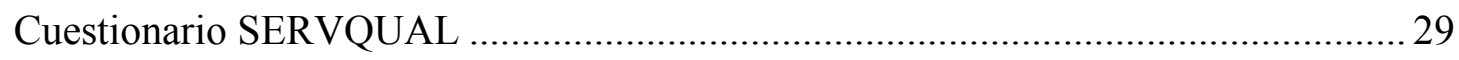

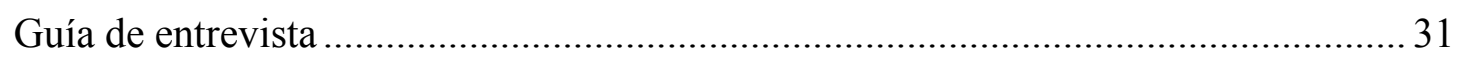

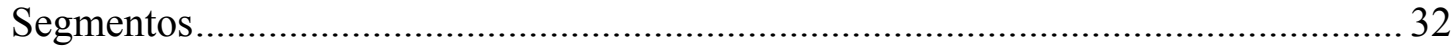


Técnicas para el procesamiento y análisis de información.............................................. 32

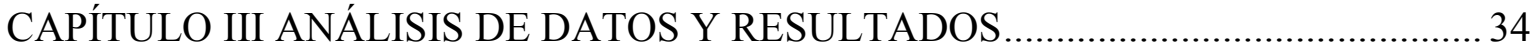

Procedimiento: Procesamiento de la información ........................................................... 34

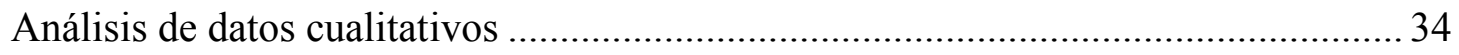

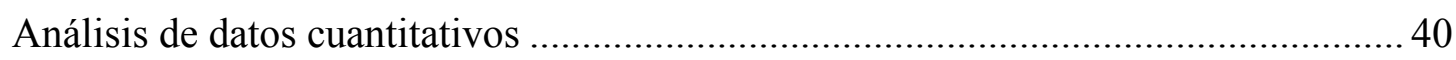

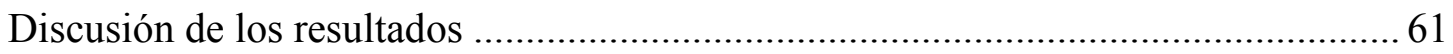

CAPÍTULO IV CONCLUSIONES, HALLAZGOS Y RECOMENDACIONES .............. 65

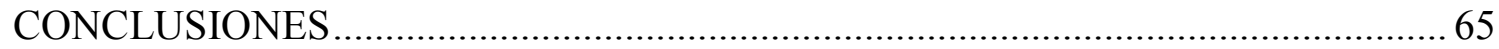

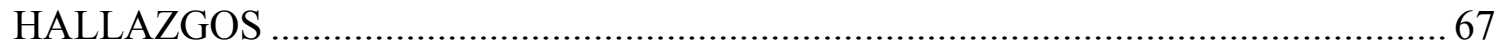

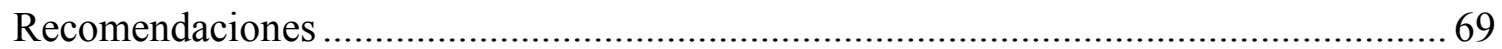




\section{Índice de Tablas}

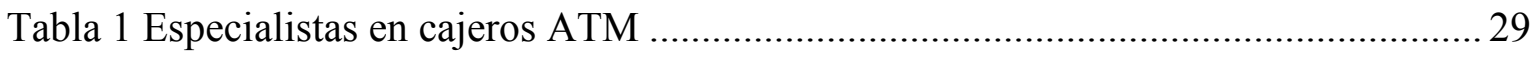

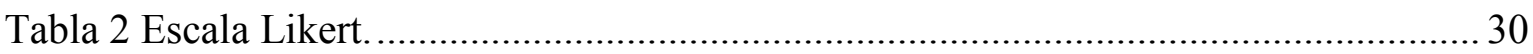

Tabla 3 Grado de correlación según coeficiente R de Pearson ......................................... 33

Tabla 4 Características generales de los estudiantes universitarios .................................. 41

Tabla 5 Promedio de resultados de las encuestas en la dimensión Fiabilidad .................... 42

Tabla 6 Promedio de resultados de las encuestas y la Capacidad de Respuesta ................. 43

Tabla 7 Promedio de resultados de las encuestas en la dimensión Seguridad ..................... 44

Tabla 8 Promedio de resultados de las encuestas en la dimensión Empatía ........................ 45

Tabla 9 Promedio de resultados de las encuestas en la dimensión Aspectos Tangibles ..... 46

Tabla 10 Promedio de resultados de las encuestas en las cinco dimensiones .....................47 47

Tabla 11 Correlación en las cinco dimensiones SERVQUAL ............................................ 48

Tabla 12 Correlación de la Calidad SERVQUAL con cada una de las cinco dimensiones 49

Tabla 13 Resumen de la Calidad del Servicio ATM y las cinco dimensiones .................... 50

Tabla 14 Anova de la ecuación de las cinco dimensiones de calidad ................................. 51

Tabla 15 Coeficientes de Regresión de Calidad del Servicio y las cinco dimensiones....... 51

Tabla 16 Resumen de Regresión de Calidad del Servicio y la Fiabilidad............................ 52

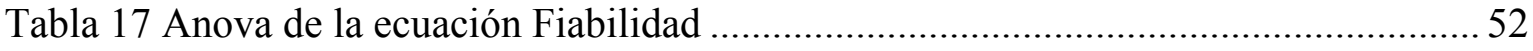

Tabla 18 Coeficientes de Regresión de Calidad de Servicio de Cajeros y la Fiabilidad..... 53

Tabla 19 Resumen de Regresión de Calidad de Servicio y la Capacidad de Respuesta ..... 54

Tabla 20 Anova de la ecuación Capacidad de Respuesta..................................................... 54

Tabla 21 Coeficiente de Calidad del Servicio y Capacidad de Respuesta .......................... 55

Tabla 22 Coeficiente de Regresión de Calidad de Servicio y Seguridad ............................. 56

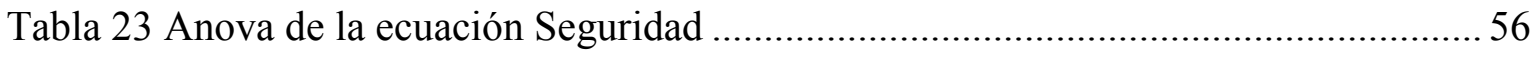

Tabla 24 Coeficiente de Regresión de Calidad de Servicio y Seguridad ............................ 57

Tabla 25 Resumen Regresión de Calidad de Servicio y Empatía ....................................... 57

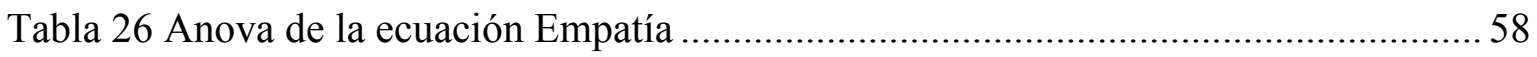

Tabla 27 Coeficiente de Regresión de Calidad de Servicio y Empatía ................................ 58

Tabla 28 Resumen Regresión de Calidad del Servicio y Aspectos Tangibles ..................... 59

Tabla 29 Anova de la ecuación Aspectos Tangibles ........................................................... 59 
Tabla 30 Coeficiente de Regresión de Calidad de Servicio y Aspectos Tangibles........ 60 


\section{Índice de Figuras}

Figura 1. Crecimiento de cajeros automáticos. Adaptado de "Impacto económico del uso de los cajeros ATM en el Perú", por ASBANC, 2017.

Figura 2. Características de los cajeros automáticos. Adaptado de la Revista Faz "Larga vida

a los cajeros", por Gutiérrez, 2007. 20

Figura 3. Grado de Satisfacción para escala Likert. Elaboración propia. 31

Figura 4. Edad de los estudiantes universitarios encuestados. Elaboración propia 40

Figura 5. Resultados de encuesta en la dimensión Fiabilidad. Elaboración propia. 42

Figura 6. Resultados de encuesta en la dimensión Capacidad de Respuesta. Elaboración propia. 43

Figura 7. Resultados de encuesta en la dimensión Seguridad. Elaboración propia. 44

Figura 8. Resultados de encuesta en la dimensión Empatía. Elaboración propia. 45

Figura 9. Resultados de encuesta en la dimensión Aspectos Tangibles. Elaboración propia.

Figura 10. Resultados de encuesta en las cinco dimensiones de la calidad de servicio. Elaboración propia. 47 


\section{EPÍGRAFE}

“... Las circunstancias particulares que llevan a cada usuario a hacer uso del cajero deben ser consideradas. El uso que le da un turista no es el mismo que le da un ciudadano, ni el de un inmigrante. Todas ellas eso sí tienen un denominador común, y es que la interfaz no puede conducirnos a la duda.

Cuántas veces nos hemos quedado dubitativos respecto de acciones ejecutadas. ¿O por qué me mostró la opción de línea de crédito cuando no tengo ese producto? ¿O cómo hago para volver al menú principal sin tener que apretar la tecla cancelar y abortar toda la operación?

El gran reto de los cajeros es hacer que la experiencia no plantee dudas al usuario y por lo tanto no conduzca a error. Por el contrario, la propuesta de uso debe ser tan clara y directa que las personas podamos sentir familiaridad con el lenguaje usado, consistencia con la secuencia para ejecutar acciones y seguridad ante el término de las operaciones."

Malisa Gutiérrez, revista de diseño e interacción "Faz"

"Sobre experiencia de uso de equipos de autoservicio: ¡Larga vida a los cajeros!” 


\section{INTRODUCCIÓN}

A nivel mundial, los cajeros automáticos (Automatic Teller Machine o ATM) representan una gran herramienta de ahorro en tiempo y dinero para el sistema bancario y sus clientes (Pijush \& Saralelimath, 2012). Los ATM no solo son una gran herramienta bancaria, sino que forman parte de la vida cotidiana de muchas personas al convertirse en una opción rápida y útil para realizar transacciones (Almenterio \& Torres, 2016). Asimismo, su funcionamiento y disponibilidad de fondos representan un elemento de valoración en la calidad de los servicios bancarios (Merino, 2001).

Entre los canales tradicionales, el cajero automático es el más valorado por los usuarios frente a los canales digitales (Lovati \& Borgo, 2017). Los ATM ganan cada vez más adeptos y las transacciones son cada vez mayores, por ello es necesario que se continúe mejorando el servicio. Durante el 2015 en el país se realizaron retiros de efectivo por un monto global aproximado de 102 millones de soles. El uso de cajeros automáticos se ha vuelto tan rutinario que no es posible calcular los beneficios que su uso trae consigo (ASBANC, 2017). El ATM permite hacer transacciones como retiros, depósitos, pagos y acceder al saldo de las cuentas de los usuarios, existiendo un promedio de 7,648 cajeros automáticos en Lima y provincias según la Asociación de Bancos (El Comercio, 2017).

Diversos estudios demuestran una notable evolución de la participación de los ATM en las transacciones monetarias al pasar de una participación del 20,3\% al 24,6\% por este canal (Zavala, 2013). Un cajero automático debe ofrecer sus servicios las 24 horas del día, estos pueden ser instalados en centros comerciales, supermercados, edificios de oficinas, etc. donde los clientes puedan efectuar sus operaciones con total comodidad, sin la necesidad de asistir a las oficinas bancarias. Sin embargo, existen problemas como la retención de tarjetas y el fraude, haciendo que un determinado segmento se encuentre insatisfecho por no habérsele brindado una buena experiencia de servicio (Aredo, 2016).

Por estas razones, es importante que se continúe mejorando la calidad de los servicios bancarios, más aún cuando la gestión de la calidad de este tipo de servicios influye favorablemente en la satisfacción del usuario ATM (Vega, 2017). 
El uso del ATM no solo aporta competitividad al mercado financiero, sino que optimizan el costo de retiro en agencias, permitiendo ahorrar a las personas un total de S/217.7 millones de soles al año (El Comercio, 2016).

Por otro lado, estudios confirman que la calidad es un componente básico, al momento de prestar servicios y se basan en cinco dimensiones como atención al cliente, infraestructura, aspectos funcionales, gestión de servicios y aspectos generales (Mejías, Villegas \& Maneiro, 2009). Por ello, es importante la realización de un estudio como éste, en el que se conozca el nivel de satisfacción de servicio de ATM's a través de la percepción que tienen los estudiantes sobre la calidad del servicio de los cajeros ATM dentro de las universidades. 


\section{CAPÍTULO I ANTECEDENTES}

\section{Tema}

Percepción de la calidad del servicio de cajeros ATM (Automatic Teller Machine) en los alumnos de la modalidad Working Adult de las universidades particulares de San Isidro.

\section{Situación problemática inicial}

¿Cuál es la percepción de la calidad del servicio de cajeros ATM en los alumnos de la modalidad Working Adult de las universidades particulares del distrito San Isidro?

\section{Preguntas de investigación}

Con la investigación se responderán las siguientes interrogantes:

- ¿Cuál es la percepción de la fiabilidad del servicio de cajeros ATM en los alumnos de las universidades particulares de San Isidro?

- ¿Cuál es la percepción de la capacidad de respuesta del servicio de cajeros ATM en los alumnos de las universidades particulares de San Isidro?

- ¿Cuál es la percepción de la seguridad de respuesta del servicio de cajeros ATM en los alumnos de las universidades particulares de San Isidro?

- ¿Cuál es la percepción de la empatía del servicio de cajeros ATM en los alumnos de las universidades particulares de San Isidro?

- ¿Cuál es la percepción de los aspectos tangibles del servicio de cajeros ATM en los alumnos de las universidades particulares de San Isidro?

- ¿Cuál es la percepción de los expertos acerca del servicio de los cajeros ATM instalados en las universidades particulares de San Isidro?

\section{Hipótesis}

Hipótesis general

Los universitarios de la modalidad Working Adult se encuentran altamente satisfechos con el servicio de cajeros ATM instalados en las universidades particulares del distrito de San Isidro. 
Hipótesis específicas

- Existe una alta satisfacción de la fiabilidad de los servicios de cajeros ATM en las universidades particulares de San Isidro.

- Existe una alta satisfacción de la capacidad de respuesta de los servicios de cajeros ATM en las universidades particulares de San Isidro.

- Existe una alta satisfacción de la seguridad de los servicios de cajeros ATM en las universidades particulares de San Isidro.

- Existe una alta satisfacción de la empatía de los servicios de cajeros ATM en las universidades particulares de San Isidro.

- Existe una alta satisfacción de los aspectos tangibles de los servicios de cajeros ATM en las universidades particulares de San Isidro.

- Los expertos consideran que existe una alta satisfacción de los usuarios con el servicio de cajeros ATM instalados en las universidades particulares de San Isidro.

\section{Objetivo general}

Determinar cuál es la percepción de calidad de los servicios de cajeros ATM en los alumnos de las universidades particulares del distrito San Isidro.

\section{Objetivos específicos}

- Determinar la percepción en la fiabilidad del servicio de cajeros ATM en los alumnos de las universidades particulares de San Isidro.

- Determinar la percepción en la capacidad de respuesta del servicio de cajeros ATM en los alumnos de las universidades particulares de San Isidro.

- Determinar la percepción en la seguridad del servicio de cajeros ATM en los alumnos de las universidades particulares de San Isidro.

- Determinar la percepción en la empatía del servicio de cajeros ATM en los alumnos de las universidades particulares de San Isidro. 
- Determinar la percepción en los aspectos tangibles del servicio de cajeros ATM en los alumnos de las universidades particulares de San Isidro.

- Determinar la calidad del servicio percibida por los expertos en cajeros ATM instalados en las universidades particulares de San Isidro.

\section{Marco teórico}

\section{Antecedentes}

Con el objetivo de identificar las dimensiones que determinan la Calidad de los Servicios Bancarios en la Universidad de Carabobo en Venezuela, se realizó un estudio (Mejías \& Maneiro, 2008) titulado "Dimensiones de la Calidad de los Servicios Bancarios en el Sector Universitario". Fue un estudio descriptivo, transversal y de campo en el que se encuestaron a 175 estudiantes universitarios mediante un cuestionario creado en base al SERVQUAL. Como resultado identificaron cinco dimensiones: Atención al Cliente, Elementos Tangibles, Gestión de Servicios, Infraestructura Interna y Enlace Universidad-Banco cuyos coeficientes alfa de Cronbach fueron superiores a 0,590 demostrando su fiabilidad, evaluaron la validez de contenido, criterio y constructo obteniendo resultados favorables. Los autores concluyeron que las dimensiones que determinan la calidad de los servicios bancarios en la Universidad de Carabobo son atención al cliente, elementos tangibles, gestión de servicios, infraestructura interna y enlace universidad-banco.

Asimismo, en otro estudio realizado en Venezuela titulado "Factores determinantes de la calidad de los servicios bancarios en un campus universitario venezolano" (Mejías, Villegas $\&$ Maneiro, 2009) cuyo objetivo fue identificar los factores que determinan la calidad de los servicios bancarios en entidades ubicadas en el campus de una universidad venezolana. Fue un estudio exploratorio, de campo, en el que encuestaron a 175 usuarios de cuatro agencias bancarias localizadas en el interior de un campus universitario, para lo cual utilizaron un modelo de encuesta con base en el SERVQUAL. Entre sus resultados encontraron cinco dimensiones cuyos coeficientes de fiabilidad Alfa de Cronbach fueron aceptables: Atención al cliente $(\alpha=0.85)$, Infraestructura $(\alpha=0.583)$, Aspectos funcionales $(\alpha=0.568)$, Gestión de servicios $(\alpha=0.658)$ y Aspectos generales $(\alpha=0.540)$; además, el nivel de fiabilidad general fue alto $(\alpha=0.802)$. También evaluaron la validez de criterio (concurrente y predictiva) y de constructo, y demostraron que el instrumento era válido. Concluyeron que la atención al 
cliente, infraestructura, aspectos funcionales, gestión de servicios y aspectos generales son factores que determinan la calidad de los servicios bancarios dentro del campus universitario estudiado. Una adecuada gestión de dichos factores permitirá el uso racional de los recursos disponibles y la mejora continua de la entidad bancaria y la universitaria.

En un estudio de investigación en Cuba titulada "Dimensiones de la satisfacción de clientes bancarios universitarios: Una aproximación mediante el análisis de factores" (Mejías \& Manrique, 2011) con el objetivo de identificar las dimensiones que determinan la Satisfacción de los Clientes Bancarios en el ámbito de influencia (Campus) de una Universidad Pública en Venezuela. Fue un estudio exploratorio, se diseñó y aplicó una encuesta a los estudiantes usuarios de las agencias bancarias con sede en el campus universitario para medir su nivel de satisfacción. El análisis permitió identificar cinco dimensiones con buenos niveles de fiabilidad alfa de Cronbach: Calidad técnica $(\alpha=0.868)$, Calidad funcional $(\alpha=0.786)$, Expectativas $(\alpha=0.872)$, Valor percibido $(\alpha=0.791)$ y Confianza $(\alpha=0.676)$, además de manera global la fiabilidad fue $\alpha=0.935$ destacando la consistencia interna del instrumento usado. En conclusión, el estudio permitió a los autores diseñar un instrumento que mide la satisfacción de los clientes bancarios universitarios de una universidad pública venezolana, no obstante, el instrumento puede ser utilizado para otras universidades si previamente se demuestra la adecuación de los datos.

En una investigación en México titulado "Uso de Tarjetas de Crédito" cuyo objetivo fue conocer el uso que los estudiantes de la Universidad Pedagógica Nacional Francisco Morazán (UPNFM) del primer período del año 2014 les dan a las tarjetas de crédito, así como conocer el impacto financiero (Ilías, Rosales, Santelí \& Galo, 2014). Fue una investigación exploratoria, descriptiva, se encuestaron a 393 estudiantes. Los resultados demostraron que el $15.9 \%$ utilizaban tarjetas de crédito, el $73 \%$ de ellos para compras personales, mayormente en el supermercado (16.6\%). La mayoría hacia uso de su tarjeta de tres a cuatro veces por semana, atribuyéndole como ventajas del uso de la tarjeta los descuentos $(30 \%)$, extra-financiamiento $(22 \%)$, facilidad de la compra $(12,5 \%)$ y seguridad por no andar con dinero en efectivo $(11,8 \%)$. En conclusión, los beneficios y ventajas que determinan la importancia de las tarjetas de crédito para los estudiantes radican en los descuentos, extra-financiamiento, facilidad de compra y seguridad. 
Igualmente, se realizó un estudio en Nigeria titulado "Determinants of bank selection by university undergrads in south east Nigeria: empirical evidence" con el fin de identificar y clasificar los factores que influyen en la selección bancaria por parte de los estudiantes de licenciatura en el sudeste de Nigeria (Nkamnebe, Ukenna, Anionwu \& Chibuike, 2014). En el estudio se incluyeron a 300 estudiantes de dos universidades seleccionadas intencionalmente debido a la presencia de agencias bancarias en su campus. Los resultados mostraron un ranking de los criterios de selección bancaria de los estudiantes, en primer lugar, resultó la estabilidad financiera del banco, luego la disponibilidad y funcionalidad de la red de cajeros ATM, la influencia de familiares y amigos, la proximidad de la sucursal bancaria al campus universitario, el profesionalismo del personal del banco y, finalmente, la estética interna y externa. Los autores concluyeron que los bancos deben generar una estrategia basada en los criterios mencionados para atraer clientes universitarios por las diferentes ventajas que estos generan.

En estudios recientes, se realizó una investigación en el Perú titulado "Gestión de la calidad y la satisfacción del usuario de los cajeros automáticos del Banco de la Nación en el año 2015" cuyo objetivo fue determinar la relación que existe entre la gestión de calidad y la satisfacción del usuario de los cajeros automáticos del Banco de la Nación en el año 2015 (Vega, 2017). El método del estudio fue hipotético deductivo, de diseño no experimental, de tipo correlacional y de corte transversal. Incluyó 126 trabajadores a quienes se encuestaron con dos cuestionarios en escala Likert, cada uno de 20 ítems que miden la satisfacción y la gestión de calidad. El análisis estadístico consistió en la prueba de correlación de Spearman con un nivel de significancia del 5\%. Los resultados reflejaron que la gestión de calidad fue alta para el $41.3 \%$ y medio para el 55.6\% de los usuarios de los cajeros. La gestión de calidad $(\mathrm{Rho}=0.975 ; \mathrm{p}<0.05)$ y sus dimensiones confiabilidad $(\mathrm{Rho}=0.497 ; \mathrm{p}<0.05)$, capacidad de respuesta $(R h o=0.550 ; p<0.05)$, seguridad $(R h o=0.629 ; p<0.05)$, empatía $(R h o=0.598$; $\mathrm{p}<0.05)$ y elementos tangibles $(\mathrm{Rho}=0.628 ; \mathrm{p}<0.05)$ se relacionaron directa $\mathrm{y}$ significativamente con la satisfacción del usuario en el uso de cajeros automáticos.

En conclusión, la gestión de calidad se relaciona directa y significativamente con la satisfacción del usuario en el uso de los cajeros automáticos en el Banco de la Nación, Lima 2015. 


\section{Realidad en el Perú}

Según la Asociación de Bancos del Perú - ASBANC el número de cajeros se ha incrementado tanto en Lima como en provincias, como se muestra en la figura 1. El crecimiento astronómico se debe a los beneficios de tener menor necesidad de cargar fuertes cantidades de dinero y sobre todo llegar a diversos segmentos de clientes, acercándose más a sus clientes (El Comercio, 2017).

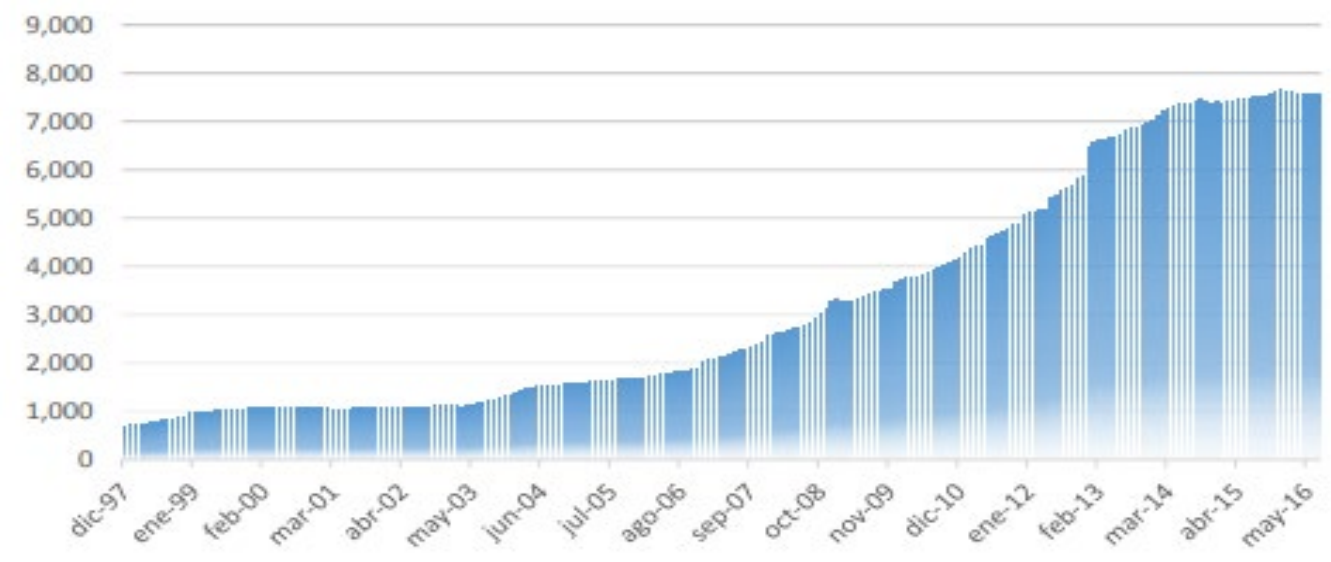

Figura 1. Crecimiento de cajeros automáticos. Adaptado de "Impacto económico del uso de los cajeros ATM en el Perú", por ASBANC, 2017.

Entre el 2005 y 2016, los distritos con más alto crecimiento en cantidad de cajeros automáticos fueron Carabayllo (2700\%) y Ventanilla (1700\%); San Isidro presentó un crecimiento del 313\% (ASBANC, 2017). Al mes de junio del 2017 existen aproximadamente 7,648 cajeros ATM en el país, de los cuales el 63\% de cajeros automáticos se encuentran concentrados en Lima Metropolitana (El Comercio, 2017).

\section{Glosario de términos}

- Calidad: La edición 23 del Diccionario de la lengua española, publicado el 2014 por la Real Academia Española, define calidad como: "la propiedad o conjunto de propiedades inherentes a algo, que permiten juzgar su valor" (párr. 1). De acuerdo con las normas ISO 9000 (2007), calidad se refiere al "grado en el que un conjunto de características 
inherentes cumple con los requisitos" (párr. 75), entendiendo requisito como la expectativa frente a un determinado producto o servicio.

- Un término que se encuentra muy asociado a la calidad es la satisfacción (Montoya et al., 2000) señala que al referirse a la calidad de los servicios deben considerarse tres factores básicos: El cliente, quien se beneficia de los procesos, productos y servicios de la empresa; El servicio, actividades intangibles de quien presta el servicio que deben satisfacer las necesidades, deseos y expectativas del cliente; El proceso, conjunto de actividades que combina recursos humanos y metodológicos, materiales y equipos, cuyo objetivo es la obtención del servicio final.

- La satisfacción es la "evaluación que analiza si una experiencia de consumo es al menos tan buena como se esperaba”, definición que respalda en la revista de la Universidad Nacional de Colombia UNAL (2010, como se cita en Hunt, 1977, p. 459) es decir si se alcanzan o superan las expectativas. A la par, es definida como el "estado psicológico final que resulta cuando se unen las discrepancias de las expectativas con los sentimientos previos acerca de la experiencia de consumo" postura apoyada en la revista UNAL (2010, como se cita en Oliver, 1981, p. 27). Igualmente, la definición es respaldada en la revista UNAL (2010, como se cita en Tse \& Wilton, 1988, p. 204) quienes señalan que la "respuesta del consumidor a la evaluación de la discrepancia percibida entre las expectativas y el resultado final percibido del producto tras su uso". La calidad de un servicio será valorada por el cliente cuando resulte positiva la diferencia entre lo que desea con lo que recibe, mientras que de resultar negativa generará insatisfacción y carecerá de valor.

- Cajeros automáticos: El cajero automático (Automatic Teller Machine - ATM) es un terminal bancario que acepta depósitos y dispensa dinero, se activa al insertarse una tarjeta de crédito o débito que contiene la cuenta del usuario (Medina, 2016). Sus características son: 
Figura 2. Características de los cajeros automáticos. Adaptado de la Revista Faz "Larga vida a los cajeros", por Gutiérrez, 2007.

El cajero automático presenta ciertos requisitos para que funcione, entre ellos se encuentran comunicación constante con el servidor de la institución, energía eléctrica constante, provisión de efectivo, encriptación del teclado del cliente y funcionamiento correcto del equipo (Medina, 2016).

\section{Los cajeros automáticos y el sistema financiero:}

A través de los años, el sistema financiero ha presentado diversos cambios vinculados a la forma en la que se relaciona con sus usuarios, debido al avance de la tecnología (Rodríguez, 2002). La rápida evolución de las tecnologías de información y comunicación (TIC) produjo enormes cambios en el aspecto económico, político y social. En los últimos años el acceso a los sistemas financieros ha cobrado gran importancia, sin embargo, comparado con América del norte y Europa, América Latina tiene bajos niveles de bancarización. Las instituciones financieras privadas se encuentran desarrollando iniciativas que impulsan el acceso de la población a tales servicios (Hinojosa, 2011).

El cajero ATM en sus inicios tuvo un gran impacto en la llamada banca electrónica ya que permitió a los bancos ofrecer casi todos sus servicios las 24 horas del día. A través del cajero el cliente puede realizar depósitos y retiros de efectivo, consultar el saldo de su cuenta de ahorro, transferir fondos entre cuentas, pagar facturas de impuestos y servicios básicos, etc. (Rodríguez, 2002).

Las instituciones bancarias están incorporando agencias dentro de las organizaciones, las universidades no son la excepción ya que en búsqueda de satisfacer las necesidades y requerimientos de la comunidad universitaria también las están instalando dentro de los campus universitarios (Mejías, Villegas \& Maneiro, 2009). Los servicios de las oficinas bancarias presentan ventajas para los universitarios y la misma universidad, pero también debilidades, sobre todo en la calidad del servicio. Sin embargo, aparecen nuevas expectativas de los clientes, los cuales pueden ser aprovechados por las universidades, los estudiantes y las entidades financieras (Mejías \& Manrique, 2011). 


\section{Análisis de Variables}

\section{Variable Dependiente: Percepción de la calidad del servicio}

Se conoce como calidad de servicio a la percepción que tiene el cliente respecto del desempeño y las expectativas de un producto o servicio (Larrea, 1991). La percepción es el corazón de la ecuación alrededor de la cual se evalúa la calidad del servicio para los consumidores. La característica del servicio es la inmaterialidad e implica que el juicio del cliente sobre un servicio recibido sea subjetivo. Por lo que al relacionarlo con la percepción implica conocer el concepto de calidad del servicio desde el punto de vista del usuario (Chávez et al., 2017). A través del Cuestionario Servqual contrastaremos los resultados entre el servicio que se espera recibir y la percepción del usuario respecto del servicio recibido en términos de satisfacción e insatisfacción. Estas están enlazadas con las cinco dimensiones de la calidad del servicio.

\section{Variable Independiente: Dimensiones del modelo SERVQUAL}

Para concluir en lo que hoy conocemos como las cinco dimensiones del modelo SERVQUAL, Parasuraman, Zeithaml y Berry realizaron diversas investigaciones. La finalidad del estudio fue determinar los criterios empleados por los consumidores para juzgar el servicio. Por ello, se realizaron estudios con grupos de enfoque y se obtuvieron insights, los cuales revelaban que el servicio era juzgado bajo diez criterios constantes tales como tangibles, fiabilidad, capacidad de respuesta, competencia, cortesía, credibilidad, seguridad, acceso, comunicación y comprensión sobre el consumidor (Parasuraman, Zeithaml \& Berry, 1988). Finalmente, se replantean bajo cinco criterios, ya que unas eran dependientes de otras y como resultado se obtienen los criterios de fiabilidad, capacidad de respuesta, seguridad, empatía y elementos tangibles.

Fiabilidad: Habilidad para ejecutar el servicio prometido de forma fiable y cuidadosa, cumplir las promesas (ofertas), el suministro del servicio y solucionar problemas (Matsumoto, 2014).

Capacidad de respuesta: Disposición para ayudar y prestar un servicio rápido y adecuado a los usuarios. Se refiere a rapidez de atención a las solicitudes, respuesta a las preguntas y quejas (Matsumoto, 2014). 
Seguridad: Conocimiento y atención para inspirar credibilidad y confianza (Matsumoto, 2014).

Empatía: Nivel de atención individualizada que ofrecen las empresas a sus clientes. Debe ser transmitir mediante un servicio personalizado o adaptado al gusto del cliente (Matsumoto, 2014).

Aspectos tangibles: Apariencia física, instalaciones, infraestructura, equipos, materiales, personal (Matsumoto, 2014). 


\section{CAPÍTULO II METODOLOGÍA DE INVESTIGACIÓN}

\section{Planteamiento de la investigación}

\section{Propósito de la investigación}

El objetivo de esta investigación es conocer cuál es la percepción del estudiante universitario respecto a la calidad del servicio que brindan los cajeros ATM instalados dentro del campus de la universidad. Asimismo, se busca conocer la opinión y percepción de los especialistas en cajeros ATM. En conclusión, se verificará la coherencia entre el servicio que brindan los cajeros ATM, desde el punto de vista del experto, y la percepción del servicio, desde el punto de vista del usuario. En función a esta investigación, se generarán descubrimientos sobre las deficiencias en el servicio, por lo que se sugiere sea materia de nuevas investigaciones con la finalidad ampliar el universo en estudio y trabajar sobre las propuestas de mejora en la calidad del servicio de cajeros ATM.

\section{Tipo de Investigación}

Para validar las hipótesis general y específica, resolver el problema planteado y conocer las razones de la metodología aplicada, el proceso de la investigación se ha divido en tres fases (Verjovsky et al. ,2014) que detallaremos a continuación:

\section{Fase I: Formulación del problema de Investigación}

\section{I.1. Descubrimiento del Problema}

Nivel de satisfacción de los universitarios respecto del servicio de cajeros ATM que se encuentran instalados dentro de la universidad.

\section{I.2. Definición del problema}

Determinar cuál es la percepción de calidad de los servicios de cajeros ATM en los alumnos de las universidades particulares del distrito San Isidro. 


\section{Fase II: Determinación del Diseño de Investigación}

Considerando los objetivos e interrogantes de la investigación se plantearon dos tipos de diseños, los más idóneos para el estudio.

\section{II.1. Diseño Exploratorio}

El primer paso fue reunir información sobre la situación actual del problema. Para ello, se empleó el método Cualitativo - Entrevistas en Profundidad con la finalidad de plantear una mejor definición del problema e hipótesis. Inicialmente, se realizó un análisis a través de la Entrevista en Profundidad a tres expertos en cajeros ATM. Se pudo recoger información relevante para construir y orientar las preguntas del Cuestionario dirigido a los universitarios; usuarios de los cajeros ATM.

\section{II.2. Diseño Concluyente}

En el segundo paso empleamos el método Cuantitativo - Encuestas, nos permitió reunir evidencias y definir mejor el segmento a estudiar. A través de una prueba piloto a 110 universitarios, se descubrió que el $89 \%$ pertenecía a la modalidad de estudio Working Adult y el 11\% de los encuestados pertenecían a Pre-Grado. De los cuales, 12 encuestados oscilaban entre los 18 a 24 años (11\%). Por lo que se considera pertenecen a la generación Centennials, conocida como GENERACIÓN Z. Algunos estudios revelan que la Generación Z, nacidos desde el año 1994 en adelante, aún no se encuentran insertados en el mercado laboral al 100\% (PQS, 2018). Por tal motivo, el público relevante para el estudio fue Working Adult.

\section{II.2.1. Diseño Concluyente - Descriptivo}

Asimismo, nos permitió determinar los grados de relación de las variables Calidad de Servicio y las 5 dimensiones del modelo SERVQUAL. La metodología de diseño Descriptivo empleada fue la investigación por Encuestas.

\section{FASE III: Preparación de la Investigación}

Para el desarrollo del trabajo de investigación fue necesario recabar información secundaria o existente en diversos medios e información primaria o no existente.

III.1. Determinación de información necesaria 
Para responder a los objetivos e interrogantes planteadas, en el trabajo, será fundamental recurrir no solo al tipo de información secundaria, sino también se recurrió a información primaria.

\section{III.1.1. Información Secundaria}

Nos referimos a la información bibliográfica empleada para la elaboración del trabajo. El cual se basa en la determinación de la percepción de la calidad del servicio, por lo que el Modelo SERVQUAL es el que mejor se adapta a los fines de investigación ya que es un instrumento empleado en la medición de la calidad de los servicios. Por ejemplo, se tomó como referencia el estudio realizado al Banco de la Nación en el año 2017 sobre la satisfacción del usuario de cajeros ATM y la relación significativa de las 5 dimensiones de la calidad.

\section{III.1.2. Información Primaria}

Para la obtención de la información principal se empleó la investigación Cualitativa y Cuantitativa.

III.2. Técnica de recopilación de datos

Para conseguir la información primaria se ha recurrido a las siguientes técnicas.

Técnica Cualitativa: Entrevistas en Profundidad a los expertos. El objetivo fue replantear las hipótesis y levantar información relevante para las encuestas.

Técnica Cuantitativa: Encuestas cuya herramienta es el Cuestionario SERVQUAL adaptado al tema de estudio.

\section{III.3. Diseño del Cuestionario}

Con la finalidad de contrastar y validar las hipótesis del tema de investigación se recabó información primaria. Por consiguiente, se empleó la metodología SERVQUAL con el siguiente diseño:

III.3.1. Escala LIKERT: escala de valoración empleada para la medición de las expectativas y las percepciones.

III.4. Diseño del Muestreo 
Para conocer la muestra de universitarios y expertos se utilizó dos tipos de muestreo:

\section{III.4.1. Muestreo Probabilístico}

Población Universitaria: se realizaron encuestas dentro del campus a los estudiantes que terminaban de hacer uso de los cajeros ATM. Por lo que se concluye que todos tienen la misma probabilidad de ser seleccionados para representar la muestra. Se ha empleado el Muestreo Probabilístico Aleatorio Simple para el estudio de la población Working Adult.

\section{III4.2. Muestreo No Probabilístico}

Población Expertos: para escoger la población de expertos se ha empleado criterios de homogeneidad como antigüedad laboral y experto en temas relacionados a Canales Alternativo. Se ha utilizado el Muestreo No Probabilístico por Conveniencia, ya que se ha seleccionado de forma directa e intencionada.

\section{Preguntas de la investigación}

La principal pregunta por responder fue ¿Cuál es la percepción de la calidad de servicios de cajeros ATM en las universidades particulares del distrito San Isidro? Con la finalidad de responder a la interrogante, se adaptaron las preguntas al instrumento SERVQUAL modificado para alcanzar los objetivos de la investigación (Anexo 1.A).

\section{Contexto de la investigación}

\section{Descripción del contexto interno y externo}

En primer lugar, iniciamos el proceso con las entrevistas a profundidad dirigida a los especialistas en cajeros ATM. Se seleccionaron por muestreo de conveniencia a los expertos en Canales Alternativos para realizar las entrevistas y se les indicó el objetivo de estas; amablemente aceptaron ser entrevistados. Las entrevistas se realizaron en aproximadamente dos semanas, puesto que la agenda de trabajo de los expertos es sumamente recargada y la disponibilidad de horarios es baja. Los especialistas elegidos cuentan con una sólida experiencia de nueve años en promedio, trabajando para el área de Canales Alternativos - Cajeros ATM en más de una entidad bancaria. Las entrevistas se realizaron en horarios sujetos a la disponibilidad de tiempo de los especialistas. En segundo lugar, las encuestas se realizaron los días de semana de 19:30 horas a 21:00 horas. Los encuestados fueron los estudiantes universitarios de la modalidad Working 
Adult con edades entre los 25 y 36 años de ambos sexos que se encontraban haciendo uso del cajero automático en la universidad UPC del distrito de San Isidro. Antes de realizar las encuestas las 232 encuestas se hizo una prueba piloto a 110 universitarios. De los cuales, solo el 11\% pertenecía a la modalidad Pregrado y el $89 \%$ a la modalidad de Working Adult. Por lo que se reemplazó el 11\% de encuestas pregrado por nuevas encuestas al grupo en estudio.

Finalmente, cada posible encuestado tenía que pasar las preguntas filtro para ser considerados como parte de la muestra y continuar con las siguientes preguntas. En algunos casos, los encuestados no llegaban a culminar el cuestionario por motivos de tiempo y otros seleccionados no cumplían con las preguntas filtro, por lo que se tuvo que seguir entrevistando hasta cumplir con la cantidad de personas de la muestra.

\section{Muestra}

Para determinar el número estudiantes universitarios a encuestar se calculó el tamaño de muestra mediante la fórmula para población finita o conocida, ya que se conoce con exactitud la cantidad actual de alumnos de la modalidad Working Adult en el campus de la UPC en San Isidro, el cual asciende a 1750 casos. Debido a que se desconoce la proporción de estudiantes que utilizan los cajeros automáticos, se consideró una proporción estándar de 50\% $(\mathrm{p}=0.5, \mathrm{q}=1-\mathrm{p}=0.5)$, además se considerará un nivel de confianza del $95 \%\left(Z_{1-\alpha / 2}=1.96\right)$ y un margen de error de $6 \%(d=0.06)$. La fórmula de aplicación es la de Muestreo Aleatorio Simple:

$$
n=\frac{N \times Z_{a}^{2} \times p \times q}{d^{2} \times(N-1)+Z_{a}^{2} \times p \times q}
$$
N: 1750
e: 0.06
Z: 1.96
p: 0.5
q: 0.5 
Reemplazando los valores se obtuvo un tamaño de muestra de 232 estudiantes universitarios. El resultado confiable al 95\% con un error del 6\% nos indicó que se debía tomar una muestra de 232 universitarios.

Para determinar las universidades donde se llevarían a cabo las encuestas, se consideró que a la fecha existen 35 universidades licenciadas en el Perú (SUNEDU, 2018). Catorce de ellas con al menos una sede en Lima Metropolitana, pero solo una cumplía el requisito de tener cajeros ATM dentro del campus universitario en el distrito de San Isidro. Esta es la Universidad Peruana de Ciencias Aplicadas UPC, en el interior del campus existen cajeros automáticos pertenecientes a tres entidades bancarias y módulos de pagos de servicios.

Se ha seleccionado el distrito de San Isidro conocido como el distrito Financiero, ya que las actividades empresariales y económicas representan un 58\% del total de participación de toda Lima Metropolitana (INEI, 2014).

Para determinar el tamaño de muestra de expertos en cajeros ATM se utilizó el muestreo no probabilístico. Por tal motivo se ha trabajo con tres entidades bancarias y entrevistado a tres especialistas.

Descripción de la muestra

Para encuestar a los estudiantes se tomaron en cuenta las siguientes características:

- Edad entre 25 y 36 años.

- Estudiante de la modalidad Working Adult.

- Ser cliente del banco a través de una tarjeta de ahorros o sueldo

Para entrevistar a los especialistas en cajeros ATM se consideraron los siguientes criterios.

- Especialista en Canales Alternativos y Tradicionales.

- Antigüedad laboral en el área promedio 9 años.

- Perfil laboral Gerente o Especialista en Canal Alternativo y Tradicional.

- Conocimiento de autoabastecimiento y proyección de cajeros ATM. 
- Conocimiento de análisis de demanda de cajeros ATM.

- Conocimiento de la denominación monetaria altamente demandas por zonas.

- En ambos casos, tanto para las encuestas como para las entrevistas, los participantes tenían que cumplir con los criterios mencionados.

En esta investigación colaboraron en la entrevista 3 especialistas, a continuación, se presenta sus datos generales:

Tabla 1 Especialistas en cajeros ATM

\begin{tabular}{cccc}
\hline Especialista & Cargo & $\begin{array}{c}\text { Entidad } \\
\text { Financiera }\end{array}$ & Experiencia \\
\hline $\begin{array}{c}\text { Marcos } \\
\text { Medina }\end{array}$ & $\begin{array}{c}\text { Sub Gerente del área de } \\
\text { canales alternativos } \\
\text { Gerente del área de canales } \\
\text { altemativos }\end{array}$ & Interbank & 9 años \\
Odar Chuy & $\begin{array}{c}\text { BCP } \\
\text { Especialista en canales } \\
\text { alternativos }\end{array}$ & BBVA años & 9 años \\
\hline
\end{tabular}

Nota: Datos de los especialistas entrevistados. Elaboración propia

\section{Diseño y abordaje principal}

En este apartado se detalla el cuestionario SERVQUAL con sus respectivas dimensiones (fiabilidad, capacidad de respuesta, seguridad, empatía y aspectos tangibles), al igual que el rango de evaluación (categorías). Además, se aplicó la confiabilidad del cuestionario, donde se empleaba la prueba estadística Alfa de Cronbach, la cual mide el grado en el que un instrumento produce resultados consistentes coherentes. Asimismo, se utilizó la técnica de entrevistas en profundad con los expertos en cajeros ATM.

\section{Cuestionario SERVQUAL}

La técnica cuantitativa de recolección de datos fue la encuesta, el instrumento de recolección fue el cuestionario. Las encuestas se aplicaron a 232 estudiantes universitarios de la modalidad Working Adult. Este es una versión modificada del SERVQUAL (Ver anexo 1.A), el original fue creado por Parasuraman et al. (1988), el 
cual mide la calidad que percibe el usuario expresado en términos de satisfacción e insatisfacción. Esto resulta de la comparación entre el comportamiento de las expectativas y percepciones (grado de discrepancias), los primeros miden el servicio que los usuarios esperan recibir, los segundos el servicio recibido.

Tanto las expectativas como las perspectivas se analizaron en base a 22 preguntas medidas en escala de Likert del 1 a 5, donde 1="Muy en desacuerdo", 2="En desacuerdo", $3=$ ="Ni de acuerdo ni en desacuerdo", 4="De acuerdo" y 5="Muy de acuerdo".

Las 22 preguntas conforman 5 dimensiones de la calidad:

Fiabilidad: $\quad$ Del 1 al 5

Capacidad de respuesta: Del 6 al 9

Seguridad: Del 10 al 13

Empatía: $\quad$ Del 14 al 18

Aspectos tangibles: $\quad$ Del 19 al 22

Para determinar satisfacción o insatisfacción se calculó la diferencia de puntajes (brechas) entre las perspectivas y las expectativas (P-E) de cada pregunta. Luego, se calculó el grado de satisfacción del estudiante para cada dimensión y de manera global para medir la calidad del servicio, tal como se muestra en la tabla 2 donde observamos la puntuación para evaluar la calidad del servicio, empleando la escala de Likert en las encuestas.

Tabla 2 Escala Likert.

\begin{tabular}{c|c|c|c|c}
\hline $\mathbf{1}$ & $\mathbf{2}$ & $\mathbf{3}$ & $\mathbf{4}$ & $\mathbf{5}$ \\
$\begin{array}{c}\text { Muy en } \\
\text { desacuerdo }\end{array}$ & $\begin{array}{c}\text { En } \\
\text { desacuerdo }\end{array}$ & $\begin{array}{c}\text { Ni de acuerdo } \\
\text { Ni en desacuerdo }\end{array}$ & De acuerdo & $\begin{array}{c}\text { Muy de } \\
\text { acuerdo }\end{array}$ \\
\hline
\end{tabular}

Nota. Se ha empleado la puntuación con escala del 1 al 5. 


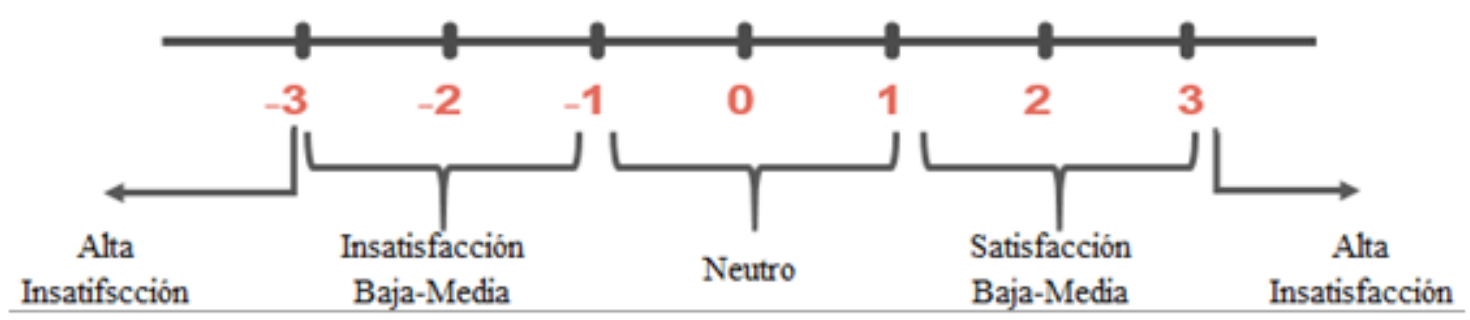

Figura 3. Grado de Satisfacción para escala Likert. Elaboración propia.

Validez y confiabilidad del instrumento:

El instrumento SERVQUAL fue creado y validado por Parasuraman et al. (1988) sin embargo, esto fue para un contexto distinto al de la presente investigación. No obstante, en la investigación titulada la "Gestión de la calidad y la satisfacción del usuario de los cajeros automáticos del Banco de la Nación en el año 2015" (Vega, 2017), siendo uno de los objetivos determinar la calidad del servicio en el uso de cajeros ATM, elaboraron un instrumento con las mismas dimensiones utilizadas en esta investigación siendo validado en contenido por juicio de expertos. Por tal motivo, no fue necesario realizar una comprobación, ya que el instrumento utilizado fue validado.

Por otro lado, al ser un instrumento adaptado del SERVQUAL, y aplicado a una población de estudio con características similares como uso de cajeros ATM y estudiantes de la modalidad Working Adult de la Universidad UPC, se realizó la estimación de la confiabilidad del instrumento. Para la realización de este procedimiento, se utilizó una prueba o muestra piloto, que según la literatura revisada no existe un tamaño ideal, solo se recomienda que la muestra seleccionada proceda de la misma población con características similares a la muestra de estudio. En este caso la muestra piloto fue de 110 estudiantes, obteniéndose un coeficiente de confiabilidad alfa de Cronbach de 0.8, considerándose un instrumento altamente confiable, tal como se observa en el Anexo 4.

\section{Guía de entrevista}

En el anexo 1.B se muestra la guía de entrevista, esta contiene 6 preguntas abiertas que sirvieron de introducción, buscando que el entrevistado (especialista en cajeros ATM) detalle en gran medida la calidad que, desde su punto de vista, presentan los cajeros ATM que se encuentran dentro de la universidad. Además, se buscó obtener información formal 
acerca del impacto que generan los cajeros ATM en los estudiantes universitarios y cuáles son los aspectos que más valoran los usuarios.

Finalmente, las respuestas fueron contrastadas con la calidad percibida por los estudiantes universitarios usuarios de los ATM y las expectativas que tienen frente al servicio.

\section{Segmentos}

Los cuestionarios fueron dirigidos a estudiantes universitarios usuarios de los cajeros ATM que se encontraban dentro del campus de la universidad, varones y mujeres con edades entre los 25 y 36 años, estudiantes bajo la modalidad Working Adult.

Las entrevistas fueron dirigidas a expertos en cajeros ATM quienes tienen una amplia experiencia laboral promedio 9 años trabajando en el área de Canales Alternativos de tres entidades bancarias, desempeñando cargos de especialistas o gerenciales con amplio conocimiento en temas relacionados a cajeros ATM, información validada con LinkedIn.

\section{Técnicas para el procesamiento y análisis de información}

Considerando la cantidad de variables analizadas en simultáneo, el análisis fue:

Análisis univariado:

Se realizó el análisis estadístico de las ambas variables mediante el cálculo de las medidas de tendencia central (media, mediana, moda, varianza) y de dispersión (desviación estándar, mínimo, máximo). El análisis estadístico de las variables se realizó mediante el cálculo de las frecuencias absolutas (conteo) y relativas (\%).

Análisis bivariado:

Para la evaluación de la relación entre las dimensiones: fiabilidad, capacidad de respuesta, seguridad, empatía, aspectos tangibles y la calidad de servicio, se empleó el Coeficiente de Correlación de Pearson. El Coeficiente de Correlación de Pearson: es un índice que mide el grado de relación entre dos variables cuantitativas y varía entre 0 y 1 , donde 0 es considerado como "No existe correlación alguna entre las variables" y 1 como “Correlación positiva perfecta" tal como se muestra en la tabla 3. 
Tabla 3 Grado de correlación según coeficiente R de Pearson

\begin{tabular}{cc}
\hline Coeficiente & Grado de correlación \\
\hline & No existe correlación alguna entre las \\
variables \\
$+0<\mathrm{r}<+0.2$ & Correlación muy baja \\
$+0.2<\mathrm{r}<+0.4$ & Correlación baja \\
$+0.4<\mathrm{r}<+0.6$ & Correlación moderada \\
$+0.6<\mathrm{r}<+0.8$ & Correlación alta \\
$+0.8<\mathrm{r}<+1$ & Correlación muy alta \\
1 & Correlación perfecta \\
\hline
\end{tabular}

Nota: Relación de variables. Adaptado de "Introducción a la estadística" por Bisquerra, 1987.

Regresión

El esquema básico de análisis de regresión se basa en un modelo en el cual se analiza la relación entre una variable dependiente y una o más variables independientes. Es decir, resulta de interés conocer el efecto que una o más variables pueden causar sobre otra. Los métodos de regresión estudian la construcción de modelos para explicar la dependencia entre una variable dependiente (Y) y la(s) variable(s) independiente(s), X.

La estructura de un modelo lineal es de la siguiente manera:

$$
\mathrm{Y}=\mathrm{B}_{0}+\mathrm{B}_{1} \mathrm{X}+\mathrm{e}
$$

Estimación de los parámetros

Donde:

$$
\begin{gathered}
\hat{\beta_{1}}=\frac{S S_{x y}}{S S_{x x}} \\
\hat{\beta_{0}}=\bar{y}-\hat{\beta_{1}} \bar{x} \\
S S_{x y}=\sum_{i=1}^{n}\left(x_{i}-\bar{x}\right)\left(y_{i}-\bar{y}\right)=\sum_{i=1}^{n} x_{i} y_{i}-n \bar{x} \bar{y} \\
S S_{x x}=\sum_{i=1}^{n}\left(x_{i}-\bar{x}\right)^{2}=\sum_{i=1}^{n} x_{i}^{2}-n \bar{x}^{2}=n \sigma_{x}^{2}
\end{gathered}
$$




\section{CAPÍTULO III ANÁLISIS DE DATOS Y RESULTADOS}

\section{Procedimiento: Procesamiento de la información}

\section{Análisis de datos cualitativos}

Se presenta un análisis acerca de la entrevista realizada a los especialistas en cajeros ATM, con la finalidad de identificar las necesidades en las operaciones bancarias realizadas mediante cajeros automáticos.

A continuación, se citará de manera literal las respuestas de los entrevistados:

E1: Entrevistado $\mathrm{N}^{\circ} 1$.

Odar Chuy, gerente del área de Canales Alternativos en el BCP con 10 años de experiencia en canales alternativos.

\section{E2: Entrevistado $\mathrm{N}^{\circ} 2$.}

Marcos Medina, subgerente del área de Canales Alternativos en Interbank con 9 años de experiencia en temas relacionados a cajeros ATM.

E3: Entrevistado $N^{\circ} 3$.

Isabel Bravo, especialista en Canales Alternativos en BBVA con 9 años de experiencia en control de demandas y abastecimiento de cajeros ATM.

1.- Desde su punto de vista ¿nos podría indicar qué necesidades no cubiertas ha podido identificar en tu banco, respecto a los usuarios de cajeros automáticos instalados en la universidad? ¿Cuál es la más constante?

E1: ..., bueno en este caso nuestros clientes o usuarios también, requieren prácticamente ese tipo de canales (canales alternativos), hemos pasado de lo que es un cajero automático convencional, a pasar a un cajero que puede darte una multifunción... lo que se ha podido identificar son las operaciones de servicio de pago, lo depósitos en efectivo, 
las diferentes cuentas de ahorro, cuentas corrientes. Todo esto ha sido a través de las encuestas y de la información de parte de nuestras sucursales.

E2: ........ Una de las cosas que hemos podido identificar es que no está cubriendo todavía una necesidad, es un poco la viabilidad de las operaciones de las transacciones como por ejemplo: este sería ideal que ahora un cajero automático pueda tener operaciones, no sé, de pagos de algunos credipagos,...., no sería mucho más eficiente tener un medio como una ATM donde te permitiría realizar la transacción de pago por ahi mismo sin mover ninguna moneda, sin contar con ningún personal, este y haciéndolo desde in house probablemente porque van a estar hasta en su misma institución, sin embargo tenemos que ir de a pocos, ..., estamos entrando pero todavía falta.

E3:...., podemos encontrar debilidades, las cuales sería bueno corregir. Estamos hablando por ejemplo la facilidad de poder retirar dinero de bajo valor, como las monedas. ...., si bien es cierto, los bancos te dan la facilidad de poder retirar en sus cajeros con tarjetas de otros bancos, están deberían ser gratuitas, al menos dentro de las instalaciones de la universidad.

\section{2.- ¿Cuál es su percepción respecto a la calidad del servicio que brindan los cajeros} ATM instalados en la universidad? ¿Consideras que los usuarios se encuentren satisfechos?

E1:..., hacemos una análisis y un seguimiento de manera constante y la verdad es que nosotros tenemos varias ventajas una de las tantas es que acá queda nula la posibilidad de vandalismo, de estafas,..., el usuario valora mucho de estos ATM instalados en universidades, institutos o hasta en algunas empresas que también lo tenemos es un poco que puedan transaccionar con la confianza y con la seguridad que no va a pasar.

E2:..., es una percepción sumamente positiva,..., hacemos todo un despliegue, un protocolo de enseñanza, de educación a nuestros clientes de cara al uso de estos canales alternativos, creo que es positivo porque a los clientes permite acercase a las operaciones que normalmente pueden realizar dentro de una sucursal,..., asimismo permite una disposición, una viabilidad también de las transacciones diferentes que pueden realizar y pues una mejora, optimización, dentro de lo que son los tiempos de espera en una sucursal para poder realizar una operación de estos tipos. 
E3: ... no creo que satisfaga las necesidades a un 100\%, la calidad se trata de mejorar día a día pero tengamos en cuenta que un ATM o cajero automático tiene al menos 10 años de uso,..., lo ideal sería cambiarlo por ATM modernas, pero la realidad es distinta,...., por esta razón las mejoras son solamente sistemáticas.

\section{¿Consideras que los usuarios se encuentren satisfechos?}

E1: Sí, ya que pueden transaccionar con confianza y seguridad que no va a pasar nada.

E2: Consideramos que sí, hay una satisfacción,......debido al estudio del mercado financiero,..., tenemos una ardua labor con respecto a esto y se ve el impacto positivo dentro de los clientes financieros con respecto a los canales alternativos.

E3: Es de acuerdo completamente

\section{3.- De las 5 dimensiones relacionadas con la calidad del servicio: fiabilidad, capacidad de respuesta, seguridad, empatía y aspectos tangibles. ¿En qué orden colocaría tú las 5 dimensiones, evaluando a los cajeros ATM instalados en la universidad?}

E1: ...., lo primero tendría que ser la seguridad, la fiabilidad para transacción por este medio, el tercero sería los aspecto tangibles también y como cuarto la capacidad y como quinto la empatía

E2: ...una de las cosas más importantes es la seguridad, es un aspecto muy delicado, debido a que nos encontramos de cara a lo que es una previsión de fraude, robos, los cambiazos de tarjeta,..., lo segundo creo que sería la fiabilidad, donde buscamos que estos cajeros nos reduzca esos niveles de espera en la atención y ellos puedan realizar sus transacciones, el tercero creo que es la capacidad de respuesta es un canal que es sumamente positivo en el aspecto de que genera aun la satisfacción al cliente,..., como cuarto creo que son los aspectos tangibles, y tal vez el quinto en el orden que nosotros hemos podido identificar la empatía.

E3: Seguridad, fiabilidad, capacidad de respuesta, empatía, aspectos tangibles. 


\section{4.- ¿Cuáles son los problemas más frecuentes que reportan los estudiantes universitarios al utilizar el cajero ATM de la universidad? ¿Qué solución darían a los problemas más frecuentes?}

E1: ... los errores con la lectora, una desmagnetización de la banda electrónica con respecto a las tarjetas o los deteriores de los chips de las nuevas tarjetas que hacen que no permitan que salga la transacción, otras de las cosas podrían ser los pagos truncos,..., es por ende que los ATM siempre deben ser abastecidos con billetes de óptima calidad para que no sucedan estos casos.

E2: ....,con mayor frecuencia dentro de nuestros cajeros automáticos es la falla de lectura tal vez de las bandas magnéticas, de las tarjetas de débito como también de las tarjetas de crédito o también por el error de lectura dentro del chip,....Por lo que se ha buscado una solución inmediata, una respuesta lo más pronto posible, tenemos un consenso de servicio de 3 días útiles para poder hacer la devolución de este efectivo y del cual tenemos todo un equipo obviamente que hace las verificaciones respectivas.

E3: Atasco de las tarjetas, la no dispensación de dinero falla en el servicio (red), falta de denominación de dinero.

\section{5.- ¿En qué porcentaje considera se encuentran satisfechos los estudiantes universitarios con el servicio de cajeros ATM instalados en la universidad?}

E1: ...., satisfacción entre un 83 a un $85 \%$, vamos en crecimiento, sin embargo, el consumidor valora mucho la transaccionalidad que puedan tener todos los medio electrónicos, ahora tienen Smartphone y puedes hacer todo a través de los HOME BANKING o de las APPS que ahora tenemos, seria repotenciar o robustecer la propuesta de valor de cara a las transacciones propias.

E2:...., satisfacción dentro del 70-80\% lo cual creo que estamos muy cerca de esto, pienso que es positivo, sin embargo, creo que todavía hay algunas cosas que nosotros podamos mejorar, como el tema de la bancarización que efectivamente es algo que nosotros venimos tratando de cambiar con las políticas de cultura de ahorros para que los clientes puedan conocer de los productos finales y los que más se adecuen a sus necesidades. 
E3: Un 70\% de personas estarían satisfecho, lo más importante es inversión por las empresas bancarias y que estos tengan un estándar de calidad fijado para todos a través de la SBS (fiscalizadores). Se ha visto una mejoría en modernizar este tipo de servicios, pero si nos comparamos con países ya existen cajeros inteligentes en abundancia, donde puedes depositar, cobrar cheques y demás.

\section{¿Justo lo que tú me comentas como uno de los beneficios, ventajas diferenciales del monedero electrónico que tiene la entidad financiera donde tú trabajas, qué otro beneficio resaltante puedes rescatar, que te diferencie de otras entidades?}

E2:....., es precisamente el uso de nuestros cajeros multifuncionales sin la necesidad de tener una tarjeta de débito, o crédito, por lo que este usuario este aún no cliente, tiene la posibilidad de acercarse a un cajero multifuncional puede tocar la pantalla y se le apertura un menú de opciones donde pueden ellos realizar también operaciones de pagos de servicios, operaciones de pagos de tarjetas de crédito incluso, y depósitos también a través de lo que son transferencias interbancarias, esto creo que es sumamente importante ya que hará la diferencia definitivamente de la propuesta de valor que nosotros tenemos dentro de nuestros canales alternativos.

\section{6.- ¿Tiene algún comentario o sugerencia final sobre la implementación de cajeros automáticos en la universidad?}

E1: Tienen una propuesta bastante ambiciosa, en un año, estamos adquiriendo un lote de ATM, lotes funcionales o mixtos, que acepten los depósitos en billetaje o moneda, y este mismo dinero que entraría para pagar servicios o cualquier índole, este mismo dinero reciclado para pagos,..., este mismo dinero que entra serviría para pagar, reduciría tiempo de abastecimiento, horas hombre y aseguraría la operativa constante del ATM sin parar, además queremos colocar ATM para aperturas cuentas digitales, y se viene implementando en varias de oficinas, a nivel local estamos a 70\% en nivel de oficinas, y queremos llegar a noviembre a la totalidad, y de ahí desplegar a puntos neutros.

E2: Efectivamente, sí,...., es que estos cajeros automático, estos canales alternativos sean también una plataforma de fidelización de clientes, poder hacer una apertura de cuenta de ahorro electrónico que pueda realizarse a través de un cajero automático por lo que también podría entregársele un tarjeta de débito, ..., estamos en un evaluación constante, 
creo que estamos yendo de manera muy positiva,..., manejamos protocolos de omnicanalidad, ..., en el caso de un pago de tarjeta de crédito en una sucursal si el pago es menor a 400 nuevos soles es un pago que para nosotros es derivable, nosotros dentro de este protocolo omnicanalidad buscamos acompañar a nuestros clientes brindándoles este servicio adicional de cara a la experiencia que pueda tener este cliente conocer una forma más versátil de realizar sus operaciones, sus transacciones, ..., es algo que nosotros venimos gradualmente implementando y creo que el objetivo es ese, poder tener dentro de nuestros canales alternativos una plataforma de atención polifuncional...., por lo que venimos tratando de que esto ya se dé actualmente contamos con estos cajeros multifuncionales dentro de las sucursales, estamos empezando también a hacer el cambio de estos cajeros tradicionales.

E3: El tener un cajero automático dentro de las universidades es muy importante ya sea para los alumnos y personal de la misma universidad, sin embargo, para las empresas bancarias existen prioridades, es diferente modernizar un ATM dentro de un centro comercial que en una universidad, ya que la universidad presenta tiempo de cierre ya sea por vacaciones, etc. 


\section{Análisis de datos cuantitativos}

Se presentan los resultados de los 232 estudiantes universitarios de la modalidad Working Adult de la Universidad Peruana de Ciencias Aplicadas UPC quienes fueron encuestados dentro del campus de la universidad.

Se emplearon tres tipos de análisis, el primer análisis es el descriptivo, donde se detalla las frecuencias relativas (\%), absolutas (n), promedio y desviación estándar. En el segundo análisis se describe las correlaciones entre la calidad con las dimensiones. En el tercer análisis se detalla el análisis de regresión múltiple (calidad y sus dimensiones) y el análisis de regresión simple (calidad según dimensión).

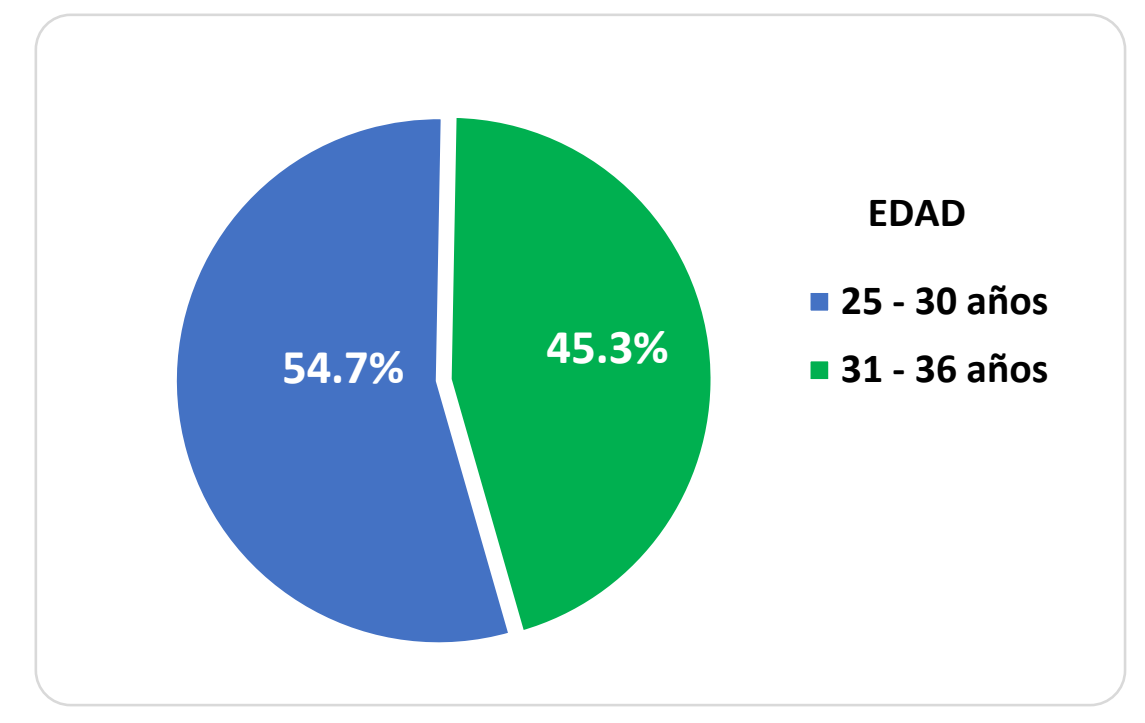

Figura 4. Edad de los estudiantes universitarios encuestados. Elaboración propia 
Tabla 4 Características generales de los estudiantes universitarios

\begin{tabular}{|c|c|c|}
\hline \multicolumn{3}{|c|}{ Caracteristicas generales } \\
\hline & \multirow{2}{*}{\multicolumn{2}{|c|}{$\begin{array}{l}? \pm \text { DS (Min. - Max.) } \\
30.5 \pm 2.9(25-36)\end{array}$}} \\
\hline \multirow[t]{2}{*}{ Edad } & & \\
\hline & $\mathrm{N}$ & $\%$ \\
\hline $25-30$ años & 127 & 54.7 \\
\hline $31-36$ años & 105 & 45.3 \\
\hline \multicolumn{3}{|l|}{ Sexo } \\
\hline Masculino & 94 & 40.5 \\
\hline Femenino & 138 & 59.5 \\
\hline \multicolumn{3}{|l|}{ Año } \\
\hline 1er año & 32 & 13.8 \\
\hline 2do año & 67 & 28.9 \\
\hline 3er año & 72 & 31.0 \\
\hline 4to año & 38 & 16.4 \\
\hline 5to año & 23 & 9.9 \\
\hline Total & 232 & 100 \\
\hline
\end{tabular}

Nota: Rango de edades y año de estudio de estudiantes encuestados. Elaboración propia.

Según la Tabla 4, de un total de 232 personas, la edad promedio de los estudiantes universitarios que participaron en esta investigación fue 30.5 años, que oscilaban mayormente entre 25 y 30 años con el $54.7 \%$, y entre 31 y 36 años con el $45.3 \%$, tal como se muestra en el Grafico 1. Existe el predominio del sexo femenino (59.5\%). 


\section{FIABILIDAD}

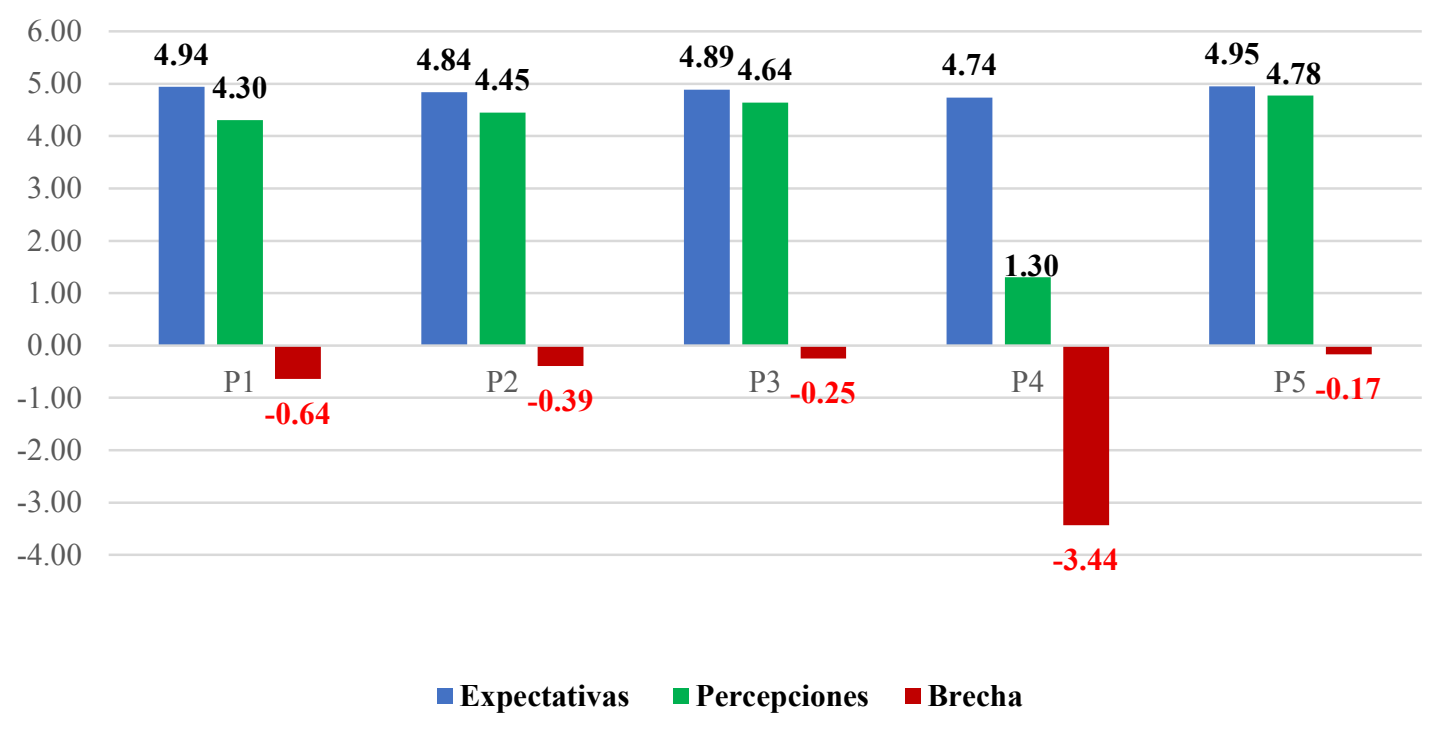

Figura 5. Resultados de encuesta en la dimensión Fiabilidad. Elaboración propia.

Tabla 5 Promedio de resultados de las encuestas en la dimensión Fiabilidad

\begin{tabular}{|c|c|c|c|c|c|c|}
\hline \multirow{3}{*}{$\begin{array}{c}\text { Fiabilidad } \\
\text { P1= Solución rápida de problemas }\end{array}$} & \multicolumn{2}{|c|}{ Expectativas (E) } & \multicolumn{2}{|c|}{ Percepciones $(\mathrm{P})$} & \multirow{2}{*}{\multicolumn{2}{|c|}{$\begin{array}{c}\text { Brechas } \\
\text { (P-E) }\end{array}$}} \\
\hline & \multirow{2}{*}{$\begin{array}{c}\text { Promedio } \\
4.94\end{array}$} & \multirow{2}{*}{$\frac{\text { DS }}{0.33}$} & \multirow{2}{*}{$\begin{array}{c}\text { Promedio } \\
4.30\end{array}$} & \multirow{2}{*}{$\frac{\mathrm{DS}}{1.16}$} & & \\
\hline & & & & & -0.64 & 0.83 \\
\hline $\mathrm{P} 2=$ Buen abastecimierto & 4.84 & 0.51 & 4.45 & 0.89 & -0.39 & 0.38 \\
\hline P3= Tiempo de uso perinente & 4.89 & 0.34 & 4.64 & 0.78 & -0.25 & 0.44 \\
\hline P4: Recepción de reclamos & 4.74 & 0.69 & 1.30 & 1.00 & -3.44 & 0.31 \\
\hline P5= Entrega de billetes genuinos & 4.95 & 0.26 & 4.78 & 0.70 & -0.17 & 0.44 \\
\hline
\end{tabular}

Nota: DS= Desviación estándar. Encuesta tomada a Working Adult. Elaboración propia.

En el gráfico 2 y la tabla 5 se observa el análisis de expectativas, percepciones y brechas para la dimensión Fiabilidad del servicio de cajeros ATM, donde el ítem 4 "Los cajeros ATM deben imprimir un ticket de reclamo cuando se tenga problemas con retención de tarjeta o retiro de dinero en efectivo" es la que presenta una alto grado de insatisfacción, ya que se obtuvo un puntaje promedio en la brecha de -3.44. A diferencia de los ítems 5 “Entrega de billetes genuinos a través de los cajeros ATM", con una brecha de -0.174, el 
ítem 3 "Tiempo de uso pertinente de uso" con una brecha de -0.25 , el ítem, 2 "Buen abastecimiento" con una brecha de -0.39 y el ítem 1 "Solución rápida de problemas" con una brecha de -0.64 , se puede observar que los estudiantes universitarios tienen un grado de satisfacción neutro.

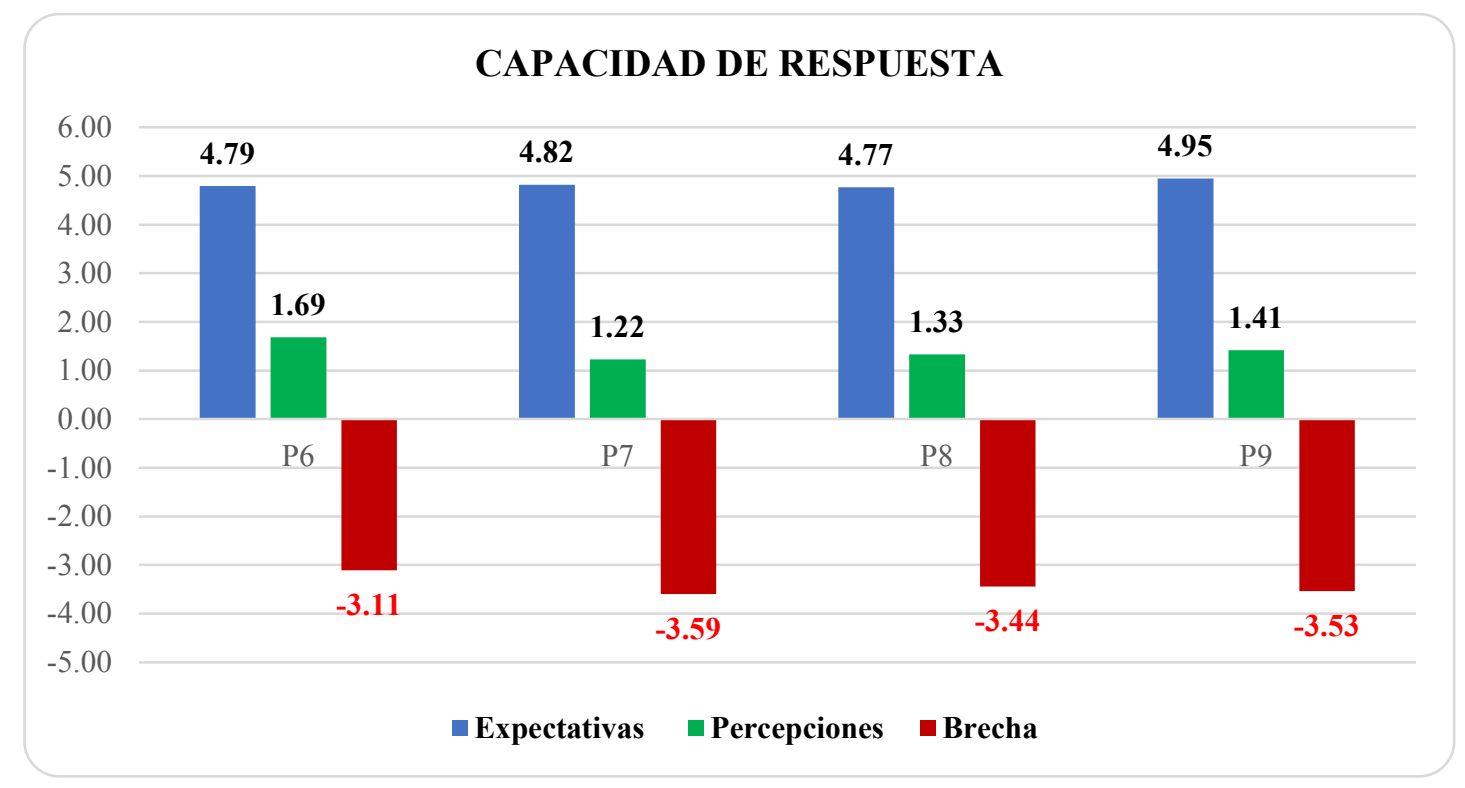

Figura 6. Resultados de encuesta en la dimensión Capacidad de Respuesta. Elaboración propia.

Tabla 6 Promedio de resultados de las encuestas y la Capacidad de Respuesta

\begin{tabular}{lccccccc}
\hline \multirow{2}{*}{ Capacidad de respuesta } & \multicolumn{2}{c}{ Expectativas } & \multicolumn{2}{c}{ Percepciones } & \multicolumn{2}{c}{ Brechas } \\
& Promedio & DS & Promedio & DS & & \\
\hline P6 = Servicio asistido & 4.79 & 0.62 & 1.69 & 1.35 & -3.11 & 0.73 \\
P7 = Servicio vinculado a la universidad & 4.82 & 0.61 & 1.22 & 0.79 & -3.59 & 0.18 \\
P8 = Posibilidad de depósito interbancario & 4.77 & 0.71 & 1.33 & 0.92 & -3.44 & 0.21 \\
P9 = Existencia de dispensador de monedas & 4.95 & 0.26 & 1.41 & 0.90 & -3.53 & 0.64 \\
\hline
\end{tabular}

Nota : DS= Desviación estándar. Encuesta tomada a Working Adult. Elaboración propia.

En el gráfico 3 y la tabla 6 se obtuvo el análisis de brechas para la dimensión Capacidad de Respuesta del servicio de cajeros ATM, donde los ítems 6, 7, 8 y 9 "Servicio asistido"; "Servicio vinculado a la universidad"; "Posibilidad de depósito interbancario" y "Existencia de dispensador de monedas" los puntajes promedios de las brechas oscilan 
entre -3.11 y -3.59 , siendo equivalente a una alta insatisfacción con el servicio que aún no se adecúa en su totalidad a las necesidades de los estudiantes.

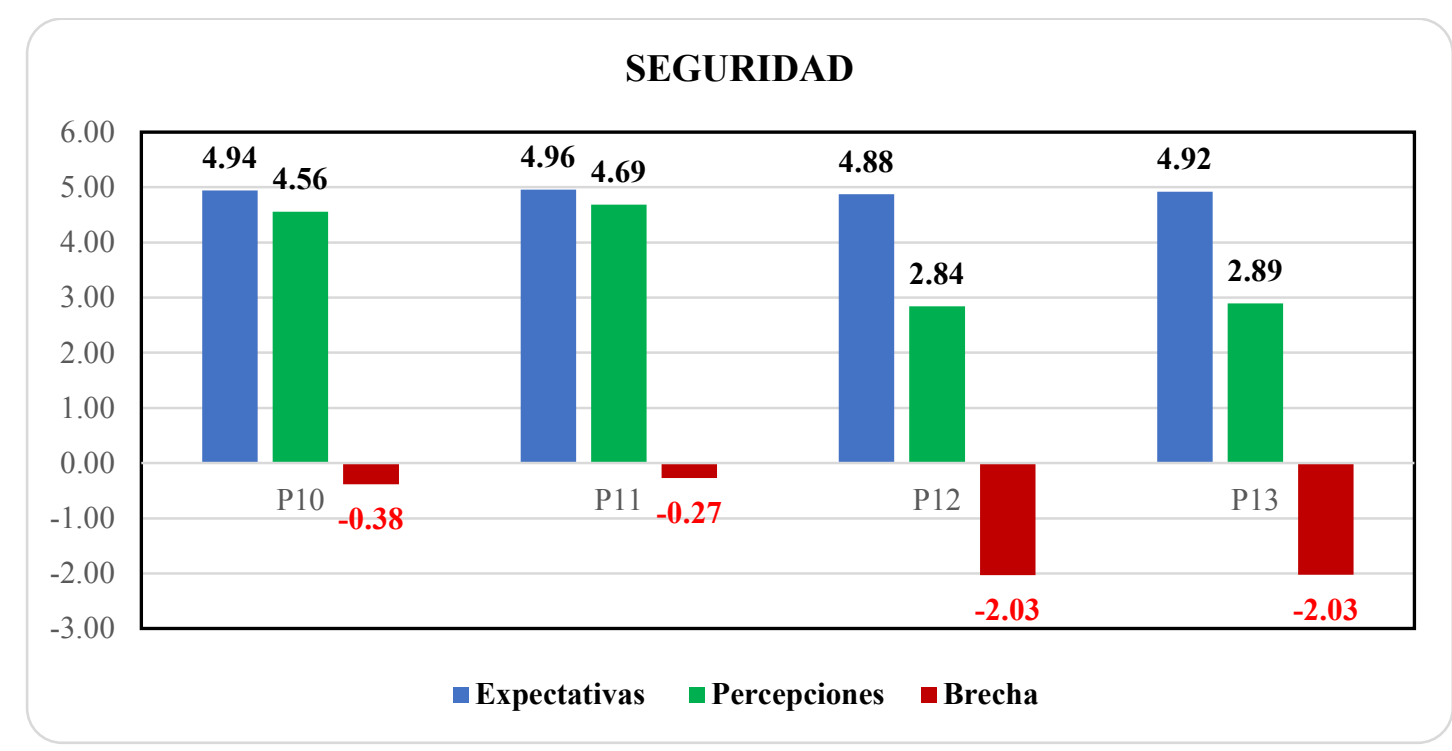

Figura 7. Resultados de encuesta en la dimensión Seguridad. Elaboración propia.

Tabla 7 Promedio de resultados de las encuestas en la dimensión Seguridad

\begin{tabular}{lccccccc}
\hline \multirow{2}{*}{ Seguridad } & \multicolumn{3}{c}{ Expectativas } & \multicolumn{3}{c}{ Percepciones } & \multirow{2}{*}{ Brechas } \\
\cline { 2 - 6 } & Promedio & DS & Promedio & DS & & \\
\hline P10 = Vigilancia adecuada & 4.94 & 0.33 & 4.56 & 1.00 & -0.38 & 0.67 \\
P11 = Protección ante fraudes o clonaciones & 4.96 & 0.24 & 4.69 & 0.94 & -0.27 & 0.69 \\
P12 = Irterfaz segura y amigable & 4.88 & 0.42 & 2.84 & 1.47 & -2.03 & 1.05 \\
P13 = Menú seguro y personalizado & 4.92 & 0.27 & 2.89 & 1.66 & -2.03 & 1.38 \\
\hline
\end{tabular}

Nota: DS= Desviación estándar. Encuesta tomada a Working Adult. Elaboración propia.

En el gráfico 4 y la tabla 7 se observa que en el análisis de brechas para la dimensión Seguridad, los ítems 12 y 13 "Interfaz segura y amigable” y "Menú seguro y personalizado" el puntaje promedio de ambas brechas fueron de -2.03 para cada uno, es decir, los estudiantes universitarios tienen un grado de insatisfacción baja-media. En cambio, en los ítems 10 y 11, "Vigilancia adecuada" y "Protección ante fraudes o clonaciones", los estudiantes universitarios presentan un grado de satisfacción, representado por los puntajes en cada brecha de -0.38 y -0.27 respectivamente. 


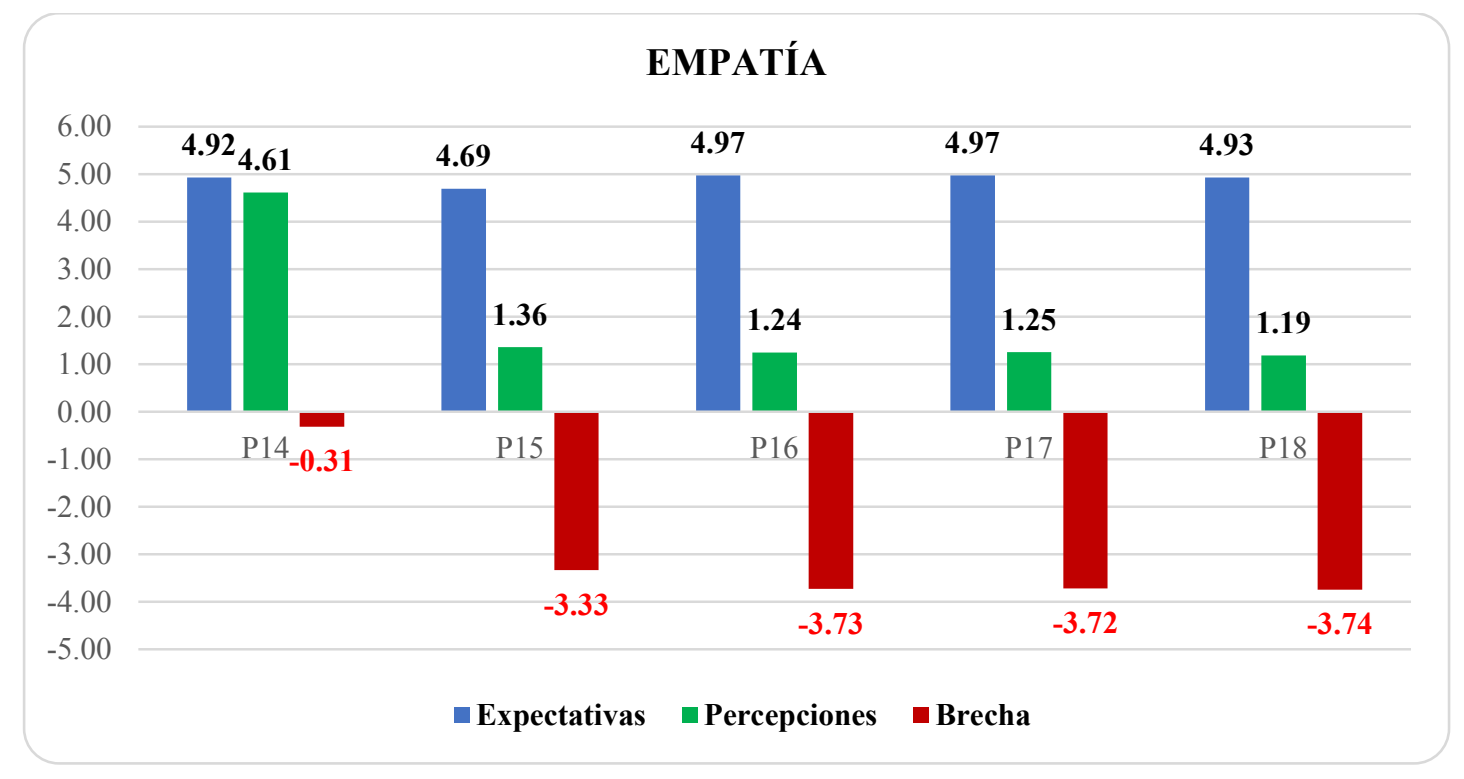

Figura 8. Resultados de encuesta en la dimensión Empatía. Elaboración propia.

Tabla 8 Promedio de resultados de las encuestas en la dimensión Empatía

\begin{tabular}{lccccccc}
\hline \multirow{2}{*}{ Empatia } & \multicolumn{3}{c}{ Expectativas } & \multicolumn{3}{c}{ Percepciones } & \multicolumn{2}{c}{ Brechas } \\
\cline { 2 - 5 } & Promedio & DS & Promedio & DS & & \\
\hline P14 = Abastecimiento constante & 4.92 & 0.31 & 4.61 & 0.92 & -0.31 & 0.61 \\
P15 = Presencia de personal de asistencia & 4.69 & 0.94 & 1.36 & 1.06 & -3.33 & 0.12 \\
P16 = Posibilidad de apertura de cuertas & 4.97 & 0.18 & 1.24 & 0.87 & -3.72 & 0.69 \\
P17 = Disponibilidad de atención a discapacitados & 4.97 & 0.23 & 1.25 & 0.89 & -3.72 & 0.67 \\
P18 = Servicio oriertada al cliente universitario & 4.83 & 0.59 & 1.19 & 0.75 & -3.64 & 0.16 \\
\hline
\end{tabular}

Nota $:$ DS= Desviación estándar. Encuesta tomada a Working Adult. Elaboración propia.

En el gráfico 5 y la tabla 8 se observa que para el análisis de brechas en cuanto a la dimensión Empatía en los ítems 15, 16, 17 y 18 "Presencia de personal de asistencia”; "Posibilidad de apertura de cuentas"; "Disponibilidad de atención a discapacitados" y "Servicio orientada al cliente universitario" el puntaje promedio de las brechas oscilaba entre -3.33 y -3.72 , es decir, los estudiantes tienen un alto grado de insatisfacción. En cambio, en el ítem 14 "Los cajeros ATM son abastecidos de dinero en horarios convenientes" la brecha fue de -0.31 , es decir un grado de satisfacción neutro. 


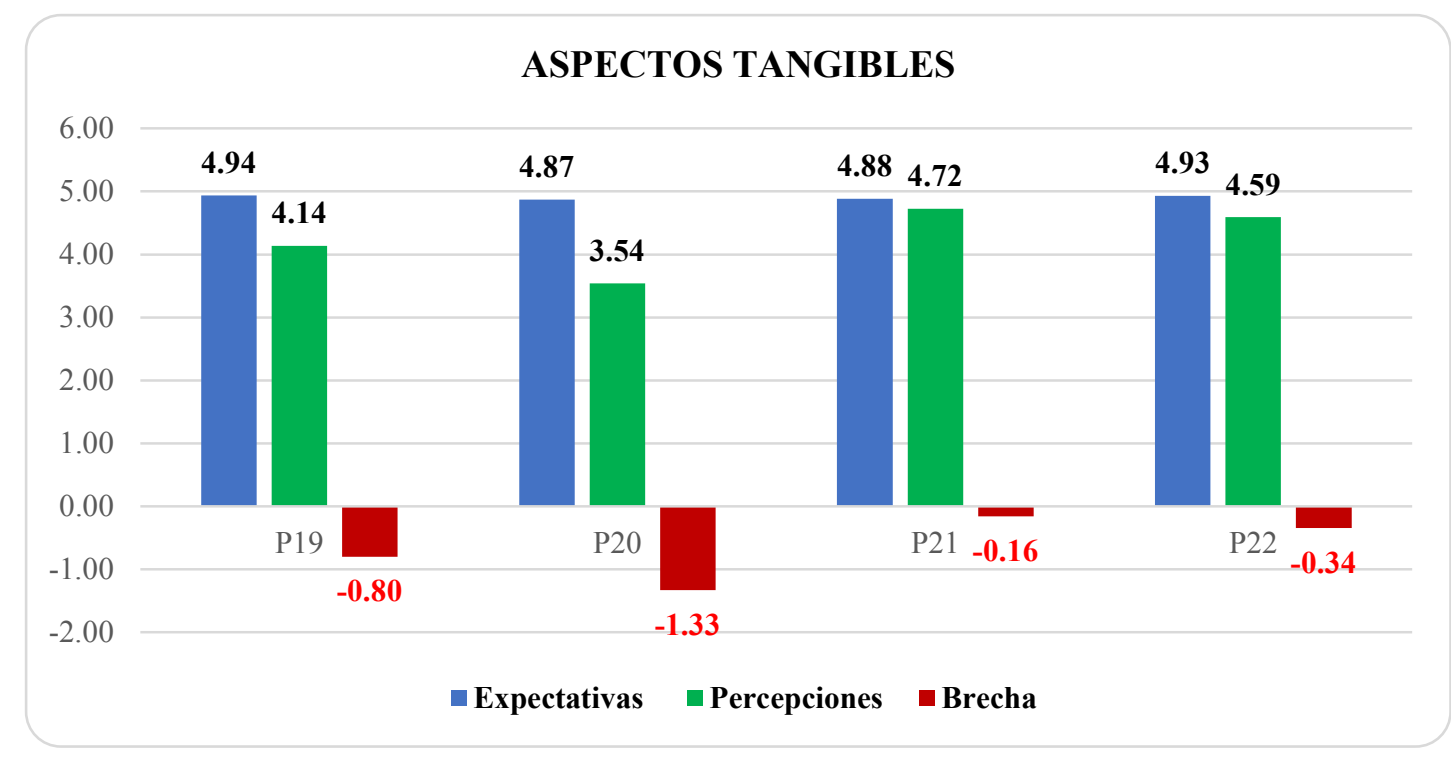

Figura 9. Resultados de encuesta en la dimensión Aspectos Tangibles. Elaboración propia.

Tabla 9 Promedio de resultados de las encuestas en la dimensión Aspectos Tangibles

\begin{tabular}{lccccccc}
\hline \multirow{2}{*}{ Aspectos tangibles } & \multicolumn{3}{c}{ Expectativas } & \multicolumn{2}{c}{ Percepciones } & & \multirow{2}{*}{ Brechas } \\
\cline { 2 - 6 } & Promedio & DS & Promedio & DS & & \\
P19= Operatividad de cajero ATM & 4.94 & 0.28 & 4.14 & 1.33 & -0.80 & 1.05 \\
P20 = Disponibilidad de monedas y billetes más usados & 4.87 & 0.47 & 3.54 & 1.40 & -1.33 & 0.94 \\
P21 = Ubicación estratégica & 4.88 & 0.45 & 4.72 & 0.80 & -0.16 & 0.35 \\
P22= Limpieza adecuada & 4.93 & 0.34 & 4.59 & 0.81 & -0.34 & 0.46 \\
\hline
\end{tabular}

Nota: DS= Desviación estándar. Encuesta tomada a Working Adult. Elaboración propia.

En el gráfico 6 y la tabla 9 para la dimensión de Aspectos Tangibles se observa en el ítem 20 "Los cajeros ATM se encuentren mayormente abastecidos con billetes de s/20" que los estudiantes tienen una insatisfacción baja, debido a que el puntaje promedio en la brecha fue de -1.33. En cambio, en los ítems P19, P21 y P22, los estudiantes presentan un grado de satisfacción neutro respecto a la "Operatividad del cajero ATM"; "Ubicación estratégica" y "Limpieza adecuada", debido a que el puntaje promedio oscila entre -0.16 y -0.80. 


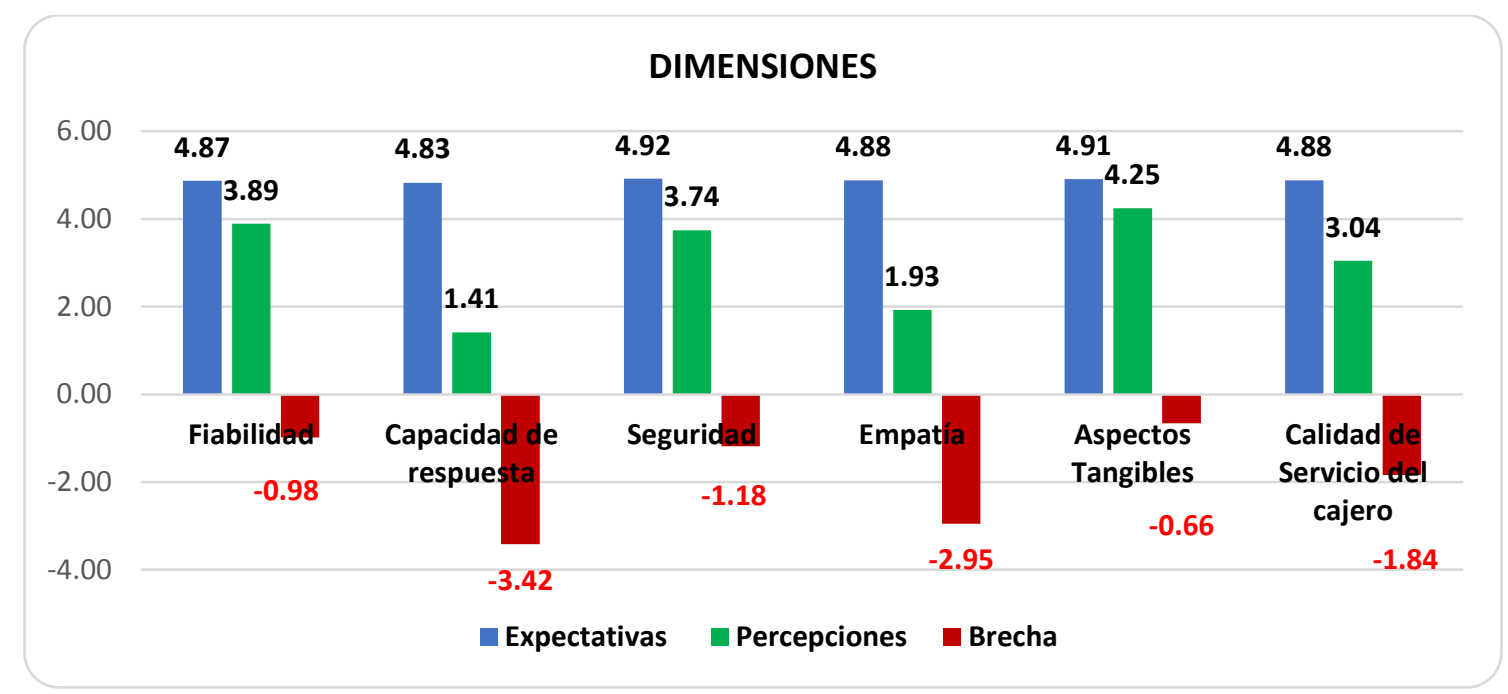

Figura 10. Resultados de encuesta en las cinco dimensiones de la calidad de servicio. Elaboración propia.

Tabla 10 Promedio de resultados de las encuestas en las cinco dimensiones

\begin{tabular}{lccccccc}
\hline \multirow{2}{*}{ Dimensiones } & \multicolumn{2}{c}{ Expectativas } & \multicolumn{2}{c}{ Percepciones } & \multicolumn{2}{c}{ Brechas } \\
\cline { 2 - 5 } & Promedio & DS & Promedio & DS & & \\
\hline Fiabilidad & 4.87 & 0.29 & 3.89 & 0.55 & -0.98 & 0.25 \\
Capacidad de respuesta & 4.83 & 0.43 & 1.41 & 0.81 & -3.42 & 0.38 \\
Segunidad & 4.92 & 0.22 & 3.74 & 0.82 & -1.18 & 0.60 \\
Empaja & 4.88 & 0.32 & 1.93 & 0.65 & -2.94 & 0.33 \\
Aspectos Tangibles & 4.91 & 0.29 & 4.25 & 0.78 & -0.66 & 0.49 \\
Calidad de Servicio del cajero & 4.88 & 0.31 & 3.05 & 0.72 & -1.84 & 0.41 \\
\hline
\end{tabular}

Nota : DS= Desviación estándar. Encuesta tomada a Working Adult. Elaboración propia.

En el gráfico 7 y la tabla 10 observamos que el resultado final del grado de satisfacción para la Calidad del Servicio de ATM fue de -1.84, significa que los estudiantes tienen un grado de insatisfacción bajo con el servicio. En la dimensión Capacidad de Respuesta la brecha es -3.42 es decir, los estudiantes tienen un alto grado de insatisfacción. En el caso de las dimensiones Empatía con -2.94 y Seguridad con -1.18 reflejan un grado de insatisfacción medio. En las dimensiones Aspectos Tangibles y Fiabilidad con -0.66 y 0.98 de brecha, nos revela que los estudiantes tienen un grado de satisfacción neutro con la calidad de servicio. 
Análisis de correlación de Pearson

Tabla 11 Correlación en las cinco dimensiones SERVQUAL

\begin{tabular}{lccc}
\hline \multirow{2}{*}{ Correlación de Pearson } & \multicolumn{3}{c}{ Calidad del servicio del cajero } \\
\cline { 2 - 4 } & $\mathrm{r}$ & Sig. (bilateral) & $\mathrm{N}$ \\
\hline Fiabilidad & 0.918 & 0.000 & 232 \\
Capacidad de Respuesta & 0.491 & 0.000 & 232 \\
Seguridad & 0.623 & 0.000 & 232 \\
Empatia & 0.545 & 0.000 & 232 \\
Aspectos Tangibles & 0.508 & 0.000 & 232 \\
\hline
\end{tabular}

Nota: Dimensión más cercana a r=1 tiene mayor relevancia para considerar Calidad. Elaboración propia.

En la Tabla 11 se observa que la dimensión Fiabilidad está entre 0.90 y 1 , el cual es considerado como correlación positiva perfecta. Esto quiere decir que es considerada por los universitarios encuestados como la dimensión con la percepción más alta, ya que contiene puntos sumamente relevantes dentro de la Calidad del Servicio tales como: "Solución rápida", "Buen abastecimiento de dinero", "Tiempo de uso del ATM pertinente", "Recepción de reclamos" y "Billetes genuinos entregados".

A diferencia de la dimensión Capacidad de Respuesta cuyo coeficiente de correlación es de 0.491 , es decir tiene correlación media y positiva, debido a que es necesario que se complemente de otra dimensión para que exista una alta calidad de servicio. 
Tabla 12 Correlación de la Calidad SERVQUAL con cada una de las cinco dimensiones

\begin{tabular}{|c|c|c|c|}
\hline \multirow{2}{*}{ Items } & \multicolumn{3}{|c|}{ Calidad del servicio del cajero } \\
\hline & $\mathrm{r}$ & Sig. (bilateral) & $\mathrm{N}$ \\
\hline \multicolumn{4}{|l|}{ Fiabilidad } \\
\hline P1= Solución rápida de problemas & 0.562 & 0.000 & 232 \\
\hline $\mathrm{P} 2=$ Buen abastecimiento & 0.647 & 0.000 & 232 \\
\hline P3= Tiempo de uso pertinente & 0.528 & 0.000 & 232 \\
\hline P4= Recepción de reclamos & 0.527 & 0.000 & 232 \\
\hline P5= Entrega de billetes genunos & 0.549 & 0.000 & 232 \\
\hline \multicolumn{4}{|l|}{ Capacidad de Respuesta } \\
\hline P6 = Servicio asistido & 0.290 & 0.000 & 232 \\
\hline P7 = Servicio vinculado a la universidad & 0.505 & 0.000 & 232 \\
\hline P8= Posibilidad de depósito interbancario & 0.412 & 0.000 & 232 \\
\hline $\mathrm{Pg}=$ Existencia de dispensador de monedas & 0.441 & 0.000 & 232 \\
\hline \multicolumn{4}{|l|}{ Seguridad } \\
\hline P10 = Vigilancia adecuada & 0.334 & 0.000 & 232 \\
\hline P11 = Protección ante fraudes o clonaciones & 0.318 & 0.000 & 232 \\
\hline P12 = Irterfaz segura y amigable & 0.492 & 0.000 & 232 \\
\hline P13 = Menú seguro y personalizado & 0.439 & 0.000 & 232 \\
\hline \multicolumn{4}{|l|}{ Empatia } \\
\hline P14 = Abastecimiento constarte & 0.375 & 0.000 & 232 \\
\hline P15 = Presencia de personal de asistencia & 0.295 & 0.000 & 232 \\
\hline P16 = Posibilidad de apertura de cuentas & 0.437 & 0.000 & 232 \\
\hline P17 = Disponibilidad de atención a discapacitados & 0.481 & 0.000 & 232 \\
\hline P18 = Servicio orientada al clierte universitario & 0.388 & 0.000 & 232 \\
\hline \multicolumn{4}{|l|}{ Aspectos Tangibles } \\
\hline P19= Servicio $24 / 7$ & 0.277 & 0.000 & 232 \\
\hline P20 = Disponibilidad de monedas y billetes más usados & 0.385 & 0.000 & 232 \\
\hline P21= Ubicación estratégica & 0.367 & 0.000 & 232 \\
\hline P22= Limpieza adecuada & 0.346 & 0.000 & 232 \\
\hline
\end{tabular}

Nota: Dimensión más cercana a $\mathrm{r}=1$ tiene mayor relevancia para considerar Calidad. Elaboración propia.

En la Tabla 12 se muestran los resultados del coeficiente de Pearson para cada ítem por dimensión correlacionada con la calidad de servicio. Se evidencia que el ítem 2 "Los cajeros ATM brindan un buen servicio al mantenerse abastecidos" es la que tiene un mayor valor del coeficiente de correlación $(\mathrm{r}=0.647 ; \mathrm{p}<0.001)$ el cual es considerado como una correlación positiva perfecta, es decir, cada vez que los estudiantes usan el servicio de retiro de dinero y los cajeros ATM se encuentran abastecidos es percibido como alta calidad del servicio. En cambio en los ítem P6 "Servicio asistido"; ítem P10 "Vigilancia adecuada"; ítem P11 "Protección ante fraudes o clonaciones"; ítem P14 
"Abastecimiento constante" ítem P15 "Presencia de personal de asistencia"; ítem P18 "Servicio orientada al cliente universitario"; ítem P19 "Servicio 24/7"; ítem P20 "Disponibilidad de monedas y billetes más usados"; ítem P21 "Ubicación estratégica" e ítem P22 “Limpieza adecuada” los valores de la correlación oscilan entre 0.27 y 0.40, los cuales son considerados como una correlación muy débil pero positiva. Es decir que, a medida que los estudiantes perciban de manera satisfactoria en mayor frecuencia los ítems antes mencionados será mejor la calidad del servicio de los cajeros.

Análisis de regresión

Tabla 13 Resumen de la Calidad del Servicio ATM y las cinco dimensiones

\begin{tabular}{cccc}
\hline \multicolumn{4}{c}{ Resum en del modelo $^{\circ}$} \\
\hline Modelo & $\mathrm{R}$ & $\mathrm{R}$ cuadrado & R cuadrado aju stado \\
\hline 1 & $0.9955^{\circ}$ & 0.990 & 0.990 \\
\hline
\end{tabular}

Nota: a. Predictores (constante): Aspectos Tangibles, Capacidad de Respuesta, Seguridad, Fiabilidad, Empatía. b. Variable Dependiente: Calidad de servicio de Cajeros ATM. Elaboración propia.

La Tabla 13 muestra que el $\mathrm{R}^{2}$; coeficiente de determinación, alcanzó el valor igual a 0.990, el cual indica que las cinco dimensiones explican el 99\% de la calidad del servicio de cajeros ATM en la Universidad Peruana de Ciencias Aplicadas. En otras palabras, el modelo de regresión es adecuado para que la fiabilidad, capacidad de respuesta, seguridad, empatía y aspectos tangibles en conjunto determinen la calidad del servicio. 
Tabla 14 Anova de la ecuación de las cinco dimensiones de calidad

\begin{tabular}{|c|c|c|c|c|c|}
\hline \multicolumn{6}{|c|}{ ANOVA $^{a}$} \\
\hline Mbdelo & $\begin{array}{l}\text { Suma de } \\
\text { cuadrados }\end{array}$ & gl & Media cuadrática & $\mathrm{F}$ & Sig. \\
\hline Regresión & 162.246 & 5 & 32.449 & 4670.823 & $0.000^{\circ}$ \\
\hline Residuo & 1.570 & 226 & 0.007 & & \\
\hline Total & 13.817 & 231 & & & \\
\hline
\end{tabular}

Nota: a. Predictores (constante): Aspectos Tangibles, Capacidad de Respuesta, Seguridad, Fiabilidad, Empatía. b. Variable Dependiente: Calidad de servicio de Cajeros ATM. Elaboración propia.

En la Tabla 14 se presenta el Anova de la regresión, la cual muestra que el nivel de significancia de la distribución $\mathrm{F}$ es menor a 0.05 , lo que indica que existe una asociación significativa entre las dimensiones y la calidad total. Es decir que la calidad del servicio de los cajeros ATM se estima o predice muy bien a partir de la capacidad de respuesta, fiabilidad, seguridad, empatía y aspectos tangibles de los mismos cajeros.

Tabla 15 Coeficientes de Regresión de Calidad del Servicio y las cinco dimensiones

\begin{tabular}{|c|c|c|c|c|c|}
\hline \multicolumn{6}{|c|}{ Coeficientes $^{2}$} \\
\hline \multirow[t]{2}{*}{ Modelo } & \multicolumn{2}{|c|}{ Coeficientes no estandarizados } & \multirow{2}{*}{$\begin{array}{c}\begin{array}{c}\text { Coeficientes } \\
\text { estandarizados }\end{array} \\
\text { Beta }\end{array}$} & \multirow[t]{2}{*}{$\mathrm{t}$} & \multirow[t]{2}{*}{ Sig. } \\
\hline & $\mathrm{B}$ & Error estándar & & & \\
\hline (Constante) & -0.193 & 0.024 & & -7.907 & 0.000 \\
\hline Fiabilidad & 1.005 & 0.012 & 0.683 & 87.310 & 0.000 \\
\hline Capacidad de Respuesta & 0.190 & 0.008 & 0.215 & 25.315 & 0.000 \\
\hline Seguridad & 0.175 & 0.008 & 0.170 & 22.037 & 0.000 \\
\hline Empatia & 0.192 & 0.010 & 0.169 & 19.223 & 0.000 \\
\hline Aspectos Tangibles & 0.164 & 0.008 & 0.142 & 19.332 & 0.000 \\
\hline
\end{tabular}

Nota: Dimensiones de la Calidad del Servicio. Elaboración propia.

La Tabla 15 muestra los coeficientes de la ecuación de regresión. La columna denominada coeficientes no estandarizados contiene los coeficientes de regresión que definen la ecuación. El nivel de significancia, de la prueba $t$, de ambos coeficientes para todas las 
dimensiones es de cero absoluto y, al ser menor a 0.05 , se puede decir que las cinco dimensiones influyen en la calidad de servicio de cajeros ATM en la Universidad Peruana de Ciencias Aplicadas UPC. Así, la ecuación de la calidad total en función a las cinco dimensiones queda expresada de la siguiente manera:

$$
\mathrm{C}=1.005 * \mathrm{~F}+0.190 * \mathrm{CR}+0.175 * \mathrm{~S}+0.192 * \mathrm{E}+0.164 * \mathrm{~T}-0.193
$$

Tabla 16 Resumen de Regresión de Calidad del Servicio y la Fiabilidad

\begin{tabular}{lccc}
\hline \multicolumn{5}{c}{ Resumen del modelo } \\
\hline Modelo & $\mathrm{R}$ & R cuadrado & $\begin{array}{c}\text { R cuadrado } \\
\text { ajustado }\end{array}$ \\
\hline 1 & $0.900^{\circ}$ & 0.809 & 0.808 \\
\hline
\end{tabular}

Nota: a. Predictores (constante): Fiabilidad. b. Variable Dependiente: Calidad de servicio de ATM. Elaboración propia.

La Tabla 16 muestra que el $\mathrm{R}^{2}$ alcanza el valor igual a 0.809 , el cual indica que la dimensión fiabilidad explica el $80.9 \%$ de la calidad total en el servicio de cajeros ATM en la Universidad Peruana de Ciencias Aplicadas UPC. En otras palabras, el modelo de regresión es $80.9 \%$ adecuado para que la dimensión fiabilidad determine la calidad del servicio.

Tabla 17 Anova de la ecuación Fiabilidad

\begin{tabular}{|c|c|c|c|c|c|c|}
\hline \multicolumn{7}{|c|}{ ANOVA $^{2}$} \\
\hline \multicolumn{2}{|c|}{ Modelo } & Suma de cuadrados & $\mathrm{gl}$ & $\begin{array}{c}\text { Media } \\
\text { cuadrática }\end{array}$ & $\mathrm{F}$ & Sig. \\
\hline \multirow{3}{*}{1} & Regresión & 132.545 & 1 & 132.545 & 974.865 & $0.000^{\circ}$ \\
\hline & Residuo & 31.271 & 230 & 0.136 & & \\
\hline & Total & 163.817 & 231 & & & \\
\hline
\end{tabular}

Nota: a. Predictores (constante): Fiabilidad. b. Variable Dependiente: Calidad de servicio de ATM. Elaboración propia. 
En la Tabla 17 se presenta el Anova de la regresión, la cual muestra que el nivel de significancia de la distribución $\mathrm{F}$ es menor a 0.05 , lo que indica que existe una asociación significativa entre la dimensión fiabilidad y la calidad total. Es decir que la calidad del servicio se estima o predice bastante bien a partir de la Fiabilidad, a partir de la solución de problemas, buen abastecimiento, tiempo de uso pertinente, recepción de reclamos y entrega de billetes genuinos; donde a mayor fiabilidad en el servicio brindado por los cajeros ATM mayor será la calidad.

Tabla 18 Coeficientes de Regresión de Calidad de Servicio de Cajeros y la Fiabilidad

\begin{tabular}{|c|c|c|c|c|c|c|}
\hline \multicolumn{7}{|c|}{ Coeficientes ${ }^{2}$} \\
\hline \multirow{2}{*}{\multicolumn{2}{|c|}{ Modelo }} & \multicolumn{2}{|c|}{$\begin{array}{l}\text { Coeficientes no } \\
\text { estandarizados }\end{array}$} & \multirow{2}{*}{$\begin{array}{c}\begin{array}{c}\text { Coeficientes } \\
\text { estandanizados }\end{array} \\
\text { Beta }\end{array}$} & \multirow{2}{*}{$\mathrm{t}$} & \multirow{2}{*}{ Sig. } \\
\hline & & B & $\begin{array}{c}\text { Error } \\
\text { estándar }\end{array}$ & & & \\
\hline \multirow{2}{*}{1} & (Constante) & 1.036 & 0.048 & & 21.408 & 0.000 \\
\hline & Fiabilidad & 1.325 & 0.042 & 0.900 & 31.223 & 0.000 \\
\hline
\end{tabular}

Nota: a. Predictores (constante): Fiabilidad. b. Variable Dependiente: Calidad de servicio de ATM. Elaboración propia.

La Tabla 18 muestra los coeficientes de la ecuación de regresión. La columna denominada coeficientes no estandarizados contiene los coeficientes de regresión que definen la ecuación. El nivel de significancia, de la prueba $\mathrm{t}$, de ambos coeficientes para la dimensión es de cero absoluto y, al ser menor a 0.05 , se puede decir que la dimensión fiabilidad influye en la calidad de servicio de cajeros ATM en la Universidad Peruana de Ciencias Aplicadas UPC.

Así, la ecuación de la calidad total en función a la dimensión fiabilidad queda expresada de la siguiente manera:

$$
\mathrm{C}=1.325^{*} \mathrm{~F}+1.036
$$


Tabla 19 Resumen de Regresión de Calidad de Servicio y la Capacidad de Respuesta

\begin{tabular}{lccc}
\hline \multicolumn{3}{c}{ Resumen del modelo } & \\
Modelo & $\mathrm{R}$ & Rcuadrado & $\begin{array}{c}\text { Rcuadrado } \\
\text { ajustado }\end{array}$ \\
\hline 1 & $0.491^{\mathrm{s}}$ & 0.241 & 0.237 \\
\hline
\end{tabular}

Nota: a. Predictores (constante): Capacidad de Respuesta. b. Variable Dependiente: Calidad de servicio de ATM. Elaboración propia.

La Tabla 19 muestra que el $\mathrm{R}^{2}$ alcanza el mínimo valor, el cual indica que la dimensión capacidad de respuesta explica el $24.1 \%$ de la calidad total en el servicio de cajeros ATM en la Universidad Peruana de Ciencias Aplicadas UPC. En otras palabras, el modelo de regresión es $24.1 \%$ adecuado para que la capacidad de respuesta determine la calidad del servicio.

Tabla 20 Anova de la ecuación Capacidad de Respuesta

\begin{tabular}{|c|c|c|c|c|c|}
\hline \multicolumn{6}{|c|}{ ANOVA ${ }^{2}$} \\
\hline Modelo & $\begin{array}{l}\text { Suma de } \\
\text { cuadrados }\end{array}$ & gl & $\begin{array}{c}\text { Media } \\
\text { cuadrática }\end{array}$ & $F$ & Sig. \\
\hline Regresión & 39.414 & 1 & 39.414 & 72.871 & $0.000^{\circ}$ \\
\hline Residuo & 124.402 & 230 & 0.540 & & \\
\hline Total & 163.817 & 231 & & & \\
\hline
\end{tabular}

Nota: a. Predictores: (Capacidad de Respuesta). b. Variable Dependiente: Calidad de servicio de ATM. Elaboración propia.

En la Tabla 20 se presenta el Anova de la regresión, la cual muestra que el nivel de significancia de la distribución $\mathrm{F}$ es menor a 0.05 , lo que indica que existe una asociación significativa entre la dimensión capacidad de respuesta y la calidad total. Es decir que la calidad del servicio se estima o predice regularmente a partir de la capacidad de respuesta, a partir de un servicio asistido, servicio vinculado a la universidad, posibilidad de depósito interbancario y existencia de dispensador de monedas; donde no necesariamente a mayor capacidad de respuesta del servicio brindado por los cajeros ATM mayor será la calidad. 
Tabla 21 Coeficiente de Calidad del Servicio y Capacidad de Respuesta

\begin{tabular}{|c|c|c|c|c|c|}
\hline \multicolumn{6}{|c|}{ Coeficientes $^{2}$} \\
\hline \multirow[t]{2}{*}{ Modelo } & Coeficier & estandarizados & $\begin{array}{c}\text { Coeficiertes } \\
\text { estandarizados }\end{array}$ & \multirow[t]{2}{*}{$\mathrm{t}$} & \multirow[t]{2}{*}{ Sig. } \\
\hline & $\mathrm{B}$ & Error estándar & Beta & & \\
\hline (Constante) & 0.859 & 0.180 & & 4.757 & 0.000 \\
\hline Capacidad de Respuesta & 0.434 & 0.051 & .491 & 8.536 & 0.000 \\
\hline
\end{tabular}

Nota: Variable Dependiente: Capacidad de Respuesta. Elaboración propia.

La Tabla 21 muestra los coeficientes de la ecuación de regresión. La columna denominada coeficientes no estandarizados contiene los coeficientes de regresión que definen la ecuación. El nivel de significancia, de la prueba $t$, de ambos coeficientes para la dimensión es de cero absoluto y, al ser menor a 0.05 , se puede decir que la dimensión capacidad de respuesta influye en la calidad de servicio de cajeros ATM en la Universidad Peruana de Ciencias Aplicadas UPC. Así, la ecuación de la calidad total en función a la dimensión capacidad de respuesta queda expresada de la siguiente manera:

$$
\mathrm{C}=0.434 * \mathrm{CR}+0.859
$$


Tabla 22 Coeficiente de Regresión de Calidad de Servicio y Seguridad

\begin{tabular}{lccc}
\hline \multicolumn{4}{c}{ Resumen del modelo } \\
\hline Modelo & $\mathrm{R}$ & R cuadrado & $\begin{array}{c}\text { R cuadrado } \\
\text { ajustado }\end{array}$ \\
1 & $0,635^{\circ}$ & 0.403 & 0.400 \\
\hline
\end{tabular}

Nota: Variable Dependiente: Seguridad. Elaboración propia

La Tabla 22 muestra que el $\mathrm{R}^{2}$ alcanza valor igual a 0.403 , el cual indica que la dimensión seguridad explica el $40.3 \%$ de la calidad total en el servicio de cajeros ATM en la Universidad Peruana de Ciencias Aplicadas UPC. En otras palabras, el modelo de regresión es $40.3 \%$ adecuado para que la seguridad determine la calidad del servicio.

Tabla 23 Anova de la ecuación Seguridad

\begin{tabular}{lccccc}
\hline Modelo & $\begin{array}{c}\text { ANOVA2 } \\
\text { Suma de } \\
\text { cuadrados }\end{array}$ & gl & $\begin{array}{c}\text { Media } \\
\text { cuadrática }\end{array}$ & F & Sig. \\
\hline \multicolumn{1}{c}{ Regresión } & 65.954 & 1 & 65.954 & 155.008 & $0.000^{\circ}$ \\
1 Residuo & 97.862 & 230 & 0.425 & & \\
$\quad$ Total & 163.817 & 231 & & & \\
\hline
\end{tabular}

Nota: Variable Dependiente: Seguridad. Elaboración propia

En la Tabla 23 se presenta el ANOVA de la regresión, la cual muestra que el nivel de significancia de la distribución $\mathrm{F}$ es menor a 0.05 , lo que indica que existe una asociación significativa entre la dimensión seguridad y la calidad total. Es decir que la calidad del servicio se estima o predice regularmente a partir de la seguridad, a partir de una vigilancia adecuada, protección ante fraudes o clonaciones, interfaz segura y amigable y menú seguro y personalizado; donde no necesariamente a mayor seguridad en el servicio brindado por los cajeros ATM mayor será la calidad. 
Tabla 24 Coeficiente de Regresión de Calidad de Servicio y Seguridad

\begin{tabular}{|c|c|c|c|c|c|}
\hline \multicolumn{6}{|c|}{ Coeficientes } \\
\hline \multirow{2}{*}{ Modelo } & \multicolumn{2}{|c|}{$\begin{array}{l}\text { Coeficientes no } \\
\text { estandarizados }\end{array}$} & \multirow{2}{*}{$\begin{array}{c}\text { Coeficientes } \\
\text { estandarizados } \\
\text { Beta }\end{array}$} & \multirow{2}{*}{$\mathrm{t}$} & \multirow{2}{*}{ Sig. } \\
\hline & B & $\begin{array}{c}\text { Error } \\
\text { estándar }\end{array}$ & & & \\
\hline (Constante) & 1.544 & 0.077 & & 19.993 & 0.000 \\
\hline 1 Seguridad & 0.653 & 0.052 & 0.635 & 12.450 & 0.000 \\
\hline
\end{tabular}

Nota: Variable Dependiente: Calidad del servicio de cajeros ATM. Elaboración propia

La Tabla 24 muestra los coeficientes de la ecuación de regresión. La columna denominada coeficientes no estandarizados contiene los coeficientes de regresión que definen la ecuación. El nivel de significancia, de la prueba $t$, de ambos coeficientes para la dimensión es de cero absoluto y, al ser menor a 0.05 , se puede decir que la dimensión seguridad influye en la calidad de servicio de cajeros ATM en la Universidad Peruana de Ciencias Aplicadas UPC.

Así, la ecuación de la calidad total en función a la dimensión seguridad queda expresada de la siguiente manera:

$$
\mathrm{C}=0.653 * \mathrm{~S}+1.544
$$

Tabla 25 Resumen Regresión de Calidad de Servicio y Empatía

\begin{tabular}{lccc}
\hline \multicolumn{4}{c}{ Resumen del modelo } \\
\hline Modelo & $\mathrm{R}$ & R cuadrado & $\begin{array}{c}\text { R cuadrado } \\
\text { ajustado }\end{array}$ \\
\hline 1 & $0.545 \mathrm{~s}$ & 0.297 & 0.294 \\
\hline
\end{tabular}

Nota: Variable Dependiente: Empatía. Elaboración propia.

La Tabla 25 muestra que el $\mathrm{R}^{2}$ alcanza un valor igual a 0.297 , el cual indica que la dimensión empatía explica el $29.7 \%$ de la calidad total en el servicio de cajeros ATM en la Universidad Peruana de Ciencias Aplicadas UPC. En otras palabras, el modelo de regresión es $29.7 \%$ adecuado para que la empatía determine la calidad del servicio. 
Tabla 26 Anova de la ecuación Empatía

\begin{tabular}{|c|c|c|c|c|c|}
\hline \multicolumn{6}{|c|}{ ANOVA ${ }^{2}$} \\
\hline Modelo & $\begin{array}{l}\text { Suma de } \\
\text { cuadrados }\end{array}$ & g & $\begin{array}{c}\text { Media } \\
\text { cuadrática }\end{array}$ & $F$ & Sig. \\
\hline Regresión & 48.688 & 1 & 48.688 & 97.266 & 0,000 \\
\hline 1 Residuo & 115.129 & 230 & 0.501 & & \\
\hline Total & 163.817 & 231 & & & \\
\hline
\end{tabular}

Nota: Variable Dependiente: Empatía. Elaboración propia.

En la Tabla 26 se presenta el Anova de la regresión, la cual muestra que el nivel de significancia de la distribución $\mathrm{F}$ es menor a 0.05 , lo que indica que existe una asociación significativa entre la dimensión empatía y la calidad total. Es decir que la calidad del servicio se estima o predice regularmente a partir de la empatía, a partir de un abastecimiento constante, presencia de personal de asistencia, posibilidad de apertura de cuentas, disponibilidad de atención a discapacitados y servicio orientada al cliente universitario; donde no necesariamente a mayor empatía en el servicio brindado por los cajeros ATM mayor será la calidad.

Tabla 27 Coeficiente de Regresión de Calidad de Servicio y Empatía

\begin{tabular}{|c|c|c|c|c|c|}
\hline \multicolumn{6}{|c|}{ Coeficientes $^{2}$} \\
\hline \multirow{2}{*}{ Modelo } & Coeficiente & estandarizados & $\begin{array}{c}\text { Coeficientes } \\
\text { estandarizados }\end{array}$ & $\mathrm{t}$ & Sig. \\
\hline & $B$ & Error estándar & Beta & & \\
\hline (Constante) & 0.514 & 0.191 & & 2.688 & 0.008 \\
\hline 1 Empaja & 0.621 & 0.063 & 0.545 & 9.862 & 0.000 \\
\hline
\end{tabular}

Nota: Variable Dependiente: Empatía. Elaboración propia.

La Tabla 27 muestra los coeficientes de la ecuación de regresión. La columna denominada coeficientes no estandarizados contiene los coeficientes de regresión que definen la ecuación. El nivel de significancia, de la prueba $t$, de ambos coeficientes para la dimensión es de cero absoluto y, al ser menor a 0.05 , se puede decir que la dimensión empatía influye en la calidad de servicio de cajeros ATM en la Universidad Peruana de 
Ciencias Aplicadas UPC. Así, la ecuación de la calidad total en función a la dimensión seguridad queda expresada de la siguiente manera:

$$
\mathrm{C}=0.621 * \mathrm{E}-0.514
$$

Tabla 28 Resumen Regresión de Calidad del Servicio y Aspectos Tangibles

\begin{tabular}{lccc}
\hline \multicolumn{4}{c}{ Resumen del modelo } \\
\hline Modelo & $\mathrm{R}$ & $\mathrm{R}$ cuadrado & $\begin{array}{c}\text { R cuadrado } \\
\text { ajustado }\end{array}$ \\
\hline 1 & $0.498^{\circ}$ & 0.248 & 0.245 \\
\hline
\end{tabular}

Nota: Variable Dependiente: Aspecto Tangible. Elaboración propia.

La Tabla 28 muestra que el $\mathrm{R}^{2}$ alcanza un valor igual a 0.248 , el cual indica que la dimensión aspecto tangible explica el $24.8 \%$ de la calidad total en el servicio de cajeros ATM en la Universidad Peruana de Ciencias Aplicadas UPC. En otras palabras, el modelo de regresión es $24.8 \%$ adecuado para que el aspecto tangible determine la calidad del servicio.

Tabla 29 Anova de la ecuación Aspectos Tangibles

\begin{tabular}{llccccc}
\hline \multicolumn{7}{c}{ ANOVA $^{2}$} \\
\hline Modelo & & $\begin{array}{c}\text { Suma de } \\
\text { cuadrados }\end{array}$ & g & $\begin{array}{c}\text { Media } \\
\text { cuadrática }\end{array}$ & F & Sig. \\
\hline \multirow{3}{*}{1} & Regresión & 40.702 & 1 & 40.702 & 76.038 & $0.000^{\circ}$ \\
& Residuo & 123.115 & 230 & 0.535 & & \\
& Total & 163.817 & 231 & & & \\
\hline
\end{tabular}

Nota: Variable Dependiente: Aspecto Tangible. Elaboración propia.

En la Tabla 29 se presenta el Anova de la regresión, la cual muestra que el nivel de significancia de la distribución $\mathrm{F}$ es menor a 0.05 , lo que indica que existe una asociación significativa entre la dimensión aspecto tangible y la calidad total. Es decir que la calidad del servicio se estima o predice regularmente a partir del aspecto tangible, a partir de un 
servicio 24/7, mayor disponibilidad de monedas y billetes más usados, ubicación estratégica y limpieza adecuada; donde no necesariamente a mejores aspectos tangibles de los cajeros ATM mayor será la calidad.

Tabla 30 Coeficiente de Regresión de Calidad de Servicio y Aspectos Tangibles

\begin{tabular}{|c|c|c|c|c|c|c|}
\hline \multicolumn{7}{|c|}{ Coeficientes ${ }^{2}$} \\
\hline \multirow[t]{2}{*}{ Modelo } & & & $\begin{array}{l}\text { cientes no } \\
\text { darizados }\end{array}$ & $\begin{array}{c}\text { Coeficientes } \\
\text { estandarizados }\end{array}$ & \multirow[t]{2}{*}{$\mathrm{t}$} & \multirow[t]{2}{*}{ Sig. } \\
\hline & & $\mathrm{B}$ & Error estándar & Beta & & \\
\hline \multirow{2}{*}{1} & (Constante) & 1.952 & 0.066 & & 29.684 & 0.000 \\
\hline & Aspectos Tangibles & 0.575 & 0.066 & 0.498 & 8.720 & 0.000 \\
\hline
\end{tabular}

Nota: Variable Dependiente: Aspecto Tangible. Elaboración propia.

La Tabla 30 muestra los coeficientes de la ecuación de regresión. La columna denominada coeficientes no estandarizados contiene los coeficientes de regresión que definen la ecuación. El nivel de significancia, de la prueba $t$, de ambos coeficientes para la dimensión es de cero absoluto y, al ser menor a 0.05 , se puede decir que la dimensión aspecto tangible influye en la calidad de servicio de cajeros ATM en la Universidad Peruana de Ciencias Aplicadas UPC.

Así, la ecuación de la calidad total en función a la dimensión seguridad queda expresada de la siguiente manera:

$$
\mathrm{C}=0.575 * \mathrm{E}+1.952
$$




\section{Discusión de los resultados}

Las instituciones bancarias vienen implementando agencias bancarias como cajeros ATM como parte de la estrategia de acercar sus servicios en los campus de muchas universidades del país, y así satisfacer los requerimientos de la comunidad universitaria de realizar sus operaciones bancarias de una manera más rápida y segura (Mejías, Villegas \& Maneiro, 2009). Sin embargo, este tipo de servicios también ha originado inconvenientes relacionados con la calidad de dichos servicios.

Debido a ello, ha surgido la necesidad de medir la calidad de los servicios que de los ATM. La finalidad fue identificar los factores que influyen en la calidad del servicio que permitan realizar las acciones correctivas, que redunden en la satisfacción del usuario universitario.

En cuanto a los resultados observados, la mayor parte de universitarios encuestados tenían entre 25 y 30 años (54.7\%), con un promedio de edad de 30.5 años, y predominio del sexo femenino (59.5\%), en su mayoría cursaba el 2 do y 3 er año de estudios (59.9\%).

Respecto a la dimensión Fiabilidad, el grado de satisfacción fue, es decir que no se encuentran satisfechos ni insatisfechos. Las características que representan este nivel de satisfacción fueron el buen abastecimiento, el tiempo de uso pertinente y la entrega de billete. Sin embargo, hay un aspecto por atender por su alta insatisfacción como la necesidad que "los cajeros ATM impriman un ticket de reclamo cuando tenga problemas como retención de su tarjeta o retiro de dinero en efectivo".

Por su parte, en la dimensión Capacidad de Respuesta, el grado de insatisfacción es alto, es decir se deben tomar medidas correctivas respecto al menú de apoyo para transacciones, al servicio vinculado a la universidad, a la posibilidad de depósito interbancario y la existencia de dispensador de monedas. Al respecto, los especialistas en cajeros ATM entrevistados señalaron que aún existen operaciones no cubiertas, altamente demandados por los universitarios como tener cajeros de múltiples opciones tales como el depósito de efectivo a diferentes cuentas de ahorro de otros bancos, servicio de pagos diversos, credipagos, facilidades de retirar dinero de bajo valor y monedas, retirar dinero de otros bancos de forma gratuita, entre otras. 
En cuanto a la dimensión Seguridad, el grado de insatisfacción fue medio, existen aspectos a tener en cuenta como la necesidad de que la interfaz sea segura y amigable y se cuente con un menú seguro y personalizado. Sin embargo, temas como la vigilancia adecuada y la protección ante fraude o clonaciones se encuentran en grado neutro de satisfacción. Este resultado tiene cierto grado de concordancia con lo manifestado por los especialistas entrevistados, quienes afirmaron que la seguridad es el aspecto más importante, no solo por hechos ocurridos en los cajeros ATM externos o en agencias bancarias, sino que estas prácticas de fraude, robos, cambiazos de tarjeta, etc. no pueden trasladarse a los centros de educación universitarios, ya que el nivel de seguridad y confianza es distinto al de los cajeros ATM que se ubican fuera del campus.

Otra característica estudiada es la Empatía, donde se observó un alto grado de insatisfacción, esto se debe a que hay aspectos por atender como el servicio orientado al cliente universitario, mejorar la adaptación del servicio para discapacitados, posibilidad de apertura de cuentas de ahorro y la presencia de personal de asistencia. Solo un aspecto fue valorado de manera neutra y se trata del abastecimiento constante.

El Aspecto Tangible fue otra característica valorada por los estudiantes universitarios con un grado de satisfacción neutro. Los ítems que la conforman son operatividad del servicio 24/7, la ubicación estratégica y la limpieza adecuada, que fueron apreciados de forma neutra. Por otro lado, se debe trabajar en el aspecto de abastecimiento de billetes con baja denominación.

En resumen, la Calidad de Servicio de los cajeros ATM presenta una insatisfacción bajamedia siendo, la fiabilidad, y los aspectos tangibles las características mejor valoradas respecto al servicio brindado por los cajeros ATM. Por el contrario, los menos valorados fueron la empatía, seguridad y la capacidad de respuesta, siendo este último el que presento el mayor grado de insatisfacción. Estos resultados se confirman con el análisis correlacional donde la fiabilidad es el aspecto mejor correlacionado con la calidad de servicio del cajero ATM, entretanto la capacidad de respuesta es el menos correlacionado.

Estos resultados distan de la opinión de los especialistas entrevistados, quienes aseguran que sí existe una alta satisfacción, cercana al 100\%, de los usuarios de cajeros ATM y es sumamente positiva, esto refleja que las instituciones bancarias no están sintonizando adecuadamente con las necesidades de los usuarios universitarios. Sin embargo, 
afirmaron que las instituciones bancarias tratan de mejorar el servicio día a día a pesar de que muchos de los cajeros ATM no son modernos (algunos de ellos tienen al menos 10 años de uso), comparados a otros países, que realizan múltiples operaciones como realizar depósitos, cobrar cheques, recepción de depósitos de efectivo etc. Conjuntamente, al valorar el servicio de cajeros ATM en los centros de educación superior, señalaron que la seguridad es el aspecto más importante, seguido de la fiabilidad, la capacidad de respuesta, los aspectos tangibles y la empatía. Igualmente, los especialistas mencionaron que los problemas más frecuentes reportados por los estudiantes universitarios son la falla de lectura de las tarjetas de debido o de crédito, así como el error de lectura del chip, atasco de las tarjetas, falta de sistema, entre las más importantes.

Según el análisis de regresión, donde evaluamos en conjunto si las cinco dimensiones explican o están relacionados con la calidad de servicio, se determinó que todas las dimensiones, es decir la capacidad de respuesta, fiabilidad, seguridad, empatía y aspectos tangibles influyen en la calidad de servicio de cajeros ATM $\left(\mathrm{R}^{2}=99 \%\right)$. Estos resultados son muy congruentes a los encontrados por Mejías Maneiro (2008) en Mejías, Villegas \& Maneiro (2009), quienes identificaron cinco dimensiones basados en el Cuestionario SERVQUAL, que determinaban la calidad de los servicios bancarios. En el primer caso, comprobaron que la atención al cliente, elementos tangibles, gestión de servicios, infraestructura interna y enlace universidad-banco influían en la calidad de los servicios bancarios en la Universidad de Carabobo. En cuanto al segundo estudio, ellos encontraron que la atención al cliente, infraestructura, aspectos funcionales, gestión de servicios y aspectos generales son factores que determinaban la calidad de los servicios bancarios. Cabe señalar, que muchas de las características trabajadas en dichos estudios son semejantes al estudiado de la presente investigación.

De esta forma, en el análisis bivariado o análisis uno a uno de cada dimensión con la calidad de servicio, se comprobó que todos los aspectos tenían una relación significativa $(\mathrm{p}<0.05)$ con la calidad de servicio. Sin embargo, el porcentaje de explicación de esta relación era distinto por cada aspecto, siendo la fiabilidad la que mejor porcentaje tenía con una $80.9 \%$, seguido de la seguridad $40.3 \%$. Por el contrario, la que tenía menor porcentaje de explicación fue la capacidad de respuesta $24.1 \%$, seguido del aspecto tangible $24.8 \%$ y la empatía $29.7 \%$. Estos resultados son similares a los observados por Vega (2017), quien estudio la relación entre la gestión de calidad y la satisfacción del 
usuario de cajeros automáticos del Banco de la Nación, encontrando que las dimensiones confiabilidad, capacidad de respuesta, seguridad, empatía y elementos tangibles estaban relacionados significativamente con la satisfacción del usuario de cajeros automáticos en el Banco de la Nación. No obstante, se evidenció una diferencia en cuanto al grado de correlación que tenían con la satisfacción, siendo el aspecto de seguridad ( $R h o=0.629)$ y elementos tangibles $(\mathrm{Rho}=0.628)$ los que mantenían un buen grado de correlación. Por el contrario, la confiabilidad $(\mathrm{Rho}=0.497)$, la capacidad de respuesta $(\mathrm{Rho}=0.550)$ y la empatía $(\mathrm{Rho}=0.598)$ tenían un grado de correlación moderado.

Es importante señalar que existen estudios que descubrieron otras dimensiones que determinaban la satisfacción de clientes bancarios universitarios, como el realizado por Mejías \& Manrique (2011), donde identificaron 5 aspectos o características con buenos niveles de fiabilidad tales como la calidad técnica, la calidad funcional, expectativas, valor percibido y la confianza. Estos atributos podrían tomarse en cuenta para próximos estudios donde se evalué la calidad de servicio de los cajeros ATM, previa adaptación a las necesidades particulares de la comunidad universitaria.

Al mismo tiempo, las instituciones bancarias están proyectando realizar muchos cambios, muchos de ellos ambiciosos como la compra de cajeros ATM funcionales o mixtos, que acepten depósitos de billete o moneda, y que este mismo dinero sirva para los retiros, permitiendo reducir tiempos de abastecimiento, así como cajeros ATM que permitan la apertura de cuentas digitales, y concientizar al usuario a que puede realizar operaciones de pago en los cajeros ATM cuando el importe a cancelar es menor a cierta cantidad establecida por el banco. 


\section{CAPÍTULO IV CONCLUSIONES, HALLAZGOS Y RECOMENDACIONES}

\section{CONCLUSIONES}

Los estudiantes universitarios presentan un grado de insatisfacción bajo-medio con la calidad de servicio de los cajeros ATM, determinados principalmente por un alto grado insatisfacción en la Capacidad de Respuesta del servicio y un grado de insatisfacción bajo-medio en cuanto a la Empatía y Seguridad. Respecto a la Fiabilidad y Aspectos tangibles se encuentran neutrales.

1. Los estudiantes universitarios muestran un grado de satisfacción neutral respecto a la Fiabilidad, ellos consideran que los cajeros ATM están muy cercanos a cumplir sus expectativas en cuanto a la solución rápida de problemas, abastecimiento oportuno, tiempo de uso pertinente y entrega de billetes genuinos, pero que no existe una adecuada recepción de reclamos.

2. Los estudiantes universitarios tienen un alto grado de insatisfacción en la Capacidad de Respuesta del servicio. Ellos consideran que el servicio no es asistido ni vinculado a la universidad, no tienen posibilidades de realizar depósitos interbancarios y no existe muchos dispensadores de monedas.

3. Los estudiantes universitarios tienen un grado de insatisfacción bajo-medio en cuanto a la Seguridad. Ellos consideran que la interfaz de los cajeros ATM tiene bajos niveles de seguridad y es poco amigable, además que el menú no es muy seguro ni personalizado a sus necesidades.

4. Los estudiantes universitarios tienen un grado de insatisfacción bajo-medio en cuanto a la Empatía. Ellos consideran que existe poca presencia de personal de asistencia, escasa posibilidad de apertura de cuentas de ahorro, dificultad para la atención a discapacitados y que el servicio no está orientado al cliente universitario.

5. Los estudiantes universitarios presentan un grado de satisfacción neutral respecto a los Aspectos tangibles. Ellos consideran que los cajeros ATM están muy cercanos a cumplir sus expectativas en cuanto a la operatividad del servicio (24/7), ubicación 
estratégica y limpieza, pero que la disponibilidad de monedas y billetes más usados podría mejorar.

6. Los especialistas en cajeros ATM aseguran que, si existe una alta satisfacción no del $100 \%$ de los usuarios de cajeros ATM, pero es sumamente positiva. A pesar de los problemas que perciben que son la falla de lectura, error en el chip, pagos truncos, atascos de las tarjetas, la no dispensación de dinero, la falla en el servicio y falta de denominación de dinero, etc., esto refleja que las instituciones bancarias no están sintonizando adecuadamente con las necesidades de los usuarios universitarios. Sin embargo, afirmaron que tratan de mejorar el servicio día a día a pesar de que muchos de los cajeros ATM no son modernos. 


\section{HALLAZGOS}

1. Las cinco dimensiones se correlacionaron directa y positivamente con la calidad de servicio donde a mayor Fiabilidad, Capacidad de Respuesta, Seguridad, Empatía y Aspectos Tangibles mayor será la Calidad.

2. El modelo de regresión es adecuado para estimar o predecir la calidad del servicio de los cajeros ATM a partir de la Capacidad de respuesta, Fiabilidad, Seguridad, Empatía y Aspectos tangibles del servicio.

3. Los aspectos que determinan la Fiabilidad se correlacionaron directamente con la calidad de servicio, siendo la pregunta $\mathrm{N}^{\circ} 2$ "los cajeros ATM brindan un buen servicio al mantenerse abastecidos" la que tiene una mayor correlación, donde su mejora elevaría la calidad del servicio.

4. El modelo de regresión es adecuado para estimar o predecir la calidad del servicio de los cajeros ATM a partir de la Fiabilidad, siendo el 80.9\%.

5. Los aspectos que determinan la Capacidad de Respuesta se correlacionaron directamente con la calidad de servicio, donde la disposición para ayudar y prestar un servicio rápido ayudaría a elevar la calidad del servicio o viceversa.

6. El modelo de regresión para estimar o predecir la calidad del servicio de los cajeros ATM a partir de la Capacidad de respuesta es del 24.1\%.

7. Los aspectos que determinan la Seguridad tienen una correlación positiva considerable con la calidad de servicio, siendo el $(\mathrm{rho}=0.62)$, es decir; a mayor percepción de los estudiantes universitarios sobre los aspectos de la Seguridad existirá una mayor calidad del servicio.

8. El modelo de regresión es regularmente adecuado para estimar o predecir la calidad del servicio de los cajeros ATM a partir de la Seguridad, siendo el 40.3\%.

9. Los aspectos que determinan la Empatía se correlacionaron directamente, con la calidad de servicio, siendo el rho=0.545 (correlación positiva media).

10. El modelo de regresión para estimar o predecir la calidad del servicio de los cajeros ATM a partir de la Empatía fue del 29.7\%.

11. Los Aspectos tangibles se correlacionaron directamente con la calidad de servicio, siendo el rho $=0.506$ (correlación positiva media), donde la pregunta $\mathrm{N}^{\circ} 20$ 
"Disponibilidad de monedas y billetes más usados" es la que tiene una mayor correlación.

12. El modelo de regresión para estimar o predecir la calidad del servicio de los cajeros ATM a partir de los Aspectos tangibles fue del 24.8\%. 


\section{Recomendaciones}

1. En cuanto a la dimensión de Fiabilidad se recomienda que los cajeros ATM tengan la posibilidad de imprimir tickets de reclamo cuando presenten problemas como retención de tarjetas o dinero en efectivo.

2. Referente a la Capacidad de Respuesta del servicio de cajeros ATM se sugiere que las entidades bancarias contemplen la posibilidad de colocar cajeros multifuncionales dentro del campus, ya que no solo se emplearía para hacer retiros de dinero, sino también depósitos de efectivo a diversas entidades bancarias, pago de diferentes servicios y retirar monedas.

3. En cuanto a la Seguridad del servicio de cajeros ATM se sugiere que los bancos consideren la factibilidad de generar una interfaz con mayor nivel de seguridad y que cuente con una versión amigable y personalizada.

4. En el caso de la Empatía del servicio de cajeros ATM se recomienda que los cajeros ATM de las entidades bancarias cuenten con servicio orientado al cliente universitario, adaptar mejor el servicio a discapacitados, implementar la apertura de cuentas de ahorro y asignar un personal de asistencia bancaria.

5. En la dimensión de Aspectos Tangibles se sugiere que los bancos puedan abastecer los cajeros ATM con mayores billetes de menor denominación.

6. Finalmente, se sugiere que los bancos en conjunto con su área encargada de Canales Alternativos sintonicen con las necesidades de los universitarios. Se recomienda que los bancos con presencia de ATM dentro de los campus universitarios implementen los cambios que plantean tales como: colocación de ATM's multifuncionales para depósito de billetes, apertura de cuentas digitales y dispensadores de monedas. 


\section{REFERENCIAS BIBLIOGRÁFICAS}

Almenterio, L., \& Torres, J. (2016). Caracterización de la población de la tercera edad en los estratos 3-4 de la ciudad de Cartagena en función de sus necesidades, gustos preferencias que permitan la definición de un nicho de mercado inexplorado. (Tesis de grado Universidad de Cartagena, Facultad de Ciencias Económicas. Cartagena de Indias, Colombia). Recuperado de https://bit.ly/2OwAFeS [Consulta: 7 de diciembre de 2017]. Aredo, U. (2016). Influencia de los canales alternativos en la satisfacción de los clientes del centro de contacto del Banco de Crédito del Perú. (Tesis de grado Universidad Nacional de Trujillo, Facultad de Ciencias Económicas. Trujillo, Perú). Recuperado de https://bit.ly/2BunU2u [Consulta: 20 de enero 2018].

Asociación de Bancos del Perú (ASBANC). (2017). Impacto económico del uso de los cajeros automáticos en el Perú. Lima: ASBANC. Recuperado de https://bit.ly/2P4eMV5 [Consulta: 15 de diciembre de 2017].

Chávez, C. Quezada, R., \& Tello, D. (2017). Calidad en el servicio en el sector transporte interprovincial terrestre. (Tesis de maestría Pontificia Universidad Católica del Perú, Escuela de Posgrado. Lima, Perú). Recuperado de https://bit.ly/2BnbIRr [Consulta: 13 de enero de 2018].

El Comercio. (2016). Uso de cajeros automáticos permite ahorro anual de s/217 mlls. El Comercio. Recuperado de https://bit.ly/2L3I2s2 [Consulta: 10 de diciembre de 2017].

El Comercio. (2017). El cajero automático cumple 50 años: ¿Cuándo llegó y cuántos hay en el Perú? El Comercio. Recuperado de https://bit.ly/2wcRe82. [Consulta: 16 de diciembre de 2017].

Gutiérrez, M. (2007). Sobre experiencia de uso en equipos de autoservicio: Larga vida a los cajeros. Revista Faz de diseño de interacción, 1(1) 47-49. Recuperado de http://www.revistafaz.org/numero1/cajeros.pdf [Consulta: 12 de febrero de 2018].

Hinojosa, D. (2011). Bancarización en Milagro: Utilización de servicios electrónicos. Ciencia UNEMI. Recuperado de https://bit.ly/2OuZbwC. [Consulta: 22 de diciembre de 2017].

Ilías, N., Rosales, C., Santelí, S., \& Galo, L. (2014). Uso de tarjetas de crédito. (Tesis de grado, Universidad Pedagógica Nacional Francisco Morazán, Facultad de Humanidades. Tegucigalpa, México). Recuperado de https://bit.ly/2w0SDi0 [Consulta: 1 de marzo de 2018]. 
Instituto Nacional de Estadística e Informática (INEI). (2014). Proyectos INEI: características económicas. Recuperado de https://bit.ly/2MFZTKB [Consulta: 24 de diciembre de 2017].

Larrea, P. (1911). Calidad del servicio de marketing a la estrategia. Madrid: Díaz de Santos.

Lovati, G., \& Borgo, A. (2017). Estudio sobre hábitos y comportamientos de los clientes bancarios HSA. Accenture Research. Recuperado de https://accntu.re/2KLLWWn [Consulta: 28 de diciembre de 2017].

Matsumoto, R. (octubre, 2014). Desarrollo del Modelo Servqual para la medición de la calidad del servicio en la empresa de publicidad Ayuda Experto. Perspectivas, (34), 181209. Recuperado de https://bit.ly/2OvNq9g [Consulta: 30 de diciembre de 2017].

Medina, E. (2016). Propuesta de un modelo de confiabilidad para cajeros automáticos de marca Diebold de la serie 510, 512, 520, 522, 560, 562 ubicados en el Azuay. (Tesis de maestría Universidad del Azuay, Escuela de Posgrado. Cuenca, Ecuador). Recuperado de https://bit.ly/2nvHG3T [Consulta: 1 de enero de 2018].

Mejías, A., \& Maneiro, N. (2008). Dimensiones de la Calidad en los Servicios Bancarios en el Sector Universitario. Recuperado de https://bit.ly/2vDdw35 [Consulta: 4 de enero de 2018].

Mejías, A., \& Manrique, S. (2011). Dimensiones de la satisfacción de clientes bancarios universitarios: una aproximación mediante el análisis de factores. Ingeniería Industrial, 32(1), 43-47. Recuperado de http://www.redalyc.org/pdf/3604/360433575007.pdf [Consulta: 5 de enero de 2018].

Mejías, A., Villegas, D., \& Maneiro, N. (2009). Factores determinantes de la calidad de los servicios bancarios en un campus universitario venezolano. Recuperado de https://bit.ly/2OwaEMz [Consulta: 8 de enero de 2018].

Merino, S. (2001). La calidad de servicio bancario: una escala específica de medida. Recuperado de https://bit.ly/2Ma3fWs [Consulta: 8 de enero de 2018].

Montoya, L., Montoya, I., \& Rojas, S. (2000). Percepción de la calidad y satisfacción de la elección de los estudiantes de primer semestre en la facultad de ciencias económicas de la universidad Nacional de Colombia. Recuperado de https://bit.ly/2vZKQkp [Consulta: 26 de diciembre de 2017].

Nkamnebe, A., Ukenna, S., Anionwu, C., \& Chibuike, V. (2014). Determinants of bank selection by university undergrads in south east Nigeria: empirical evidence. African Journal of Economic and Management Studies, 5(3), 369-382. 
Organisation International de Normalization (ISO) (2007). Online Browsing Platform ISO 9000:2007. Recuperado de https://bit.ly/2nwtOq4 [Consulta: 9 de enero de 2018]. Para Quitarse el Sombrero (PQS). (2018). Emprendimiento: Qué es la generación Z. Lima: PQS. Recuperado de https://bit.ly/2w0V0kU [Consulta: 5 de enero de 2018]. Parasuraman, A., Zeithaml, V., \& Berry, L. (1988). A multiple item scale for measuring consumer perceptions of service quality. Journal of Retailing, 64 (1), 12-40. Recuperado de https://bit.ly/2qt2hqg [Consulta: 6 de marzo de 2018].

Pijush, C., \& Saralelimath, S. (2012). Customer preference towards use of ATM services in Pune city. International Journal of Marketing, 230(1), 230-241. Recuperado de https://bit.ly/2vZNsyJ [Consulta: 29 de diciembre de 2017].

Real Academia Española (RAE). (2001). Diccionario. España: RAE. Recuperado de https://bit.ly/2w2xuE9 [Consulta: 3 de mayo de 2018].

Rodríguez, A. (2002). Reseña histórica de las innovaciones financieras en Venezuela y en el mundo. Recuperado de https://bit.ly/2Bo3kRC [Consulta: 2 de abril de 2018].

Superintendencia Nacional de Educación Superior Universitaria (SUNEDU). (2018). Universidades licenciadas. Lima: Sunedu. Recuperado de https://bit.ly/2ED2DAf [Consulta: 25 de febrero de 2018].

Universidad Nacional de Colombia (UNAL). (2018). Valoración de los factores determinantes de la calidad del servicio público local: un análisis de la percepción de los ciudadanos y sus repercusiones sobre la satisfacción y credibilidad. Revista Innovar, 20(36), 139-156 Recuperado de https://bit.ly/2KJaUFO [Consulta 13 de marzo de 2018]. Vega, G. (2017). Gestión de la calidad y la satisfacción del usuario de los cajeros automáticos del Banco de la Nación en el años 2015. (Tesis de maestría Universidad César Vallejo. Escuela de Posgrado. Lima, Perú). Recuperado de https://bit.ly/2vFlOaT [Consulta: 10 de marzo de 2018].

Verjovsky, B., Higa, T., Vidal, J., Túpac R., \& Berdejo, P. (2014). Investigación de mercados: Fases del proceso de investigación de mercados. Universidad Peruana de Ciencias Aplicadas, Facultad de Negocios, Lima, Perú.

Zavala, A. (2013). Modelo pronóstico de demanda de efectivo para las oficinas de una entidad bancaria en una ciudad del interior del país. (Tesis de grado Pontificia Universidad Católica del Perú, Facultad de Ciencias e Ingeniería. Lima, Perú). Recuperado de https://bit.ly/2tOaCXF [Consulta: 4 de mayo de 2018]. 


\section{ANEXOS}

Anexo 1. Instrumentos de recolección de datos

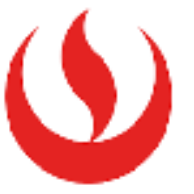

"Percepción de la calidad del servicio de cajeros ATM en

universidades particu la res de San Isid ro"

\section{A.- PARA EVAluAR LA CALIDAD DEL SERVICIO DE CAJEROS ATM EN UNIVERSIDADES PARTICULARES DEL DISTRITO DE SAN ISIDRO.}

Estimado usuario (a), estamos interesados en conocer su opinión sobre la calidad del servicio de cajeros ATM en las universidades particulares del distrito de San Isidro. Sus respuestas son totalmente confidenciales. Por favor, sírvase contestar todas las preguntas.

\section{I.- Datos generales:}

Edad:

Sexo:

Universidad:

Facultad:

Ciclo: 


\section{II.- Cuestionario de Expectativas}

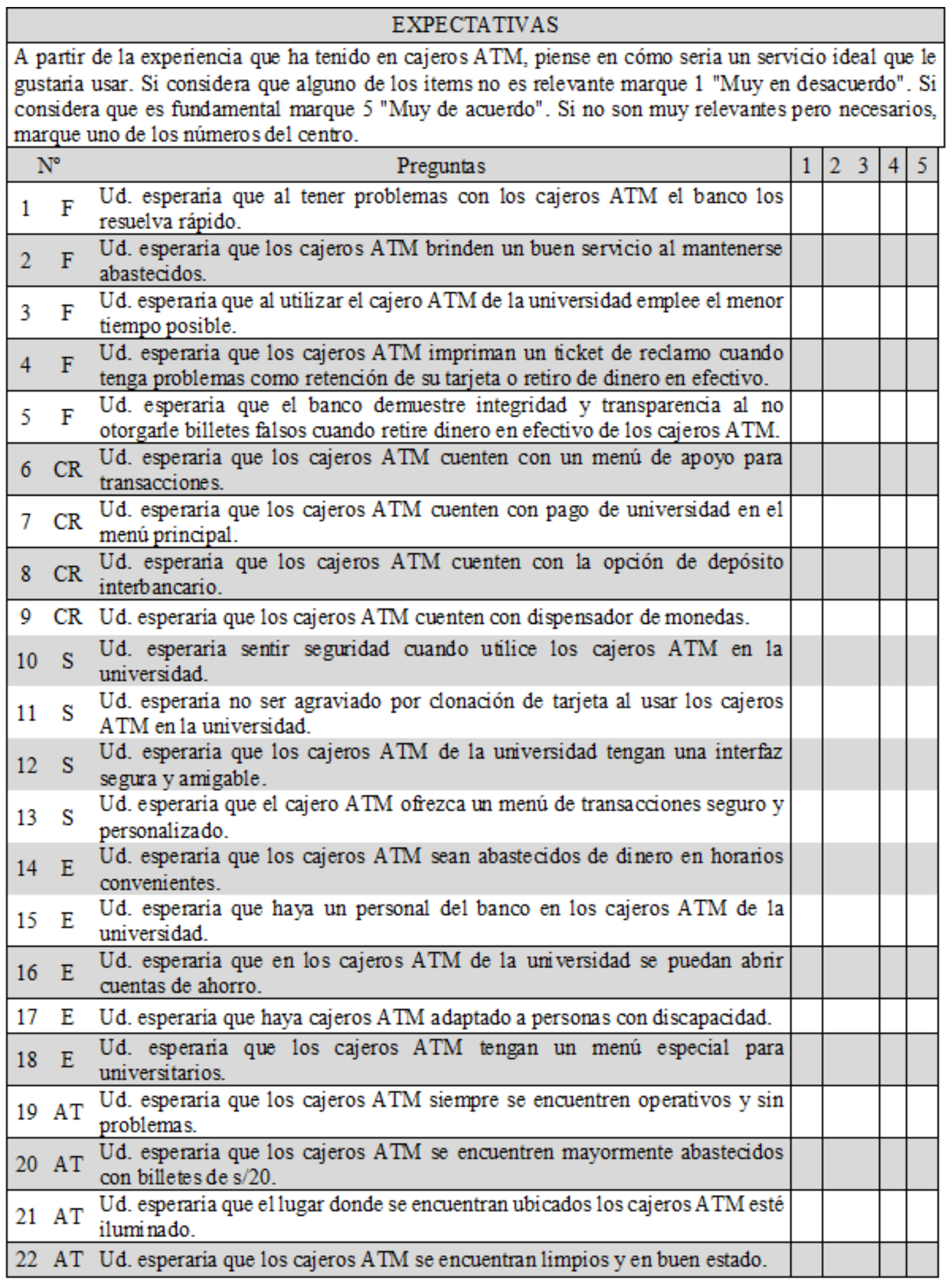




\section{II.- Cuestionario de Percepciones}

\section{PEPCEPCIONES}

De acuerdo con su percepción sobre el servicio de cajeros A TM. Indiquenos en qué medida el servicio de cajero ATM de la universidad cumplió con cada item mencionado. Donde 1 significa "Muy en desacuerdo y 5 significa "Muy de acuerdo". Puede marcar los números del centro si considera que su percepción se encuentra entre el 1 y el 5 .

\begin{tabular}{|c|c|c|c|c|c|c|}
\hline \multicolumn{2}{|c|}{$\mathrm{N}^{\circ}$} & Preguntas & 1 & 2 & 3 & 45 \\
\hline 1 & & $\begin{array}{l}\text { Cuando Ud. tuvo problemas con el cajero ATM, el banco los resolvió de } \\
\text { manera rápida. }\end{array}$ & & & & \\
\hline 2 & $\mathrm{~F}$ & $\begin{array}{l}\text { Los cajeros ATM se encontraban abastecidos cuando hizo uso del servicio } \\
\text { de retiro de dinero. }\end{array}$ & & & & \\
\hline 3 & $\mathrm{~F}$ & E1 tiempo empleado en los cajeros ATM de la universidad es corto. & & & & \\
\hline 4 & & $\begin{array}{l}\text { Los cajeros ATM imprimen un ticket de reclamo cuando hay problemas } \\
\text { con retención de tarjeta o retiro de efectivo. }\end{array}$ & & & & \\
\hline 5 & & $\begin{array}{l}\text { E1 servicio de cajeros ATM de los bancos es transparente y no entregó } \\
\text { billetes falsos. }\end{array}$ & & & & \\
\hline 6 & CR & Los cajeros ATM cuentan con un menú de apoyo para las transacciones. & & & & \\
\hline 7 & & $\begin{array}{l}\text { Los cajeros ATM cuentan con la opción "Pago de universidad" en el menú } \\
\text { principal. }\end{array}$ & & & & \\
\hline 8 & $\mathrm{CR}$ & Los cajeros ATM cuentan con la opción "Depósito Interbancario". & & & & \\
\hline 9 & $\mathrm{CR}$ & Los cajeros ATM cuentan con dispensador de monedas. & & & & \\
\hline 10 & $\mathrm{~S}$ & Sintió seguridad cuando utilizó los cajeros ATM de la universidad. & & & & \\
\hline 11 & & $\begin{array}{l}\text { No ha sido agraviado por clonación de tarjeta al usar los cajeros ATM de } \\
\text { la universidad. }\end{array}$ & & & & \\
\hline 12 & $\mathrm{~S}$ & Los cajeros A TM ofrecen una interfaz segura y amigable. & & & & \\
\hline 13 & $\mathrm{~S}$ & Los cajeros A TM tienen un menú de transacciones seguro y personalizado. & & & & \\
\hline 14 & $\mathrm{E}$ & Los cajeros ATM son abastecidos en horarios convenientes y adecuados. & & & & \\
\hline 15 & $\mathrm{E}$ & Existe un personal del banco en los cajeros ATM de la universidad. & & & & \\
\hline 16 & E & En los cajeros ATM de la universidad se pueden abrir cuentas de ahorro. & & & & \\
\hline 17 & $\mathrm{E}$ & Existen cajeros ATM adaptados a personas con discapacidad. & & & & \\
\hline 18 & & $\begin{array}{l}\text { Los cajeros ATM poseen un menú de transacciones especial para } \\
\text { universitarios. }\end{array}$ & & & & \\
\hline 19 & & $\begin{array}{l}\text { Los cajeros ATM siempre se encuentran operativos y no presentan } \\
\text { problemas. }\end{array}$ & & & & \\
\hline 20 & AT & Se puede retirar en los cajeros A TM de la universidad billetes de $s / 20$ soles. & & & & \\
\hline 21 & & $\begin{array}{l}\text { E1 lugar donde se ubican los cajeros ATM de la universidad siempre está } \\
\text { iluminado. }\end{array}$ & & & & \\
\hline 22 & AT & Los cajeros ATM siempre se encuentran limpios y en buen estado. & & & & \\
\hline
\end{tabular}




\section{B.- GUÍA de ENTREVISTA A LOS ESPECIALISTAS EN CAJEROS ATM SOBRE LA CALIDAD DEL SERVICIO DE LOS CAJEROS EN LAS UNIVERSIDADES PARTICULARES DE SAN ISIDRO.}

Buenos días/tardes, somos de la universidad UPC, y estamos realizando un estudio sobre la "Calidad del servicio de cajeros ATM en universidades particulares de San Isidro", con la finalidad de identificar las necesidades en las operaciones bancarias realizadas mediante cajeros automáticos. Para captar todos los detalles de la entrevista se utilizará una grabadora, contenido que será solo con fines de investigación. Agradecernos su confianza y participación.

Entrevistado:

Cargo:

Fecha:

Entidad:

1.- Desde su punto de vista ¿nos podría indicar qué necesidades no cubiertas ha podido identificar en tu banco, respecto a los usuarios de cajeros automáticos instalados en la universidad? ¿Cuál es la más constante?

2.- ¿Cuál es su percepción respecto a la calidad del servicio que brindan los cajeros ATM instalados en la universidad? ¿Consideras que los usuarios se encuentren satisfechos? 
3.- De las 5 dimensiones relacionadas con la calidad del servicio: fiabilidad, capacidad de respuesta, seguridad, empatía y aspectos tangibles. ¿En qué orden colocaría tú las 5 dimensiones, evaluando a los cajeros ATM instalados en la universidad?

4.- ¿Cuáles son los problemas más frecuentes que reportan los estudiantes universitarios al utilizar el cajero ATM de la universidad? ¿Qué solución darían a los problemas más frecuentes?

5.- ¿En qué porcentaje considera se encuentran satisfechos los estudiantes universitarios con el servicio de cajeros ATM instalados en la universidad?

6.- ¿Tiene algún comentario o sugerencia final sobre la implementación de cajeros automáticos en la universidad?

Gracias por su participación. 


\section{ENTREVISTA - N¹}

\section{1.- ¿Desde tu punta de vista nos podría indicar que necesidades no cubiertos has podido identificar en los usuarios de los cajeros automáticos instalados en las universidades cual es lo más constantes?}

Mira, este te lo voy a decir a grandes rasgos la verdad que acá en el sistema financiero a nivel local para serte sincero nosotros todavía estamos bancarizando a los clientes, la verdad es que nosotros vamos viendo otros ideas de negocios de otros países y la verdad que nosotros estamos acá un poco como que en pañales, por decirte un ejemplo así muy simple, acá en Colombia tú vas a un cajero automático y el cajero te puede votar 500 transacciones dentro de las cuales te pueden hasta inclusive te pueden dar ofertas comerciales como ventas de crédito, tarjetas de crédito en el momento, evaluaciones en línea, entonces nosotros para llegar a esto la verdad es que todavía nos falta un montón, sin embargo con respecto a la pregunta que me haces, una de las cosas que es pues una constante y que nosotros identificamos es que no está cubriendo todavía una necesidad es un poco la viabilidad de las operaciones de las transacciones como por ejemplo: este sería ideal que ahora un cajero automático pueda tener operaciones, no sé, de pagos de algunos credipagos, por ejemplo tu qué quieres idear y poner la idea de colocar estos cajeros transaccionales a nivel de la universidad no sería mucho más eficiente tener un medio como una ATM donde te permitiría realizar la transacción de pago por ahí mismo sin mover ninguna moneda, sin contar con ningún personal, este y haciéndolo desde inhouse probablemente porque van a estar hasta en su misma institución, entonces esas son unas de la probabilidades que nosotros tenemos, sin embargo tenemos que ir de a pocos porque entendemos que el mercado no está todavía como para ello, estamos metiendo, estamos entrando pero todavía falta y otras de las cosas que se pueden ver no se pagos varios, este no se pues pagos de servicios, pagos de algunos créditos, ir empezando con estas cosas no, eh, bueno y eso es básicamente con respecto a esa pregunta.

2.- ¿Cuál es la percepción respecto a la calidad del servicio que brindan los cajeros ATM instalados en las universidades, considera que los usuarios se encuentran satisfechos? 
Mira la verdad que nosotros sondeamos eso y hacemos una análisis y un seguimiento de manera constante y la verdad es que nosotros tenemos varias ventajas una de las tantas es que acá queda nula la posibilidad de vandalismo, de estafas, entonces que mejor que tener un ATM resguardada en una institución donde no va a haber el tema de estafa propiamente dicho y claro que también ayuda y que sirve como para que brinde un servicio propio dentro de la universidad una de las cosas que nuestros clientes el usuario valora mucho de estos ATM instalados en universidades, institutos o hasta en algunas empresas que también lo tenemos es un poco que puedan transaccionar con la confianza y con la seguridad que no va a pasar absolutamente nada esas es una de las ventajas.

\section{A diferencia de los cajeros ubicados fuera de los lugares o universidades} Es correcto, porque en realidad al estar resguardado, pues casi es nula la probabilidad que pueda haber un intento de estafa, vandalismo con nuestro ATM, tantas cosas que suceden en otros puntos, nosotros tenemos que si bien es cierto son cajeros del BCP, pero propiamente tenemos socios estratégicos que nos permiten poner o instalar nuestros ATM pero que no es propiamente propiedad del BCP no.

Entonces podrías decir que la calidad que perciben ellos es mucho mejor Es de acuerdo completamente.

\section{3.- De las 5 dimensiones relacionadas con la calidad de servicio, fiabilidad, capacidad} de respuesta, seguridad, empatía y aspectos tangibles en qué orden colocaría Ud. las 5 dimensiones evaluando a los cajeros ATM....de las universidades de mayor a menor relevancia.

A ver mira más o menos contestando un poco la pregunta anterior, lo primero tendría que ser la seguridad, la fiabilidad para transacción por este medio, el tercero sería los aspecto tangibles también y como cuarto la capacidad y como quinto la empatía, si bien es cierto nosotros estamos haciendo todo lo posible por tener un sistema más ameno, más amigable, más transaccionales, nosotros estamos todavía eh un poco acercando a los clientes de a pocos a la bancarización, tenemos un mercado todavía mayor adulto que hay 
un poco de resistencia sin embargo lo vemos con mucha entusiasmo ya que hay muchos clientes que ya están comenzando a perder el miedo y a transar y eso es importante

4.- ¿Cuáles son los problemas más frecuentes que reportan los estudiantes universitarios al utilizar el servicio de cajeros ATM instalados en las universidades? ¿Qué solución se podría dar a estos problemas frecuentes para evitarlos?

Buenos unos de los problemas así de cajón el más frecuente podría ser los errores con la lectora, una desmagnetización de la banda electrónica con respecto a las tarjetas o los deteriores de los chips de las nuevas tarjetas que hacen que no permitan que salga la transacción, otras de las cosas podrían ser los pagos truncos, por de repente el mal billetaje que se pueda colocar a la hora del abastecimiento del ATM propio es por ende que los ATM siempre deben ser abastecidos con billetes de óptima calidad para que no sucedan estos casos, pero básicamente esos dos, en sitios como estos establecimientos colocados acá estos dos, después cajeros que están instalados en grifos y en todo lo demás podría ser un tema de vandalismo, tema de estafa pero eso no pasa en las universidades e institutos.

Y como están trabajando referente a las soluciones que me dices, no hay errores en la lectora por el tema del chip, como están trabajando De hecho que ahora nosotros teníamos un proveedor que era CNR la verdad es que nos ha ido bien, nosotros hemos tenido un contrato con ellos por 5 años, justo esta ya por vencer, por renovar y la verdad que no estábamos completamente satisfechos con el servicio que nos estaba dando, si bien es cierto no es malo, pero queríamos tener una propuesta de valor diferente para nuestros clientes y es así como vamos a seguir con ellos definitivamente pero sin embargo está entrando otra empresa también que se llama ONEX nos está dando una propuesta de valor mejor, sin embargo no tiene el soporte para ellos podernos brindar todo el servicio que nosotros requerimos por eso nos estamos apalancando un poco con las dos empresas y eso nos va a ayudar y a monitorear y tener una tecnología mayor para poder afrontar y reducir todos estos retos. 


\section{5.- En qué porcentaje considera Ud. Se encuentran satisfechos los estudiantes universitarios en el servicio de cajeros ATM instalados en la universidad, qué limitantes se pueden superar para alcanzar el $100 \%$ de satisfacción.}

De hecho que nosotros tenemos en estadística que nosotros tenemos una satisfacción entre un 83 a un $85 \%$, vamos en crecimiento sin embargo más o menos lo que te comentaba, ahora el consumidor nuestros clientes valoran mucho la transaccionalidad que puedan tener todos los medio electrónicos, tu agarras ahora tienes tu Smartphone y puedes hacer todo a través de los HOME BANKING o delas APPS que ahora tenemos, el tema es hacer a través de un medio como un teléfono, y tenerlos esto en los ATM, esto valora mucho el cliente siendo estudiante algunas veces no tienen internet o les paso algo con el celular, y tienen la necesidad de hacerlo por el cajero, o podrían hacerlo por el cajero, sin embargo no se tiene estas operaciones uno de los aspectos para mejorar la satisfacción del usuario, seria repotenciar o robustecer la propuesta de valor de cara a las transacciones propias.

\section{6.- ¿Tiene algún comentario o sugerencia final sobre la implementación de cajeros automáticos en la universidad de Lima Metropolitana?}

Tienen una propuesta bastante ambiciosa, que desean hacerlo en un año, estamos adquiriendo un lote de ATM, lotes funcionales o mixtos, que acepten los depósitos en billetaje o moneda, y este mismo dinero que entraría para pagar servicios o cualquier índole, este mismo dinero reciclado para pagos, estos nos sería más dinámico, este mismo dinero que entra serviría para pagar, reduciría tiempo de abastecimiento, horas hombre y aseguraría la operativa constante del ATM sin parar, además queremos colocar ATM para apertura cuentas digitales, y se viene implementando en varias de oficinas, a nivel local estamos a 70\% en nivel de oficinas, y queremos llegar a noviembre a la totalidad, y de ahí desplegar a puntos neutros, y esto ayudaría a descentralizar las operaciones, nosotros en una operación convencional llegando a la ventanilla, una operación nos costaría 3.50 soles, pagando horas hombres, gastos, costos, todo. A través de un home banking, nos costaría 20 céntimos, a través de un medio electrónico 40 céntimos, mira el ahorro que tenemos, lo que queremos es la descentralización de las operaciones, con calidad estando o no estando, porque va a poder contar con diferentes medios, los ATM, los Smartphone, otros medios que están saliendo. 


\section{ENTREVISTA - N²}

\section{1.- Desde su punto de vista ¿nos podría indicar qué necesidades no cubiertas ha podido identificar en tu banco, respecto a los usuarios de cajeros automáticos instalados en la universidad? ¿Cuál es la más constante?}

Bueno de manera general, nosotros también con el pasar del tiempo nosotros hemos podido identificar que ha habido muchas necesidades que el consumidor, bueno en este caso nuestros clientes o usuarios también, requieren prácticamente ese tipo de canales, hemos pasado de lo que es un cajero automático convencional que tú puedes hacer una disposición de efectivo en el cual puedes tener disponibilidad a pasar a un cajero que puede darte una multifunción, esta multifuncionalidad dentro de los cajeros automáticos creo que es parte directamente de esta transformación, según los requerimientos de los clientes, como parte que hemos podido identificar nosotros están las operaciones de servicios de pago, lo depósitos en efectivo, las diferentes cuentas de ahorro, cuentas corrientes que también nosotros podamos identificar, en realidad, creo que son cosas que con el transcurrir del tiempo siempre está en constante transformación, vemos ahí cuales son a través de las encuestas que podamos obtener nosotros el alcance también de la información de parte de nuestras sucursales en las agencias creo que son también un tema sumamente importante porque es el corazón del banco, las agencias las sucursales en donde nosotros podemos identificar qué es lo que más requieren nuestros clientes y nuestros usuarios.

\section{2.- ¿Cuál es su percepción respecto a la calidad del servicio que brindan los cajeros} ATM instalados en la universidad? ¿Consideras que los usuarios se encuentren satisfechos?

Yo creo que la percepción, es un percepción sumamente positiva, porque a pesar de que tenemos actualmente todavía tenemos mucho campo de trabajo todavía con respecto a lo que es la bancarización, del tema también de conocimiento de nuestros clientes por estos usos de canales alternativos, por lo cual nosotros hacemos todo un despliegue, un protocolo de enseñanza, de educación a nuestros clientes de cara al uso de estos canales alternativos, creo que es positivo porque de cara al cliente, al usuario final les permite a ellos acercase a las operaciones que normalmente pueden realizar dentro de lo que son 
las sucursal, hacer uso precisamente de estos cajeros, estos canales, que les permite a ellos una disposición, una viabilidad también de las transacciones diferentes que pueden realizar y pues una mejora, optimización, dentro de lo que son los tiempos de espera en una sucursal para poder realizar una operación de estos tipos.

\section{Es decir, ¿tú consideras que se encuentran satisfechos?}

Nosotros consideramos que sí, hay una satisfacción, precisamente nosotros nos guiamos también de cara a un estudio del mercado financiero, cuáles son los requerimientos de nuestros clientes y creo que sí, efectivamente que nosotros tenemos una ardua labor con respecto a esto y se ve el impacto positivo dentro de los clientes financieros con respecto a los canales alternativos.

\section{3.- De las 5 dimensiones relacionadas con la calidad del servicio: fiabilidad, capacidad de respuesta, seguridad, empatía y aspectos tangibles. ¿En qué orden colocaría tú las 5 dimensiones, evaluando a los cajeros ATM instalados en la universidad?}

Creo que una de las cosas más importantes que nosotros hemos podido identificar dentro de nuestros clientes y usuarios es la seguridad, esto es un aspecto muy delicado porque nosotros nos encontramos también de cara a lo que es una previsión de fraude, también respecto a lo que son los robos, los cambiazos de tarjeta, en lo que frecuentemente tratamos nosotros de capacitar a nuestro personal para que podamos tener un inicio de operatividad dentro del cajero automático de que se pueda observar algún elemento extraño que pueda estar dentro de los cajeros, también con respecto a la seguridad en el uso de las cámaras, identificamos las personas que puedan realizar las operaciones dentro de nuestros canales y creo que es un aspecto muy importante de cara al cliente, al usuario por lo cual a ellos les permite sentir la tranquilidad de que pueden realizar esas operaciones dentro de esos canales, lo segundo creo que sería la fiabilidad, precisamente, que tanto para nuestros clientes, nuestros usuarios es conveniente hacer uso de estos canales ya que las operaciones que normalmente realizan dentro de las sucursales pueden tornarse digamos con un tiempo de espera prolongado lo cual buscamos que estos cajeros nos reduzca esos niveles de espera en la atención y ellos puedan realizar sus transacciones y que normalmente pueden hacer operaciones tales financieras como operaciones de 
diferentes instituciones por lo cual nosotros tenemos esos estratégicos también por ahí, el tercero creo que es la capacidad de respuesta que tenemos nosotros también porque nosotros hemos identificado que a pesar que esto es un canal que es sumamente positivo en el aspecto de que genera aun la satisfacción al cliente, también tenemos situaciones adversas que pueden tornarse una falla operativa dentro de lo que es el sistema de cajero automático por lo que los clientes pueden tener o llevarse una insatisfacción, nosotros buscamos manejar estas experiencias negativas dentro de lo que es un protocolo de escalamiento dentro de lo que son también las sucursales para poder atender a los clientes y ellos puedan tener una atención inmediata, respecto de la recuperación del efectivo que no haya podido ser depositado o el no expendio de dispositivo también en caso de un retiro de efectivo y podamos obviamente tener una atención a eso, como cuarto creo que son los aspectos tangibles, también nosotros tenemos muchos estratégicos y bueno nosotros trabajamos con Prosegur, con respecto a esto creo que tenemos una muy buena atención referente a la atención para mantener la operatividad de estos cajeros automáticos por lo que tenemos un constante monitoreo del efectivo que podamos tener con respecto al billetaje, las denominaciones que podamos tener en los cajeros automáticos y obviamente esto no afecte de cara pues al cliente, al usuario, a pesar de que es tal vez el quinto en el orden que nosotros hemos podido identificar la empatía con respecto a estos canales alternativos también es de suma importancia debido a que es lo que engancha prácticamente la atención de nuestros clientes, de nuestros usuarios, porque cada vez el sistema que nosotros manejamos buscamos tratar de hacerlo de la manera más amigablemente posible para que pues las operaciones sean realizadas con suma eficacia respecto a que hay operaciones que los clientes muchas veces no conocen como realizar, entonces debido a eso nosotros hemos reunido también un equipo especializado que han podido identificar, hacer consultas referente a lo que son estadísticas que manejamos internamente y hemos podido hacer también una mejora dentro del software que manejamos en estos canales alternativos para que pues el cliente, usuario final pueda tener una mayor facilidad de realizar sus operaciones y pues esto repercute en una experiencia positiva de cara al cliente. 


\section{4.- ¿Cuáles son los problemas más frecuentes que reportan los estudiantes universitarios al utilizar el cajero ATM de la universidad? ¿Qué solución darían a los problemas más frecuentes?}

Hemos identificado de manera general que uno de los inconvenientes que se presentan con mayor frecuencia dentro de nuestros cajeros automáticos es la falla de lectura tal vez de las bandas magnéticas, de las tarjetas de débito como también de las tarjetas de crédito o también por el error de lectura dentro del chip esto se ha en la mayoría de incidencia de casos se ha puesto que no hay un uso correcto de las tarjetas físicas o por daños, lo cual nosotros constantemente también tratamos de hacer un despliegue de cuidado para que el cliente, usuario no tenga que estar haciendo una reposición de estas tarjetas físicas dentro del plazo de vencimiento que tiene la misma, yo creo que de las incidencias que hemos podido identificar son precisamente estas fallas a veces en el tema del sistema de nuestros canales alternativos por lo que esto puede inducir en un error operativo y una no conclusión de alguna transacción u operación a realizar o la no entrega de efectivo o la no evolución de un efectivo no depositado, nosotros en este aspecto hemos buscando conjuntamente con división de experiencia al cliente poder tener una solución inmediata, una respuesta lo más pronto posible, tenemos un consenso de servicio de 3 días útiles para poder hacer la devolución de este efectivo y del cual tenemos todo un equipo obviamente que hace las verificaciones respectivas, en caso de estos cajeros puedan acercarse a la sucursal más cercana, incluso tenemos un protocolo de atención inmediata con la devolución en el mismo momento para lo cual manejamos ciertos estándares y políticas que debe cumplir obviamente la operación o transacción que no ha podido realizar este cliente, usuario.

\section{5.- ¿En qué porcentaje considera se encuentran satisfechos los estudiantes universitarios con el servicio de cajeros ATM instalados en la universidad?}

Cuando empezamos nosotros a hacer este despliegue de este cambio en las transacciones de generar la multifuncionalidad dentro de nuestros cajeros ATM teníamos nosotros una propuesta de valor que de cara al cliente buscábamos una satisfacción dentro del 70-80\% lo cual creo que estamos muy cerca de esto, pienso que es positivo referente también a que hemos podido identificar ciertas necesidades que tal vez algunas otras entidades no 
lo han podido hacer, manejamos nosotros también lo que es los canales monetarios, lo que son los monederos, el cual el cliente puede hacer retiro de efectivo en monedas, en el caso de las monedas de denominación de 5 soles, por lo que consideramos que estamos dentro de lo esperado, sin embargo, creo que todavía hay algunas cosas que nosotros podamos mejorar, siempre estamos en constante evaluación dentro de esta planificación, por lo que vemos que hay algunas cosas como el tema de la bancarización que efectivamente es algo que nosotros venimos tratando de cambiar con las políticas de cultura de ahorros para que los clientes puedan conocer de los productos finales y los que más se adecuen a sus necesidades, porque tenemos diferentes tipos de cuentas, romper directamente un poco con esa disposición, ese rechazo por parte de un público muy objetivo que tenemos muy en claro y también del conocimiento dentro de nuestros mismo colaboradores, por lo cual hacer que s esto sea un punto a nuestro favor de parte de nuestras sucursales, las tiendas, la agencias, nosotros podamos encontrar una forma de poder llegar a nuestros consumidores finales, en realidad creo que estamos muy satisfecho con el trabajo, como te repito tenemos un equipo sumamente experimentado, un equipo muy comprometido con este protocolo de canalidad que manejamos dentro de lo que son estos canales alternativos.

Perfecto... justo lo que tú me comentas como uno de los beneficios, ventajas diferenciales del monedero electrónico que tiene la entidad financiera donde tú trabajas, ¿qué otro beneficio resaltante puedes rescatar, que te diferencie de otras entidades?

Hemos identificado que para poder nosotros llegar también a nuestros usuarios a lo cual nosotros llamamos nuestros aún no clientes, es precisamente el uso de nuestros cajeros multifuncionales sin la necesidad de tener una tarjeta de débito, o crédito, por lo que este usuario este aún no cliente, tiene la posibilidad de acercarse a un cajero multifuncional puede tocar la pantalla y se le apertura un menú de opciones donde pueden ellos realizar también operaciones de pagos de servicios, operaciones de pagos de tarjetas de crédito incluso, y depósitos también a través de lo que son transferencias interbancarias, esto creo que es sumamente importante porque también nosotros de esta manera captamos también este sector, este público que nosotros buscamos formen parte de nuestros clientes y poder también de esta manera hacer una diferencia definitivamente de la propuesta de valor que 
nosotros tenemos dentro de nuestros canales alternativos, es un canal que cualquier persona puede hacer uso de la misma y beneficiarse de ella.

\section{6.- ¿Tiene algún comentario o sugerencia final sobre la implementación de cajeros automáticos en la universidad?}

Efectivamente, sí, nosotros venimos trabajando de cara también a implementar estrategias que nos hemos trazado nosotros estamos en este constante cambio y lo que apuntamos también es que estos cajeros automático, esto canales alternativos sean también una plataforma de fidelización de clientes, poder hacer una apertura de cuenta de ahorro electrónico que pueda realizarse a través de un cajero automático por lo que también podría entregársele un tarjeta de débito, estos sistemas nosotros buscamos directamente esta propuesta de valor partiendo también de como se viene realizando, pero es un tema que estamos implementándolo con el tiempo también estamos evaluando, estamos en un evaluación constante, creo que estamos yendo de manera muy positiva, referente a esta etapa, manejamos protocolos de omnicanalidad entre las sucursales también lo cual para que puedas tener un mejor conocimiento esto o puedas comprenderlo mejor, en el caso de un pago de tarjeta de crédito en una sucursal si el pago es menor a 400 nuevos soles es un pago que para nosotros es derivable, nosotros dentro de este protocolo omnicanalidad buscamos acompañar a nuestros clientes brindándoles este servicio adicional de cara a la experiencia que pueda tener este cliente conocer una forma más versátil de realizar sus operaciones, sus transacciones, nuestros colaboradores están altamente capacitados con la experiencia de un servicio adecuado, tenemos clientes muy satisfecho, los cuales nosotros podemos Salir a apoyar y un poco educar a nuestros clientes, creo que son, es un procedimiento que hemos venido siguiendo, es algo que nosotros venimos gradualmente implementando y creo que el objetivo es ese, poder tener dentro de nuestros canales alternativos una plataforma de atención polifuncional.

Perfecto y dentro de este proyecto que tiene la entidad financiera donde tú trabajas, ¿también avizoran colocar estos cajeros automáticos multifuncionales que de repente no se encuentran en la universidad, que de repente básicamente sólo se encuentran los tradicionales? 
Sí, efectivamente nosotros venimos tratando de que esto ya se dé actualmente contamos con estos cajeros multifuncionales dentro de las sucursales, estamos empezando también a hacer el cambio de estos cajeros tradicionales, nuestros ATM, ahora hemos hecho una renovación dentro del software para poder poco a poco dar a conocer a estos clientes y no clientes en el uso adecuado de estos, sí, efectivamente nosotros estamos manejando una implementación yo creo que en el mediano plazo podamos observar que esto ya se ve dentro de los puntos de atención donde no puedas encontrar una sucursal y puedas tener la opción de poder realizar este tipo de operaciones multifuncionales.

Exacto, es decir, de repente en corto plazo los cajeros multifuncionales podrían llegar a las universidades.

Sí, efectivamente eso es algo que nosotros estamos buscando realizar debido a la importancia de esta, y también un tema de conveniencia, efectivamente porque esto también les facilita a las universidades poder reducir entre ellos mismos las esperas en atención por pagos, que puedan tener ellos a su alumnado entonces creo que es algo que nosotros lo vemos así, en un corto o mediano plazo poder realizar esto de manera definitiva.

\section{¿Consideras que los clientes universitarios se sienten más seguros al usar los cajeros} ATM de la universidad que los cajeros que se encuentran fuera de la universidad?

Efectivamente, sí, hay tema aquí también de seguridad que evidentemente los tenemos identificados, los cajeros automáticos cuentan digamos con una mayor protección referente a cajeros que podamos tener ubicados en otros puntos estratégicos que sin embargo están también digamos expuestos a ciertos riesgos como el vandalismo o también con respecto a los que son los fraudes, evidentemente sí, manejamos también nosotros como te había comentado, tenemos socios estratégicos que monitorean nuestros cajeros ATM y estamos en una constante mejora de cara a esto.

\section{ENTREVISTA $\mathbf{N}^{\circ} 3$}

1.- Desde tu punta de vista nos podría indicar que necesidades no cubiertos has podido identificar en los usuarios de los cajeros automáticos instalados en las universidades cual es lo más constantes? 
Si nos referimos a cajeros automáticos instalados dentro de la universidad, podemos encontrar debilidades, las cuales sería bueno corregir. Estamos hablando por ejemplo la facilidad de poder retirar dinero de bajo valor, como las monedas. Por otro, lado, si bien es cierto, los bancos te dan la facilidad de poder retirar en sus cajeros con tarjetas de otros bancos, están deberían ser gratuitas, al menos dentro de las instalaciones de la universidad.

2.- ¿Cuál es la percepción respecto a la calidad del servicio que brindan los cajeros ATM instalados en las universidades, considera que los usuarios se encuentran satisfechos?

Definitivamente no creo que satisfaga las necesidades a un $100 \%$, la calidad se trata de mejorar día a día, pero tengamos en cuenta que un ATM o cajero automático tiene a los menos 10 años de uso. Si bien es cierto se actualizaron los sistemas por seguridad y de manera remota, lo ideal sería cambiarlo por ATM modernas, pero la realidad es distinta, estos ATM cuestan mucho dinero, por esta razón las mejoras son solamente sistemáticas.

3.- De las 5 dimensiones relacionadas con la calidad de servicio, fiabilidad, capacidad de respuesta, seguridad, empatía y aspectos tangibles en qué orden colocaría Ud. las 5 dimensiones evaluando a los cajeros ATM....de las universidades de mayor a menor relevancia.

Seguridad, fiabilidad, capacidad de respuesta, empatía, aspectos tangibles.

4.- ¿Cuáles son los problemas más frecuentes que reportan los estudiantes universitarios al utilizar el servicio de cajeros ATM instalados en las universidades? ¿Qué solución se podría dar a estos problemas frecuentes para evitarlos?

Atasco de las tarjetas, la no dispensación de dinero o falla en el servicio (red), falta de denominación de dinero. 
La solución, mejores actualizaciones del software, mantenimiento constante a los procesos mecánicos dentro del ATM. Que el aviso remoto de fallas asigne una respuesta inmediata, ya sea servicio técnico por parte de un operario o de forma remota.

5.- En qué porcentaje considera Ud. Se encuentran satisfechos los estudiantes universitarios en el servicio de cajeros ATM instalados en la universidad, que limitantes se pueden superar para alcanzar el $100 \%$ de satisfacción.

Un 70\% de personas estarían satisfecho. Las limitaciones ya fueron mencionadas al principio, pero lo más importante es inversión por las empresas bancarias y que estos tengan un estándar de calidad fijado para todos a través de la SBS (fiscalizadores). Se ha visto un cambio, una mejoría en modernizar este tipo de servicios, pero si nos comparamos con países ya existen cajeros inteligentes en abundancia, donde puedes depositar, cobrar cheques y demás.

6.- ¿Tiene algún comentario o sugerencia final sobre la implementación de cajeros automáticos en la universidad de Lima Metropolitana?

El tener un cajero automático dentro de las universidades es muy importante ya sea para los alumnos y personal de la misma universidad, sin embargo, para las empresas bancarias existen prioridades, es diferente modernizar un ATM dentro de un centro comercial que, en una universidad, ya que la universidad presenta tiempo de cierre ya sea por vacaciones, etc. 


\section{Anexo 2. Matriz de consistencia y operacionalización de variables}

\begin{tabular}{|c|c|c|c|c|c|c|c|c|c|c|c|}
\hline TÍTULO & $\begin{array}{l}\text { PROBLEMAS } \\
\text { GENERAL Y } \\
\text { ESPECÍFICO }\end{array}$ & $\begin{array}{c}\text { OBJETIVO } \\
\text { GENERAL Y } \\
\text { ESPECÍFICO }\end{array}$ & $\begin{array}{l}\text { HIPÓTESIS } \\
\text { GENERAL Y } \\
\text { ESPECÍFICA }\end{array}$ & VARIABLES & DIMENSIONES & INDICADORES & MUESTRA & DISEÑO & | INSTRUMENTO & IITEMS & ESTADÍSTICA \\
\hline \multirow{5}{*}{$\begin{array}{l}\text { Percepción } \\
\text { de la calidad } \\
\text { del servicio } \\
\text { de cajeros } \\
\text { ATM en } \\
\text { universidades } \\
\text { particulares } \\
\text { de San Isidro }\end{array}$} & $\begin{array}{c}\text { Problema } \\
\text { General }\end{array}$ & $\begin{array}{l}\text { Objetivo } \\
\text { General } \\
\end{array}$ & $\begin{array}{l}\text { Hipótesis } \\
\text { Principal }\end{array}$ & \multirow{5}{*}{$\begin{array}{l}\text { Dependiente } \\
\text { Percepción } \\
\text { de la calidad } \\
\text { de servicio }\end{array}$} & & & \multirow{5}{*}{$\begin{array}{l}\text { Estudiantes universitarios: } \\
\text { Se utilizó la fórmula para población finita o } \\
\text { conocida: } \\
\qquad n=\frac{N \times Z_{\alpha}^{2} \times p \times q}{d^{2} \times(N-1)+Z_{\alpha}^{2} \times p \times q}\end{array}$} & \multirow{5}{*}{$\begin{array}{l}\text { Cuantitativa, } \\
\text { descriptiva }\end{array}$} & \multirow{5}{*}{$\begin{array}{l}\text { Encuesta } \\
\text { SERVQUAL }\end{array}$} & & \multirow{5}{*}{$\begin{array}{c}\text { Estadística } \\
\text { descriptiva: } \\
\text { Frecuencias } \\
\text { absolutas (N) } \\
\text { y relativas (\%) } \\
\text { de los niveles } \\
\text { de percepción } \\
\text { de la } \\
\text { fiabilidad, } \\
\text { capacidad de } \\
\text { respuesta, } \\
\text { seguridad, } \\
\text { empatía y } \\
\text { aspectos } \\
\text { tangibles. }\end{array}$} \\
\hline & $\begin{array}{l}\text { ¿Cuál es la } \\
\text { percepción de } \\
\text { la calidad de } \\
\text { servicios de } \\
\text { cajeros ATM en } \\
\text { las } \\
\text { universidades } \\
\text { particulares del } \\
\text { distrito San } \\
\text { Isidro? }\end{array}$ & $\begin{array}{c}\text { Determinar } \\
\text { cuál es la } \\
\text { percepción de } \\
\text { calidad de los } \\
\text { servicios de } \\
\text { cajeros ATM en } \\
\text { los alumnos de } \\
\text { las } \\
\text { universidades } \\
\text { particulares en } \\
\text { el distrito San } \\
\text { Isidro. }\end{array}$ & $\begin{array}{l}\text { Los universitarios } \\
\text { de la modalidad } \\
\text { Working Adult se } \\
\text { encuentran } \\
\text { altamente } \\
\text { satisfechos con el } \\
\text { servicio de } \\
\text { cajeros ATM } \\
\text { instalados en las } \\
\text { universidades del } \\
\text { distrito San Isidro }\end{array}$ & & & & & & & $\begin{array}{c}1,2,3, \\
4,5\end{array}$ & \\
\hline & $\begin{array}{l}\text { Problemas } \\
\text { Específicos }\end{array}$ & \begin{tabular}{|c|} 
Objetivos \\
Específicos \\
\end{tabular} & $\begin{array}{c}\text { Hipótesis } \\
\text { Específicas }\end{array}$ & & & & & & & & \\
\hline & $\begin{array}{c}\text { ¿Cuál es la } \\
\text { percepción de } \\
\text { la fiabilidad del } \\
\text { servicio de } \\
\text { cajeros ATM en } \\
\text { los alumnos de } \\
\text { las } \\
\text { universidades } \\
\text { particulares de } \\
\text { San Isidro? } \\
\end{array}$ & \begin{tabular}{|c|} 
Determinar la \\
percepción en \\
la fiabilidad del \\
servicio de \\
cajeros ATM en \\
los alumnos de \\
las \\
universidades \\
particulares de \\
San Isidro \\
\end{tabular} & $\begin{array}{l}\text { Existe una alta } \\
\text { satisfacción de la } \\
\text { fiabilidad de los } \\
\text { servicios de } \\
\text { cajeros ATM en } \\
\text { las universidades } \\
\text { particulares de } \\
\text { San Isidro. }\end{array}$ & & Fiabilidad & $\begin{array}{l}\text { Solución rápida de problemas. } \\
\text { Buen abastecimiento. } \\
\text { Tiempo de uso pertinente. } \\
\text { Recepción de reclamos. } \\
\text { Entrega de billetes genuinos. }\end{array}$ & & & & $\begin{array}{c}6,7,8, \\
9\end{array}$ & \\
\hline & $\begin{array}{c}\text { ¿Cuál es la } \\
\text { percepción de } \\
\text { la capacidad de } \\
\text { respuesta del } \\
\text { servicio de } \\
\text { cajeros ATM en } \\
\text { los alumnos de } \\
\text { las } \\
\text { universidades } \\
\text { particulares de } \\
\text { San Isidro? }\end{array}$ & $\begin{array}{c}\text { Determinar la } \\
\text { percepción en } \\
\text { la capacidad de } \\
\text { respuesta del } \\
\text { servicio de } \\
\text { cajeros ATM en } \\
\text { los alumnos de } \\
\text { las } \\
\text { universidades } \\
\text { particulares de } \\
\text { San Isidro }\end{array}$ & $\begin{array}{l}\text { Existe una alta } \\
\text { satisfacción de la } \\
\text { capacidad de } \\
\text { respuesta de los } \\
\text { servicios de } \\
\text { cajeros ATM en } \\
\text { las universidades } \\
\text { particulares de } \\
\text { San Isidro. }\end{array}$ & & $\begin{array}{l}\text { Capacidad de } \\
\text { Respuesta }\end{array}$ & $\begin{array}{c}\text { Servicio asistido. } \\
\text { Servicio vinculado a la } \\
\text { universidad. } \\
\text { Posibilidad de depósito } \\
\text { interbancario. } \\
\text { Existencia de dispensador de } \\
\text { monedas. }\end{array}$ & & & & $\begin{array}{l}10,11, \\
12,13\end{array}$ & \\
\hline
\end{tabular}




\begin{tabular}{|c|c|c|c|c|c|c|c|c|c|}
\hline $\begin{array}{l}\text { ¿Cuál es la } \\
\text { percepción de } \\
\text { la seguridad de } \\
\text { respuesta del } \\
\text { servicio de } \\
\text { cajeros ATM en } \\
\text { los alumnos de } \\
\text { las } \\
\text { universidades } \\
\text { particulares de } \\
\text { San Isidro? } \\
\end{array}$ & $\begin{array}{c}\text { Determinar la } \\
\text { percepción en } \\
\text { la seguridad } \\
\text { del servicio de } \\
\text { cajeros ATM en } \\
\text { los alumnos de } \\
\text { las } \\
\text { universidades } \\
\text { particulares de } \\
\text { San Isidro }\end{array}$ & $\begin{array}{c}\text { Existe una } \\
\text { satisfacción de la } \\
\text { seguridad de los } \\
\text { servicios de } \\
\text { cajeros ATM en } \\
\text { las universidades } \\
\text { particulares de } \\
\text { San Isidro. }\end{array}$ & Seguridad & $\begin{array}{l}\text { Vigilancia adecuada. } \\
\text { Protección ante fraudes o } \\
\text { clonaciones. } \\
\text { Interfaz segura y amigable. } \\
\text { Menú seguro y personalizado. }\end{array}$ & & & & 14,15 & \\
\hline $\begin{array}{l}\text { ¿Cuál es la } \\
\text { percepción de } \\
\text { la empatía del } \\
\text { servicio de } \\
\text { cajeros ATM en } \\
\text { los alumnos de } \\
\text { las } \\
\text { universidades } \\
\text { particulares de } \\
\text { San Isidro? }\end{array}$ & $\begin{array}{c}\text { Determinar la } \\
\text { percepción en } \\
\text { la empatía del } \\
\text { servicio de } \\
\text { cajeros ATM en } \\
\text { los alumnos de } \\
\text { las } \\
\text { universidades } \\
\text { particulares de } \\
\text { San Isidro }\end{array}$ & $\begin{array}{c}\text { Existe una } \\
\text { satisfacción de la } \\
\text { empatía de los } \\
\text { servicios de } \\
\text { cajeros ATM en } \\
\text { las universidades } \\
\text { particulares de } \\
\text { San Isidro. }\end{array}$ & Empatía & $\begin{array}{l}\text { Abastecimiento constante. } \\
\text { Presencia de personal de } \\
\text { asistencia. } \\
\text { Posibilidad de apertura de } \\
\text { cuentas. } \\
\text { Disponibilidad de atención a } \\
\text { discapacitados. } \\
\text { Servicio orientado al cliente } \\
\text { universitario. }\end{array}$ & & & & $\begin{array}{c}16,17 \\
18\end{array}$ & \\
\hline $\begin{array}{l}\text { ¿Cuál es la } \\
\text { percepción de } \\
\text { los aspectos } \\
\text { tangibles del } \\
\text { servicio de } \\
\text { cajeros ATM en } \\
\text { los alumnos de } \\
\text { las } \\
\text { universidades } \\
\text { particulares de } \\
\text { San Isidro? } \\
\end{array}$ & $\begin{array}{l}\text { Determinar la } \\
\text { percepción en } \\
\text { los aspectos } \\
\text { tangibles del } \\
\text { servicio de } \\
\text { cajeros ATM en } \\
\text { los alumnos de } \\
\text { las } \\
\text { universidades } \\
\text { particulares de } \\
\text { San Isidro } \\
\end{array}$ & $\begin{array}{c}\text { Existe una } \\
\text { satisfacción de los } \\
\text { aspectos } \\
\text { tangibles de los } \\
\text { servicios de } \\
\text { cajeros ATM en } \\
\text { las universidades } \\
\text { particulares de } \\
\text { San Isidro. }\end{array}$ & $\begin{array}{l}\text { Aspectos } \\
\text { Tangibles }\end{array}$ & $\begin{array}{c}\text { Servicio } 24 / 7 . \\
\text { Mayor disponibilidad de } \\
\text { monedas y billetes más } \\
\text { usados. } \\
\text { Ubicación estratégica. } \\
\text { Limpieza adecuada. }\end{array}$ & & & & $\begin{array}{l}19,20 \\
21,22\end{array}$ & \\
\hline $\begin{array}{l}\text { ¿Cuál es la } \\
\text { percepción de } \\
\text { los expertos } \\
\text { acerca del } \\
\text { servicio de los } \\
\text { cajeros ATM } \\
\text { instalados en } \\
\text { las particulares } \\
\text { de San Isidro? }\end{array}$ & $\begin{array}{l}\text { Determinar la } \\
\text { calidad del } \\
\text { servicio } \\
\text { percibido por } \\
\text { los expertos en } \\
\text { cajeros ATM } \\
\text { instalados en } \\
\text { las } \\
\text { universidades } \\
\text { particulares de } \\
\text { San Isidro }\end{array}$ & $\begin{array}{l}\text { Los expertos } \\
\text { consideran que } \\
\text { existe una alta } \\
\text { satisfacción de los } \\
\text { universitarios con } \\
\text { el servicio de } \\
\text { cajeros ATM } \\
\text { instalados en las } \\
\text { universidades } \\
\text { particulares de } \\
\text { San Isidro. }\end{array}$ & - & & $\begin{array}{l}\text { Especialistas en cajeros ATM } \\
\text { Tipo de muestreo: } \\
\text { No Probabilistico. } \\
\text { Criterios de inclusión: } \\
\text { - Especialista en Canales Alternativos } \\
\text { - Antigüedad laboral en el área promedio } 9 \text { años. } \\
\text { - Conocimiento de autoabastecimiento de cajeros. } \\
\text { - Conocimiento de análisis de demanda de } \\
\text { cajeros. } \\
\text { - Conocimiento de la denominación monetaria } \\
\text { altamente demandas por zonas. }\end{array}$ & Cualitativa & $\begin{array}{l}\text { Guía de } \\
\text { entrevista }\end{array}$ & $\begin{array}{l}1,2,3 \\
4,5,6\end{array}$ & $\begin{array}{c}\text { Análisis a } \\
\text { profundidad: } \\
\text { Entrevista }\end{array}$ \\
\hline
\end{tabular}




\section{Operacionalización de variables}

\begin{tabular}{|c|c|c|c|c|c|}
\hline VARIABLES & DIMENSIONES & INDICADORES & TIPO & $\begin{array}{l}\text { ESCALA DE } \\
\text { MEDIDA }\end{array}$ & NIVELES \\
\hline \multirow{3}{*}{$\begin{array}{c}\text { Dependiente } \\
\text { Percepción de la calidad } \\
\text { del servicio }\end{array}$} & Fiabilidad & $\begin{array}{l}\text { Solución rápida de problemas. } \\
\text { Buen abastecimiento. } \\
\text { Tiempo de uso pertinente. } \\
\text { Recepción de reclamos. } \\
\text { Entrega de billetes genuinos. }\end{array}$ & Cuantitativo & Nominal & \multirow{5}{*}{$\begin{array}{c}\text { Alta } \\
\text { Insatisfacción } \\
\text { Insatisfacción } \\
\text { baja-media }\end{array}$} \\
\hline & $\begin{array}{l}\text { Capacidad de } \\
\text { Respuesta }\end{array}$ & $\begin{array}{l}\text { Servicio asistido. } \\
\text { Servicio vinculado a la universidad. } \\
\text { Posibilidad de depósito interbancario. } \\
\text { Existencia de dispensador de monedas. }\end{array}$ & Cuantitativo & Nominal & \\
\hline & Seguridad & $\begin{array}{l}\text { Vigilancia adecuada. } \\
\text { Protección ante fraudes o clonaciones. } \\
\text { Interfaz segura y amigable. } \\
\text { Menú seguro y personalizado. }\end{array}$ & Cuantitativo & Nominal & \\
\hline \multirow[t]{2}{*}{$\begin{array}{l}\quad \text { Independiente } \\
\text { Dimensiones del modelo } \\
\text { SERVQUAL }\end{array}$} & Empatía & $\begin{array}{l}\text { Abastecimiento constante. } \\
\text { Presencia de personal de asistencia. } \\
\text { Posibilidad de apertura de cuentas. } \\
\text { Disponibilidad de atención a discapacitados. } \\
\text { Servicio orientado al cliente universitario. }\end{array}$ & Cuantitativo & Nominal & \\
\hline & Aspectos Tangibles & $\begin{array}{c}\text { Operatividad del Servicio } 24 / 7 . \\
\text { Mayor disponibilidad de monedas y billetes más usados. } \\
\text { Ubicación estratégica. } \\
\text { Limpieza adecuada. }\end{array}$ & Cuantitativo & Nominal & \\
\hline
\end{tabular}




\section{Anexo 3. Confiabilidad del Instrumento}

\section{COEFICIENTE ALFA DE CRONBACH}

El Coeficiente de alfa de Cronbach sirve para medir la fiabilidad y validez; grado de medición de lo que se pretende calcular, del instrumento (cuestionario). Este coeficiente puede tener valores de 0 a 1 , cuando el valor esté más cercano a 1 , mayor es la consistencia interna de los ítems analizados. Los niveles de fiabilidad se muestran en la siguiente tabla:

$$
\alpha^{\prime} \text { Cronbach }=\frac{k}{(k-1)}\left(1-\frac{\sum_{j=1}^{k} s_{j}{ }^{2}}{S_{T}{ }^{2}}\right)
$$

\begin{tabular}{|c|c|}
\hline $\begin{array}{c}\text { Coeficiente de alfa de } \\
\text { Cronbach }\end{array}$ & Nivel de Consistencia \\
\hline$>0.8$ a 1 & Blta \\
\hline$>0.6$ a 0.8 & Moderada \\
\hline$>0.4$ a 0.6 & Baja \\
\hline$>0.2$ a 0.4 & Muy baja \\
\hline$>0$ a 0.2 & \\
\hline
\end{tabular}

Fuente de elaboración propia

Para el cálculo del coeficiente de confiabilidad alfa de Cronbach se utilizó el siguiente procedimiento: Donde $\mathrm{k}=$ número de ítems (preguntas).

Luego para el cálculo de la varianza por cada ítem se utilizó la siguiente fórmula:

$$
s_{j}^{2}=\frac{1}{(n-1)} \sum_{i=1}^{n}\left(x_{i}-\bar{X}\right)^{2}
$$


Posteriormente se calculó ST que es la Varianza del total de puntaje (la misma fórmula, pero para el total de puntaje de cada individuo). Para validar el instrumento se aplicó como mínimo el cuestionario a 110 personas.

\section{Anexo 4. Validación del Cuestionario}




\section{Cuestionario Expectativas}

\begin{tabular}{|c|c|c|c|c|c|c|c|c|c|c|c|c|c|c|c|c|c|c|c|c|c|c|c|}
\hline $\begin{array}{l}\text { Encu } \\
\text { esta }\end{array}$ & I1 & 12 & 13 & 14 & 15 & 16 & 17 & 18 & 19 & $\begin{array}{r}11 \\
0 \\
\end{array}$ & $\begin{array}{c}11 \\
1 \\
\end{array}$ & $\begin{array}{r}11 \\
2 \\
\end{array}$ & $\begin{array}{r}11 \\
3 \\
\end{array}$ & $\begin{array}{c}I 1 \\
4 \\
\end{array}$ & $\begin{array}{c}11 \\
5 \\
\end{array}$ & $\begin{array}{c}11 \\
6 \\
\end{array}$ & $\begin{array}{l}11 \\
7 \\
\end{array}$ & $\begin{array}{r}11 \\
8 \\
\end{array}$ & $\begin{array}{r}11 \\
9 \\
\end{array}$ & $\begin{array}{c}12 \\
0 \\
\end{array}$ & $\begin{array}{c}12 \\
1 \\
\end{array}$ & $\begin{array}{r}12 \\
2 \\
\end{array}$ & $\begin{array}{l}\text { To } \\
\text { tal }\end{array}$ \\
\hline 1 & 5 & 4 & 5 & 4 & 4 & 4 & 4 & 4 & 4 & 4 & 4 & 4 & 4 & 4 & 4 & 4 & 4 & 4 & 4 & 4 & 4 & 4 & 90 \\
\hline 2 & 5 & 5 & 5 & 4 & 5 & 4 & 4 & 5 & 5 & 4 & 4 & 4 & 4 & 4 & 5 & 4 & 4 & 4 & 4 & 4 & 4 & 4 & 95 \\
\hline 3 & 5 & 4 & 5 & 4 & 5 & 4 & 4 & 4 & 4 & 4 & 4 & 4 & 4 & 4 & 5 & 5 & 5 & 5 & 5 & 4 & 4 & 4 & 96 \\
\hline 4 & 4 & 5 & 5 & 4 & 5 & 4 & 4 & 4 & 4 & 4 & 4 & 4 & 4 & 5 & 4 & 4 & 4 & 4 & 4 & 4 & 4 & 4 & 92 \\
\hline 5 & 5 & 4 & 5 & 4 & 5 & 5 & 4 & 4 & 4 & 4 & 4 & 4 & 4 & 4 & 4 & 4 & 4 & 4 & 4 & 4 & 4 & 4 & 92 \\
\hline 6 & 5 & 5 & 5 & 4 & 5 & 4 & 4 & 5 & 4 & 4 & 4 & 4 & 4 & 4 & 4 & 4 & 4 & 4 & 4 & 4 & 4 & 5 & 94 \\
\hline 7 & 5 & 5 & 5 & 4 & 5 & 5 & 4 & 4 & 4 & 4 & 5 & 4 & 4 & 4 & 4 & 4 & 5 & 4 & 4 & 4 & 5 & 4 & 96 \\
\hline 8 & 5 & 5 & 5 & 4 & 5 & 4 & 4 & 5 & 4 & 4 & 4 & 4 & 4 & 4 & 4 & 4 & 4 & 4 & 4 & 4 & 4 & 4 & 93 \\
\hline 9 & 5 & 5 & 5 & 4 & 5 & 5 & 4 & 4 & 4 & 4 & 4 & 4 & 4 & 4 & 5 & 4 & 5 & 5 & 5 & 5 & 5 & 4 & 99 \\
\hline 10 & 5 & 4 & 5 & 4 & 5 & 4 & 4 & 5 & 5 & 4 & 5 & 4 & 4 & 4 & 5 & 4 & 4 & 4 & 4 & 4 & 4 & 5 & 96 \\
\hline 11 & 5 & 4 & 5 & 4 & 5 & 4 & 4 & 4 & 5 & 5 & 4 & 4 & 4 & 4 & 4 & 4 & 4 & 4 & 4 & 4 & 5 & 4 & 94 \\
\hline 12 & 5 & 4 & 5 & 4 & 5 & 5 & 4 & 4 & 4 & 4 & 4 & 4 & 4 & 5 & 5 & 5 & 4 & 4 & 5 & 4 & 4 & 4 & 96 \\
\hline 13 & 4 & 5 & 5 & 4 & 5 & 4 & 4 & 4 & 4 & 4 & 4 & 4 & 4 & 5 & 4 & 4 & 4 & 4 & 4 & 4 & 5 & 4 & 93 \\
\hline 14 & 5 & 5 & 5 & 4 & 5 & 5 & 5 & 5 & 5 & 4 & 4 & 5 & 4 & 5 & 4 & 4 & 5 & 5 & 4 & 5 & 4 & 4 & $\begin{array}{c}10 \\
1\end{array}$ \\
\hline 15 & 5 & 5 & 5 & 5 & 5 & 4 & 4 & 4 & 4 & 4 & 4 & 5 & 4 & 4 & 4 & 4 & 4 & 4 & 4 & 4 & 4 & 5 & 95 \\
\hline 16 & 5 & 5 & 5 & 4 & 5 & 5 & 5 & 5 & 5 & 4 & 4 & 4 & 4 & 5 & 4 & 4 & 5 & 4 & 5 & 4 & 4 & 4 & 99 \\
\hline 17 & 5 & 4 & 5 & 4 & 4 & 4 & 4 & 4 & 4 & 4 & 4 & 4 & 4 & 5 & 5 & 4 & 4 & 4 & 4 & 4 & 4 & 4 & 92 \\
\hline 18 & 5 & 4 & 5 & 4 & 4 & 4 & 4 & 4 & 4 & 4 & 5 & 5 & 5 & 4 & 5 & 5 & 5 & 5 & 5 & 4 & 4 & 4 & 98 \\
\hline 19 & 5 & 4 & 5 & 4 & 4 & 5 & 4 & 4 & 5 & 5 & 4 & 4 & 4 & 4 & 5 & 5 & 5 & 5 & 5 & 4 & 4 & 4 & 98 \\
\hline 20 & 5 & 4 & 5 & 4 & 4 & 4 & 4 & 4 & 5 & 5 & 4 & 4 & 4 & 5 & 5 & 5 & 4 & 4 & 4 & 4 & 4 & 4 & 95 \\
\hline 21 & 5 & 4 & 5 & 4 & 4 & 4 & 4 & 4 & 5 & 5 & 4 & 4 & 4 & 5 & 5 & 5 & 4 & 4 & 4 & 4 & 4 & 4 & 95 \\
\hline 22 & 5 & 5 & 5 & 5 & 5 & 5 & 5 & 5 & 5 & 5 & 5 & 5 & 5 & 5 & 5 & 5 & 5 & 5 & 5 & 5 & 5 & 5 & $\begin{array}{c}11 \\
0\end{array}$ \\
\hline 23 & 5 & 5 & 5 & 5 & 5 & 5 & 5 & 5 & 5 & 5 & 5 & 5 & 5 & 5 & 5 & 5 & 5 & 5 & 5 & 5 & 5 & 5 & $\begin{array}{c}11 \\
0\end{array}$ \\
\hline 24 & 5 & 5 & 5 & 5 & 5 & 5 & 5 & 5 & 5 & 5 & 5 & 5 & 5 & 5 & 5 & 5 & 5 & 5 & 5 & 5 & 5 & 5 & $\begin{array}{c}11 \\
0\end{array}$ \\
\hline 25 & 5 & 5 & 5 & 5 & 5 & 5 & 5 & 5 & 5 & 5 & 5 & 5 & 5 & 5 & 5 & 5 & 5 & 5 & 5 & 5 & 5 & 5 & $\begin{array}{c}11 \\
0\end{array}$ \\
\hline 26 & 5 & 5 & 5 & 5 & 4 & 5 & 5 & 5 & 4 & 5 & 5 & 4 & 5 & 5 & 5 & 5 & 5 & 4 & 5 & 5 & 5 & 5 & $\begin{array}{c}10 \\
6\end{array}$ \\
\hline 27 & 5 & 5 & 5 & 5 & 5 & 5 & 5 & 5 & 5 & 5 & 5 & 5 & 5 & 5 & 5 & 5 & 5 & 5 & 5 & 5 & 5 & 5 & $\begin{array}{c}11 \\
0\end{array}$ \\
\hline 28 & 5 & 5 & 5 & 5 & 5 & 5 & 5 & 5 & 5 & 5 & 5 & 5 & 5 & 5 & 5 & 5 & 5 & 5 & 5 & 5 & 5 & 5 & $\begin{array}{c}11 \\
0\end{array}$ \\
\hline 29 & 5 & 5 & 5 & 5 & 5 & 5 & 5 & 5 & 5 & 5 & 5 & 5 & 5 & 5 & 5 & 5 & 5 & 5 & 5 & 5 & 5 & 5 & $\begin{array}{c}11 \\
0\end{array}$ \\
\hline 30 & 5 & 5 & 5 & 5 & 5 & 5 & 4 & 5 & 5 & 5 & 4 & 5 & 5 & 5 & 5 & 4 & 5 & 5 & 5 & 4 & 5 & 5 & $\begin{array}{c}10 \\
6\end{array}$ \\
\hline 31 & 5 & 5 & 5 & 5 & 5 & 5 & 5 & 5 & 5 & 5 & 5 & 5 & 5 & 5 & 5 & 5 & 5 & 5 & 5 & 5 & 5 & 5 & $\begin{array}{c}11 \\
0\end{array}$ \\
\hline 32 & 5 & 5 & 5 & 5 & 5 & 5 & 5 & 5 & 5 & 5 & 5 & 5 & 5 & 5 & 5 & 5 & 5 & 5 & 5 & 5 & 5 & 5 & $\begin{array}{c}11 \\
0\end{array}$ \\
\hline 33 & 5 & 5 & 5 & 5 & 5 & 5 & 5 & 5 & 5 & 5 & 4 & 5 & 5 & 4 & 5 & 5 & 4 & 5 & 4 & 5 & 4 & 5 & $\begin{array}{c}10 \\
5\end{array}$ \\
\hline 34 & 5 & 5 & 5 & 5 & 5 & 5 & 5 & 5 & 5 & 5 & 5 & 5 & 5 & 5 & 5 & 5 & 5 & 5 & 5 & 5 & 5 & 5 & $\begin{array}{c}11 \\
0\end{array}$ \\
\hline 35 & 5 & 5 & 5 & 5 & 5 & 5 & 5 & 5 & 5 & 5 & 5 & 5 & 5 & 5 & 5 & 5 & 5 & 5 & 5 & 5 & 5 & 5 & $\begin{array}{c}11 \\
0\end{array}$ \\
\hline 36 & 5 & 5 & 5 & 5 & 5 & 5 & 5 & 5 & 5 & 5 & 5 & 5 & 5 & 5 & 5 & 5 & 5 & 5 & 5 & 5 & 5 & 5 & $\begin{array}{c}11 \\
0\end{array}$ \\
\hline 37 & 5 & 5 & 5 & 5 & 5 & 5 & 5 & 5 & 5 & 5 & 5 & 5 & 5 & 5 & 5 & 5 & 5 & 5 & 5 & 5 & 5 & 5 & $\begin{array}{c}11 \\
0\end{array}$ \\
\hline 38 & 5 & 5 & 5 & 5 & 5 & 5 & 5 & 5 & 5 & 5 & 5 & 5 & 5 & 5 & 5 & 5 & 5 & 5 & 5 & 5 & 5 & 5 & $\begin{array}{c}11 \\
0\end{array}$ \\
\hline
\end{tabular}




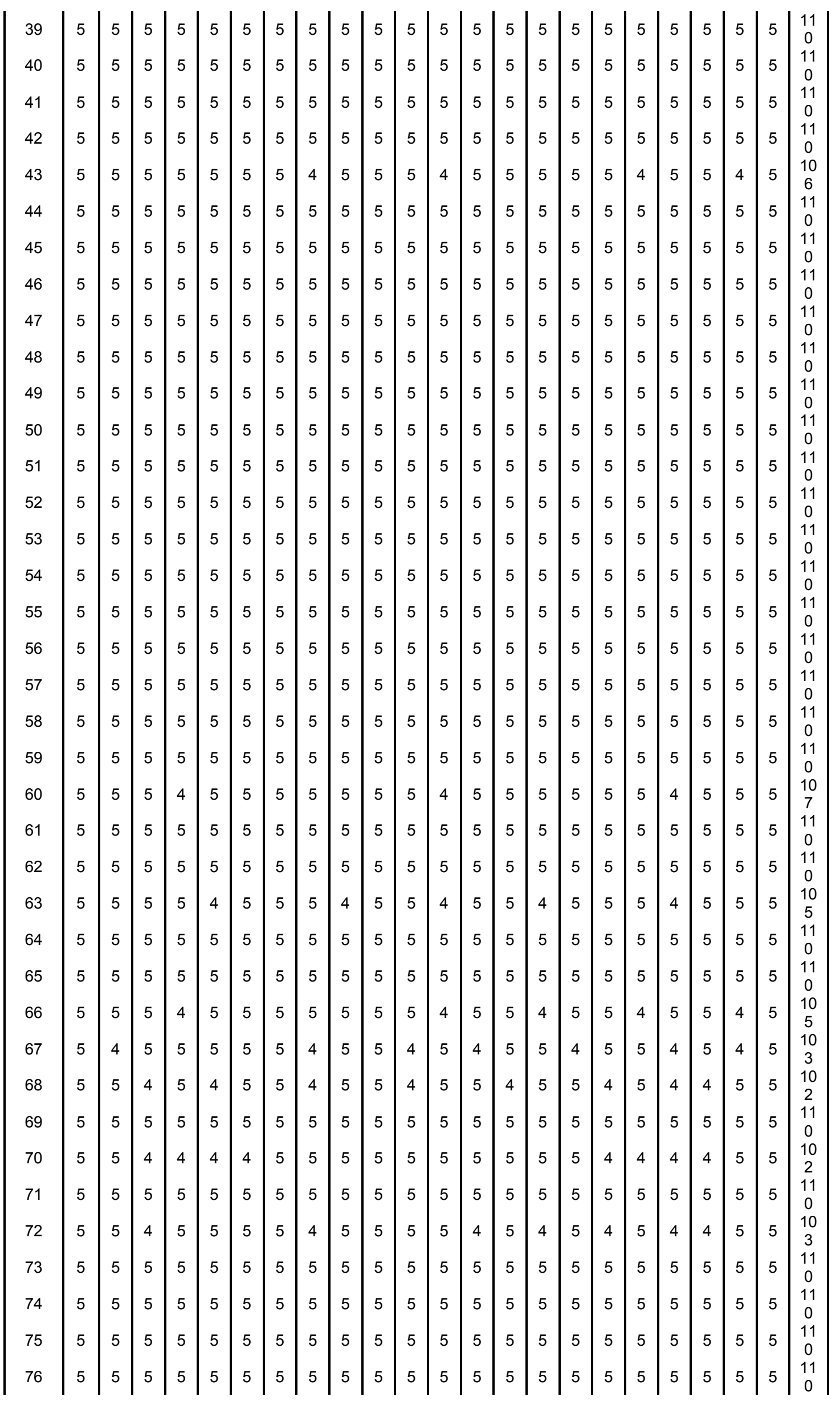




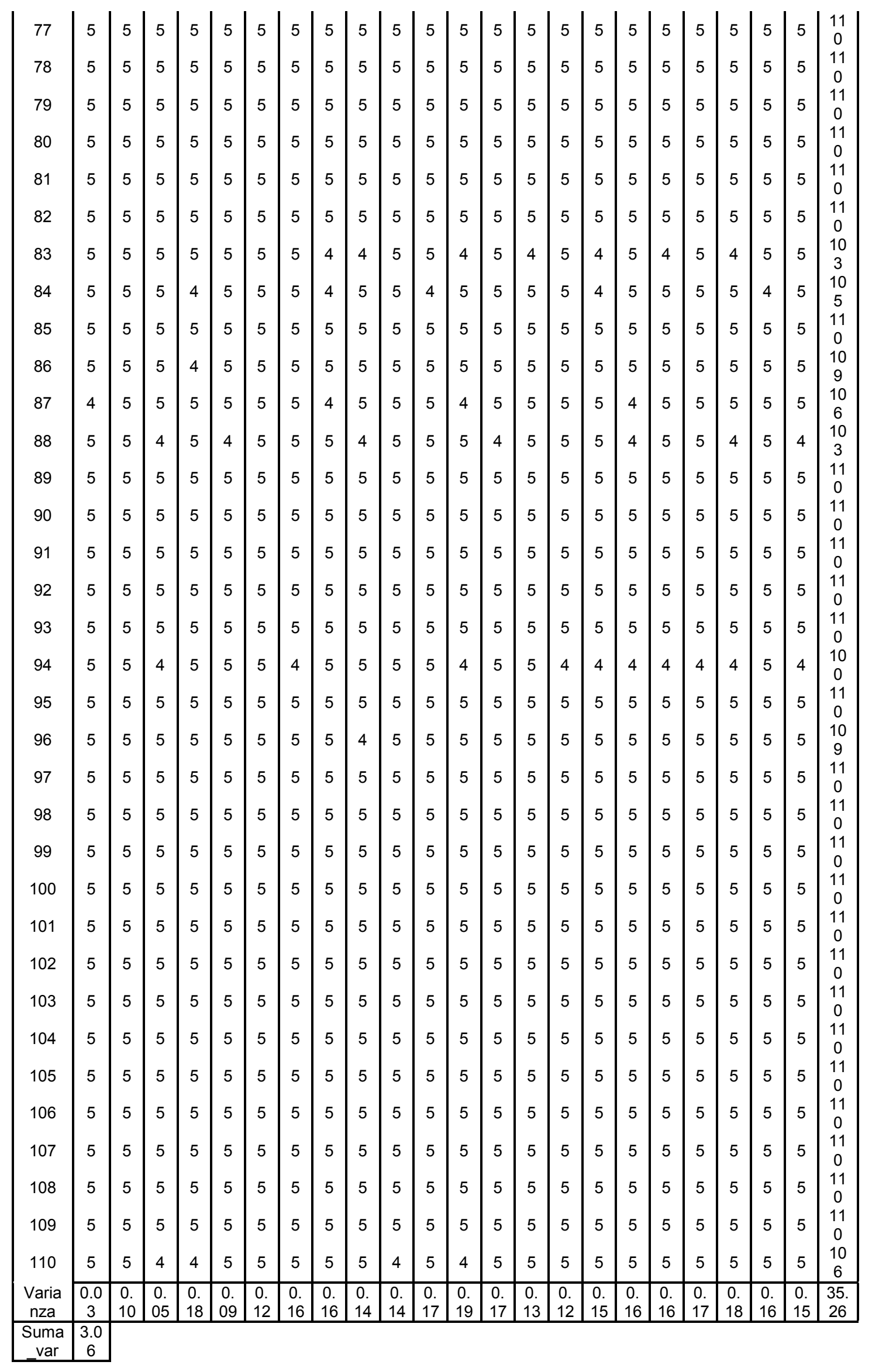




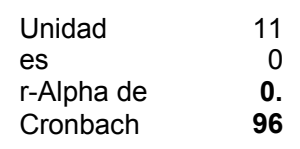

\begin{tabular}{|c|c|c|c|c|c|c|c|c|c|c|c|c|c|c|c|c|c|c|c|c|c|c|c|}
\hline $\begin{array}{l}\text { Encu } \\
\text { esta }\end{array}$ & I1 & 12 & 13 & 14 & 15 & 16 & Uל & As & or & $\begin{array}{c}\text { ar } \\
1 \\
0 \\
\end{array}$ & $\begin{array}{c}\mathbf{F} \\
1 \\
1\end{array}$ & $\begin{array}{l}\text { er } \\
\text { I1 } \\
2 \\
\end{array}$ & $\begin{array}{c}\text { epp } \\
\text { I1 } \\
3\end{array}$ & $\begin{array}{c}\text { I1 } \\
4\end{array}$ & $\begin{array}{r}\text { ne } \\
11 \\
5\end{array}$ & $\begin{array}{l}5 \\
6 \\
\end{array}$ & $\begin{array}{c}11 \\
7 \\
\end{array}$ & $\begin{array}{r}11 \\
8 \\
\end{array}$ & $\begin{array}{c}11 \\
9 \\
\end{array}$ & $\begin{array}{c}12 \\
0 \\
\end{array}$ & $\begin{array}{c}12 \\
1 \\
\end{array}$ & $\begin{array}{c}12 \\
2 \\
\end{array}$ & $\begin{array}{l}\text { To } \\
\text { tal }\end{array}$ \\
\hline 1 & 5 & 5 & 5 & 1 & 5 & 1 & 1 & 5 & 1 & 5 & 5 & 1 & 1 & 5 & 1 & 1 & 1 & 1 & 5 & 5 & 5 & 5 & 70 \\
\hline 2 & 5 & 5 & 5 & 1 & 5 & 1 & 1 & 1 & 1 & 5 & 5 & 1 & 1 & 5 & 1 & 1 & 1 & 1 & 5 & 1 & 5 & 5 & 62 \\
\hline 3 & 5 & 5 & 5 & 1 & 5 & 1 & 5 & 1 & 1 & 5 & 5 & 1 & 1 & 5 & 1 & 1 & 1 & 1 & 5 & 1 & 5 & 5 & 66 \\
\hline 4 & 5 & 5 & 5 & 1 & 5 & 5 & 1 & 1 & 1 & 5 & 5 & 1 & 1 & 5 & 1 & 1 & 1 & 1 & 5 & 5 & 5 & 5 & 70 \\
\hline 5 & 5 & 5 & 5 & 1 & 5 & 1 & 1 & 1 & 1 & 5 & 5 & 1 & 1 & 5 & 1 & 1 & 1 & 1 & 5 & 1 & 5 & 5 & 62 \\
\hline 6 & 5 & 5 & 5 & 1 & 5 & 5 & 1 & 1 & 1 & 5 & 5 & 1 & 4 & 5 & 1 & 1 & 1 & 1 & 5 & 1 & 5 & 5 & 69 \\
\hline 7 & 5 & 5 & 5 & 1 & 5 & 1 & 1 & 1 & 1 & 5 & 5 & 1 & 1 & 5 & 1 & 1 & 1 & 1 & 5 & 1 & 5 & 5 & 62 \\
\hline 8 & 5 & 5 & 5 & 1 & 5 & 5 & 1 & 1 & 1 & 5 & 5 & 1 & 1 & 5 & 1 & 1 & 1 & 1 & 5 & 1 & 5 & 5 & 66 \\
\hline 9 & 5 & 5 & 5 & 1 & 5 & 1 & 1 & 1 & 1 & 5 & 5 & 1 & 1 & 5 & 1 & 1 & 1 & 1 & 5 & 4 & 5 & 5 & 65 \\
\hline 10 & 5 & 5 & 5 & 1 & 5 & 5 & 1 & 1 & 1 & 5 & 5 & 1 & 1 & 5 & 1 & 1 & 1 & 1 & 5 & 5 & 5 & 5 & 70 \\
\hline 11 & 5 & 5 & 5 & 1 & 5 & 1 & 1 & 1 & 1 & 4 & 5 & 1 & 1 & 5 & 1 & 1 & 1 & 1 & 5 & 4 & 5 & 5 & 64 \\
\hline 12 & 5 & 5 & 5 & 1 & 5 & 1 & 1 & 1 & 1 & 5 & 5 & 1 & 1 & 5 & 1 & 1 & 1 & 1 & 5 & 1 & 5 & 5 & 62 \\
\hline 13 & 5 & 5 & 5 & 1 & 5 & 1 & 1 & 1 & 1 & 5 & 5 & 1 & 1 & 5 & 1 & 1 & 1 & 1 & 5 & 1 & 5 & 5 & 62 \\
\hline 14 & 5 & 5 & 5 & 1 & 5 & 1 & 1 & 1 & 1 & 5 & 5 & 1 & 1 & 5 & 1 & 1 & 1 & 1 & 5 & 4 & 5 & 5 & 65 \\
\hline 15 & 5 & 5 & 5 & 1 & 5 & 1 & 1 & 1 & 1 & 5 & 5 & 1 & 1 & 5 & 1 & 1 & 1 & 1 & 5 & 1 & 5 & 5 & 62 \\
\hline 16 & 5 & 5 & 5 & 1 & 5 & 1 & 5 & 1 & 1 & 5 & 5 & 1 & 5 & 5 & 1 & 1 & 1 & 1 & 5 & 1 & 5 & 5 & 70 \\
\hline 17 & 5 & 5 & 5 & 1 & 5 & 1 & 1 & 1 & 1 & 5 & 5 & 1 & 1 & 5 & 1 & 1 & 1 & 1 & 5 & 4 & 5 & 5 & 65 \\
\hline 18 & 5 & 5 & 5 & 1 & 5 & 1 & 1 & 1 & 1 & 5 & 5 & 2 & 1 & 5 & 1 & 1 & 1 & 1 & 5 & 1 & 5 & 5 & 63 \\
\hline 19 & 5 & 5 & 5 & 1 & 5 & 1 & 1 & 1 & 1 & 5 & 5 & 1 & 1 & 5 & 1 & 1 & 1 & 1 & 5 & 1 & 5 & 5 & 62 \\
\hline 20 & 5 & 5 & 5 & 1 & 5 & 1 & 1 & 1 & 1 & 5 & 5 & 1 & 1 & 5 & 1 & 1 & 1 & 1 & 5 & 5 & 5 & 5 & 66 \\
\hline 21 & 5 & 5 & 5 & 1 & 5 & 1 & 1 & 1 & 1 & 5 & 5 & 2 & 1 & 5 & 1 & 1 & 1 & 1 & 5 & 1 & 5 & 5 & 63 \\
\hline 22 & 5 & 5 & 5 & 1 & 5 & 1 & 1 & 1 & 1 & 5 & 5 & 1 & 1 & 5 & 1 & 1 & 1 & 1 & 5 & 4 & 5 & 5 & 65 \\
\hline 23 & 5 & 5 & 5 & 1 & 5 & 1 & 1 & 1 & 1 & 5 & 4 & 1 & 1 & 5 & 1 & 1 & 1 & 1 & 5 & 1 & 5 & 5 & 61 \\
\hline 24 & 5 & 5 & 5 & 1 & 5 & 5 & 1 & 1 & 1 & 5 & 5 & 2 & 4 & 5 & 1 & 1 & 1 & 1 & 5 & 1 & 5 & 5 & 70 \\
\hline 25 & 5 & 5 & 5 & 1 & 5 & 1 & 1 & 1 & 1 & 5 & 5 & 1 & 1 & 5 & 1 & 1 & 1 & 1 & 5 & 4 & 5 & 5 & 65 \\
\hline 26 & 5 & 5 & 5 & 1 & 5 & 1 & 5 & 1 & 1 & 5 & 5 & 1 & 1 & 5 & 1 & 1 & 1 & 1 & 5 & 1 & 5 & 5 & 66 \\
\hline 27 & 5 & 5 & 5 & 1 & 5 & 1 & 1 & 1 & 1 & 4 & 5 & 1 & 1 & 5 & 1 & 1 & 1 & 1 & 5 & 4 & 5 & 5 & 64 \\
\hline 28 & 5 & 5 & 5 & 1 & 5 & 1 & 1 & 1 & 1 & 5 & 5 & 1 & 1 & 5 & 1 & 1 & 1 & 1 & 5 & 1 & 5 & 5 & 62 \\
\hline 29 & 5 & 5 & 5 & 1 & 5 & 1 & 1 & 1 & 1 & 5 & 5 & 1 & 1 & 5 & 1 & 1 & 1 & 1 & 5 & 1 & 5 & 5 & 62 \\
\hline 30 & 5 & 5 & 5 & 1 & 5 & 1 & 1 & 1 & 1 & 5 & 5 & 1 & 5 & 5 & 1 & 1 & 1 & 1 & 5 & 4 & 5 & 5 & 69 \\
\hline 31 & 5 & 5 & 5 & 1 & 5 & 1 & 1 & 1 & 2 & 5 & 5 & 1 & 1 & 5 & 1 & 1 & 1 & 1 & 5 & 4 & 5 & 5 & 66 \\
\hline 32 & 5 & 5 & 5 & 1 & 5 & 1 & 1 & 1 & 1 & 5 & 5 & 1 & 1 & 5 & 1 & 1 & 1 & 1 & 5 & 1 & 5 & 5 & 62 \\
\hline 33 & 5 & 5 & 5 & 1 & 5 & 1 & 1 & 1 & 1 & 5 & 5 & 1 & 1 & 5 & 1 & 1 & 1 & 1 & 5 & 5 & 5 & 5 & 66 \\
\hline 34 & 5 & 5 & 5 & 1 & 5 & 1 & 1 & 1 & 1 & 5 & 5 & 1 & 1 & 5 & 1 & 1 & 1 & 1 & 5 & 1 & 5 & 5 & 62 \\
\hline 35 & 5 & 5 & 5 & 1 & 5 & 1 & 1 & 1 & 1 & 4 & 5 & 1 & 1 & 5 & 1 & 1 & 1 & 1 & 5 & 1 & 5 & 5 & 61 \\
\hline 36 & 5 & 5 & 5 & 1 & 5 & 1 & 5 & 1 & 1 & 5 & 5 & 1 & 1 & 5 & 1 & 1 & 1 & 1 & 5 & 1 & 5 & 5 & 66 \\
\hline 37 & 5 & 5 & 5 & 1 & 5 & 1 & 1 & 1 & 1 & 5 & 5 & 1 & 1 & 5 & 1 & 1 & 1 & 1 & 5 & 1 & 5 & 5 & 62 \\
\hline 38 & 5 & 5 & 5 & 1 & 5 & 1 & 1 & 1 & 1 & 5 & 5 & 1 & 1 & 5 & 1 & 1 & 1 & 1 & 5 & 5 & 5 & 5 & 66 \\
\hline 39 & 5 & 5 & 5 & 1 & 5 & 1 & 1 & 5 & 1 & 5 & 5 & 1 & 1 & 5 & 1 & 1 & 1 & 1 & 5 & 5 & 5 & 5 & 70 \\
\hline
\end{tabular}




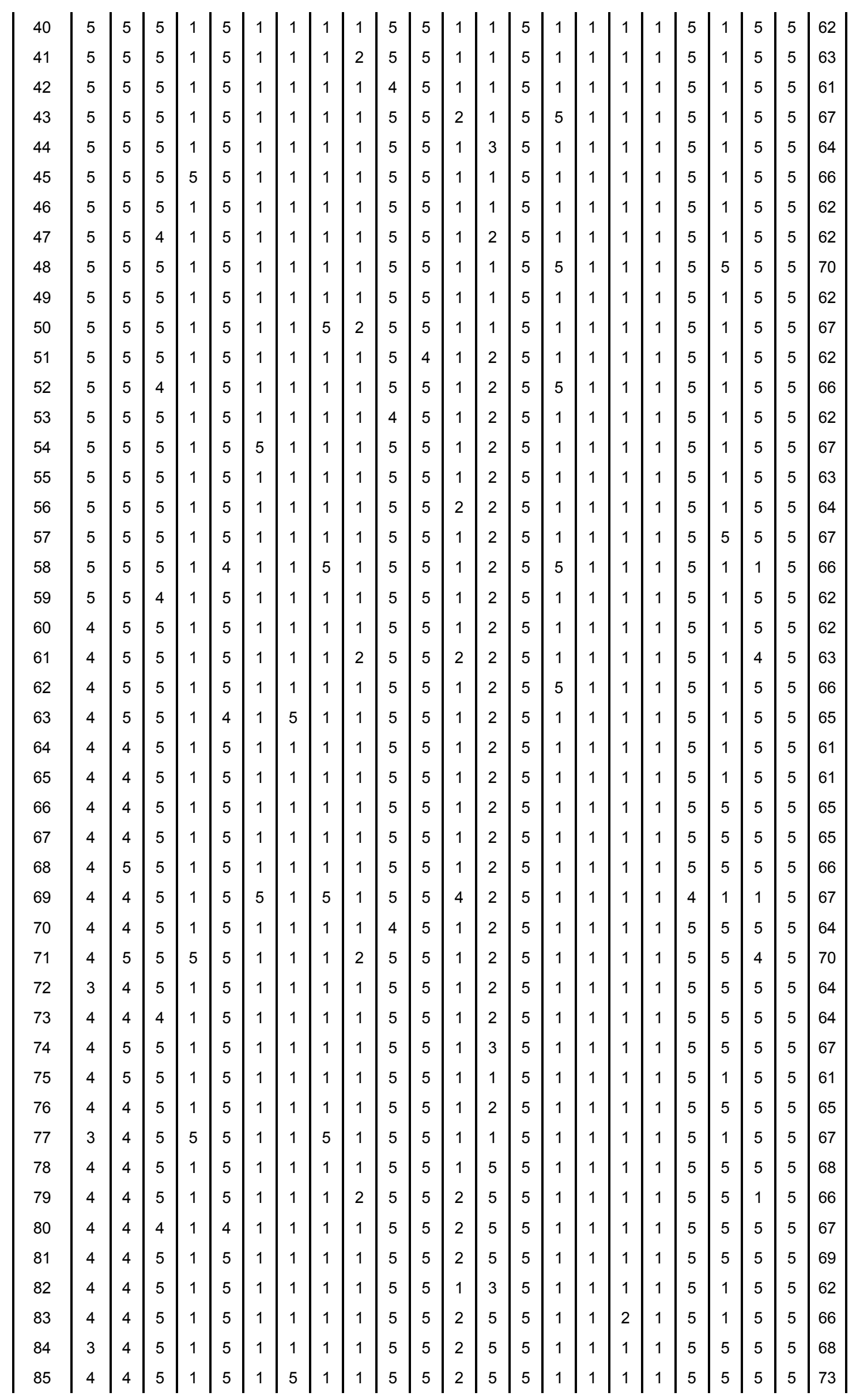




\begin{tabular}{|c|c|c|c|c|c|c|c|c|c|c|c|c|c|c|c|c|c|c|c|c|c|c|c|}
\hline 86 & 4 & 4 & 5 & 1 & 5 & 1 & 1 & 1 & 1 & 5 & 5 & 1 & 1 & 5 & 1 & 1 & 1 & 1 & 4 & 5 & 5 & 5 & 63 \\
\hline 87 & 4 & 4 & 4 & 1 & 5 & 1 & 1 & 1 & 1 & 5 & 5 & 2 & 5 & 5 & 1 & 1 & 1 & 1 & 4 & 5 & 5 & 5 & 67 \\
\hline 88 & 4 & 4 & 4 & 1 & 5 & 1 & 1 & 1 & 1 & 5 & 5 & 2 & 1 & 5 & 1 & 1 & 1 & 1 & 4 & 5 & 4 & 5 & 62 \\
\hline 89 & 4 & 4 & 4 & 5 & 5 & 1 & 1 & 1 & 1 & 5 & 5 & 2 & 1 & 5 & 1 & 2 & 1 & 1 & 4 & 5 & 4 & 5 & 67 \\
\hline 90 & 3 & 4 & 4 & 1 & 5 & 1 & 1 & 1 & 1 & 5 & 5 & 2 & 4 & 5 & 1 & 1 & 1 & 1 & 4 & 5 & 5 & 5 & 65 \\
\hline 91 & 4 & 4 & 4 & 1 & 4 & 1 & 1 & 1 & 1 & 5 & 5 & 2 & 3 & 5 & 1 & 1 & 1 & 1 & 4 & 5 & 5 & 5 & 64 \\
\hline 92 & 4 & 4 & 5 & 1 & 5 & 1 & 1 & 1 & 1 & 5 & 5 & 2 & 4 & 5 & 1 & 1 & 1 & 1 & 4 & 5 & 5 & 5 & 67 \\
\hline 93 & 3 & 4 & 3 & 1 & 5 & 1 & 1 & 1 & 1 & 5 & 5 & 2 & 1 & 5 & 1 & 1 & 1 & 1 & 4 & 1 & 5 & 5 & 57 \\
\hline 94 & 4 & 3 & 4 & 5 & 5 & 1 & 1 & 1 & 2 & 5 & 5 & 1 & 1 & 5 & 1 & 1 & 1 & 1 & 4 & 1 & 5 & 5 & 62 \\
\hline 95 & 4 & 4 & 4 & 1 & 5 & 1 & 1 & 1 & 1 & 5 & 5 & 2 & 4 & 5 & 1 & 1 & 1 & 1 & 4 & 5 & 5 & 5 & 66 \\
\hline 96 & 3 & 4 & 4 & 1 & 4 & 1 & 1 & 1 & 2 & 5 & 5 & 4 & 1 & 5 & 1 & 2 & 1 & 1 & 4 & 4 & 5 & 5 & 64 \\
\hline 97 & 4 & 4 & 4 & 1 & 5 & 1 & 1 & 1 & 1 & 5 & 4 & 2 & 1 & 5 & 1 & 1 & 1 & 1 & 4 & 4 & 5 & 5 & 61 \\
\hline 98 & 4 & 4 & 4 & 1 & 5 & 1 & 1 & 1 & 2 & 5 & 5 & 2 & 4 & 5 & 1 & 1 & 1 & 1 & 4 & 5 & 5 & 5 & 67 \\
\hline 99 & 4 & 3 & 5 & 5 & 5 & 1 & 1 & 1 & 2 & 5 & 5 & 2 & 1 & 5 & 1 & 1 & 1 & 1 & 4 & 5 & 1 & 4 & 63 \\
\hline 100 & 4 & 4 & 4 & 1 & 5 & 1 & 1 & 1 & 1 & 5 & 5 & 2 & 4 & 5 & 1 & 1 & 1 & 1 & 4 & 4 & 5 & 4 & 64 \\
\hline 101 & 3 & 4 & 4 & 1 & 4 & 5 & 1 & 1 & 1 & 4 & 5 & 2 & 3 & 4 & 1 & 1 & 1 & 1 & 4 & 1 & 5 & 4 & 60 \\
\hline 102 & 3 & 4 & 4 & 1 & 5 & 5 & 1 & 5 & 1 & 5 & 5 & 2 & 4 & 4 & 1 & 1 & 1 & 1 & 1 & 1 & 5 & 5 & 65 \\
\hline 103 & 4 & 4 & 4 & 1 & 5 & 5 & 1 & 1 & 1 & 4 & 5 & 2 & 3 & 4 & 1 & 1 & 1 & 1 & 1 & 1 & 4 & 4 & 58 \\
\hline 104 & 3 & 3 & 4 & 5 & 5 & 5 & 5 & 5 & 2 & 4 & 5 & 4 & 1 & 4 & 1 & 1 & 1 & 1 & 1 & 1 & 4 & 5 & 70 \\
\hline 105 & 3 & 4 & 5 & 1 & 4 & 5 & 1 & 1 & 2 & 5 & 5 & 4 & 1 & 4 & 1 & 1 & 1 & 1 & 1 & 1 & 4 & 4 & 59 \\
\hline 106 & 4 & 5 & 4 & 5 & 5 & 1 & 5 & 5 & 1 & 4 & 4 & 2 & 1 & 4 & 1 & 1 & 1 & 1 & 1 & 4 & 5 & 5 & 69 \\
\hline 107 & 3 & 4 & 4 & 1 & 4 & 1 & 5 & 1 & 1 & 5 & 5 & 4 & 1 & 5 & 1 & 1 & 5 & 1 & 1 & 1 & 4 & 5 & 63 \\
\hline 108 & 4 & 4 & 5 & 4 & 4 & 1 & 5 & 5 & 2 & 4 & 5 & 2 & 3 & 4 & 1 & 1 & 5 & 1 & 1 & 1 & 2 & 4 & 68 \\
\hline 109 & 3 & 4 & 4 & 5 & 5 & 5 & 1 & 1 & 1 & 4 & 4 & 4 & 3 & 4 & 1 & 1 & 5 & 1 & 1 & 1 & 2 & 4 & 64 \\
\hline 110 & 3 & 5 & 4 & 1 & 4 & 1 & 1 & 5 & 2 & 5 & 4 & 4 & 1 & 4 & 1 & 1 & 5 & 1 & 1 & 1 & 1 & 4 & 59 \\
\hline $\begin{array}{c}\text { Varia } \\
\text { nza }\end{array}$ & $\begin{array}{c}0.4 \\
8\end{array}$ & $\begin{array}{c}0 . \\
30\end{array}$ & $\begin{array}{c}0 . \\
20\end{array}$ & \begin{tabular}{|l|}
1. \\
28 \\
\end{tabular} & \begin{tabular}{|c|}
0. \\
08 \\
\end{tabular} & \begin{tabular}{|l|}
1. \\
68
\end{tabular} & $\begin{array}{c}1 . \\
33 \\
\end{array}$ & \begin{tabular}{|l|}
1. \\
45 \\
\end{tabular} & $\begin{array}{l}0 . \\
11\end{array}$ & $\begin{array}{l}0 . \\
10\end{array}$ & \begin{tabular}{|c|}
0 \\
05 \\
\end{tabular} & \begin{tabular}{|l|}
0. \\
64 \\
\end{tabular} & $\begin{array}{l}1 . \\
73\end{array}$ & \begin{tabular}{|c|}
0. \\
08 \\
\end{tabular} & \begin{tabular}{|c|}
0. \\
70 \\
\end{tabular} & \begin{tabular}{|c|}
0. \\
02 \\
\end{tabular} & \begin{tabular}{|l|}
0. \\
57
\end{tabular} & $\begin{array}{l}0 . \\
00\end{array}$ & \begin{tabular}{|l|}
1. \\
24
\end{tabular} & \begin{tabular}{|l}
3. \\
51
\end{tabular} & \begin{tabular}{|c|}
0. \\
88 \\
\end{tabular} & \begin{tabular}{|c|}
0. \\
07 \\
\end{tabular} & $\begin{array}{c}9.2 \\
0\end{array}$ \\
\hline
\end{tabular}

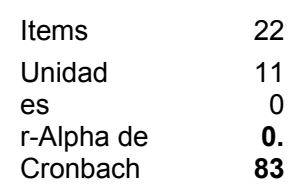

